Physical Model Study of Wave Action in New Thomsen Harbor, Sitka, Alaska

Steven A. Hughes, Julie Cohen, and Hugh F. Acuff

February 2008 


\section{Physical Model Study of Wave Action in New Thomsen Harbor, Sitka, Alaska}

Steven A. Hughes, Julie Cohen, and Hugh F. Acuff

Coastal and Hydraulics Laboratory

U.S. Army Engineer Research and Development Center

5980 Halls Ferry Road

Vicksburg, MS 39180-6199

Final report

Approved for public release; distribution is unlimited.

Prepared for U.S. Army Engineer District, Alaska

Elmendorf Air Force Base, AK 99506-0898 


\begin{abstract}
A 1-to-75 scale physical model of Sitka, Alaska, encompassing portions of the Western Channel, the region protected by the three breakwaters, New Thomsen Harbor, and the Sitka and J aponski Island shorelines, was constructed at the modeling facilities of the U.S. Army Engineer Research and Development Center's Coastal and Hydraulics Laboratory. The primary objectives of the physical model study were to (1) establish the cause for wave action within the harbor causing vertical motion of the floating docks and (2) investigate potential engineering alternatives to reduce wave action within the harbor to acceptable levels.
\end{abstract}

A total of 179 tests were conducted in the Sitka physical model during four time periods between the completion of the model in September 2005 and February 2007. Several hypotheses explaining increased wave action in New Thomsen Harbor were tested. Of these hypotheses, wave focusing by local bathymetry near New Thomsen Harbor appeared to be the most plausible; incident waves interacting with waves reflected by the shoreline at high water were a possible contributor for longer period waves. Large, short-period waves from the northwest could cause high waves in the harbor, but only when the wind blows hard from that direction. Distance between the rubble-mound breakwaters and harbor is also adequate to generate sizable short-period waves within the harbor. The short-wave energy could excite a harmonic frequency of the dock system resulting in adverse motions. At present the floating dock harmonics are unknown.

Closing one or more gaps between adjacent breakwaters and/ or breakwaters and the shoreline reduced wave heights in New Thomsen Harbor. Leaving only one gap open when waves came from the southwest reduced wave heights by about half. Closing only one gap while leaving the rest open did not create an appreciable wave height reduction when waves came from the southwest. Extending the runway on J aponski Island by $1,600 \mathrm{ft}$ to the northwest resulted in a wave height reduction on the order of $50 \%$ in the harbor when waves approached from the southwest. All other options tested caused little reduction of wave heights when waves approached from the southwest.

DISCLAIMER: The contents of this report are not to be used for advertising, publication, or promotional purposes. Citation of trade names does not constitute an official endorsement or approval of the use of such commercial products. All product names and trademarks cited are the property of their respective owners. The findings of this report are not to be construed as an official Department of the Army position unless so designated by other authorized documents. 


\section{Contents}

Figures and Tables..................................................................................................................................

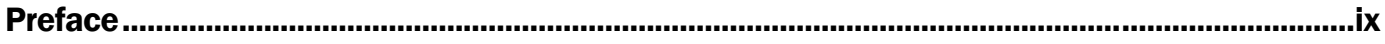

Unit Conversion Factors...........................................................................................................................



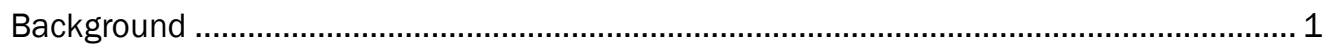

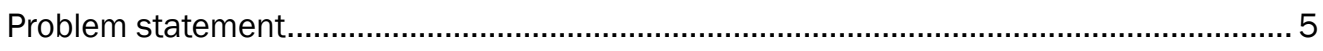

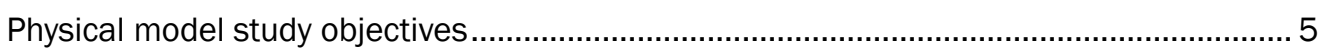

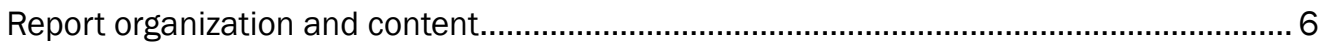

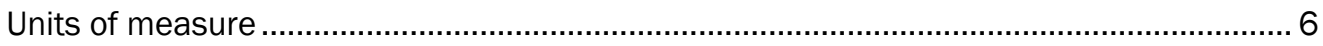

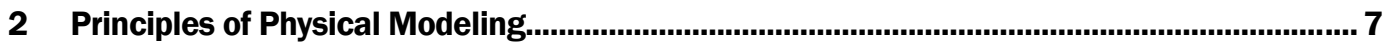

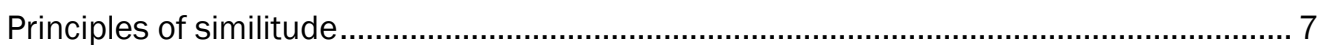

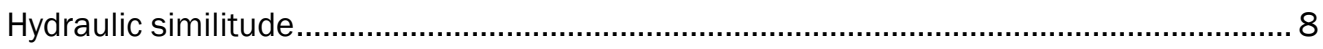

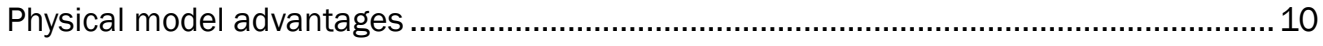

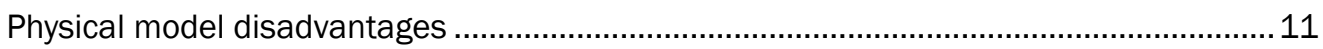

Physical model scale effects .......................................................................................11

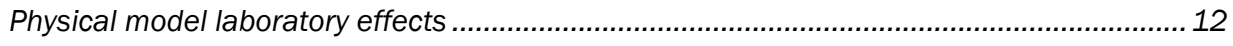

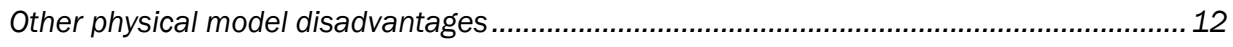



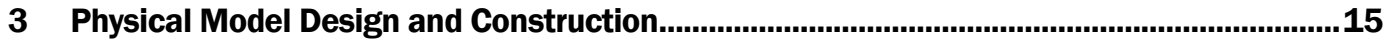

Dominant physical processes in Western Channel at Sitka ............................................. 15

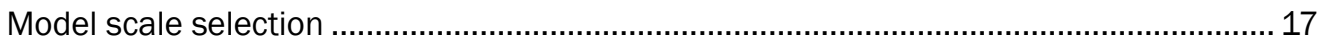

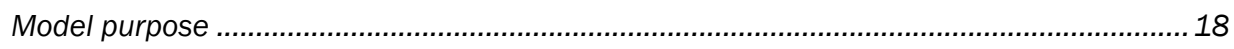

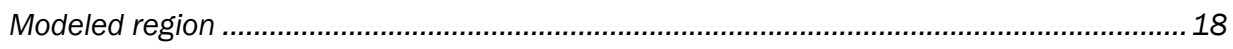

Hydrodynamic similitude criteria............................................................................. 19



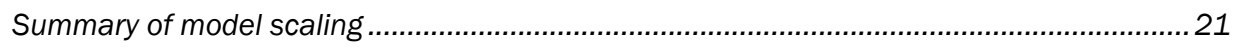

Physical model layout................................................................................................. 21

Potential scale and laboratory effects ......................................................................... 22

Scale effects in New Thomsen Harbor physical model.......................................................22

Laboratory effects in New Thomsen Harbor physical model.............................................. 23

Physical model construction ...................................................................................... 24

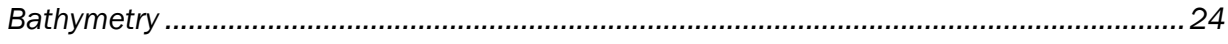

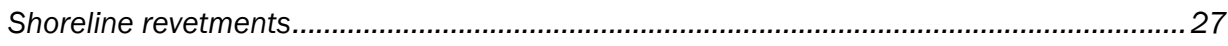

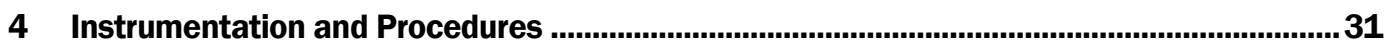

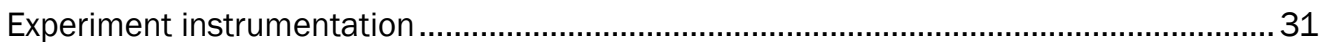



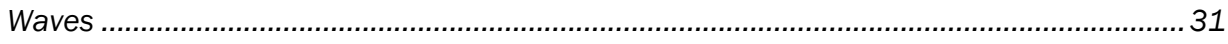

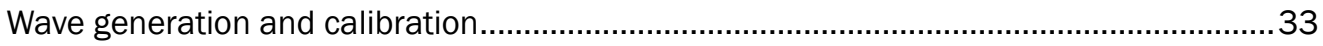




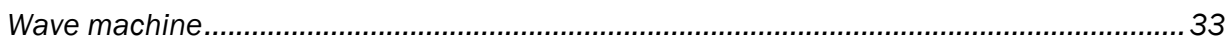



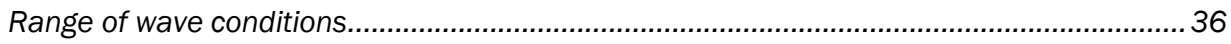





5 Overview and September 2005 Results ..............................................................................41



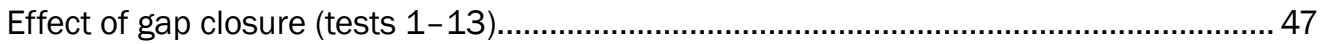

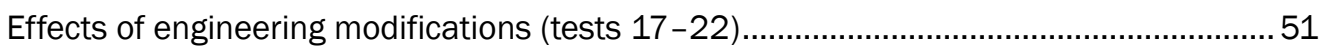

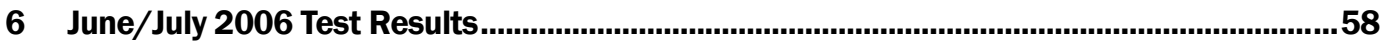

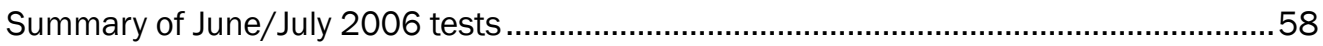

Maximum elevation differences along floating dock (tests $59-70$ ) .................................59

7 November/December 2006 Test Results........................................................................65

Summary of November/December 2006 tests...............................................................65

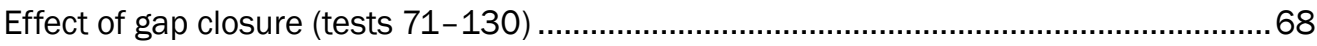

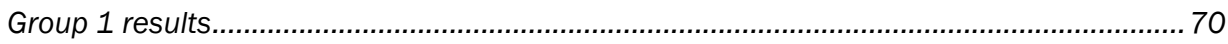

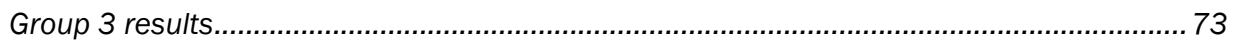

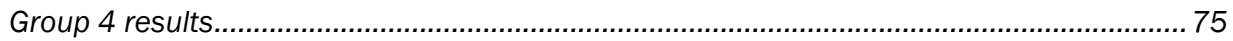

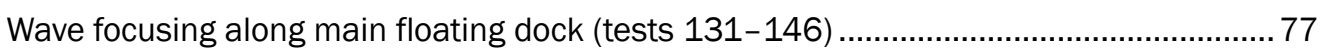

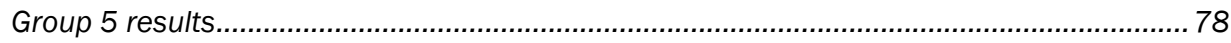

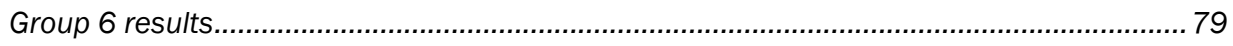

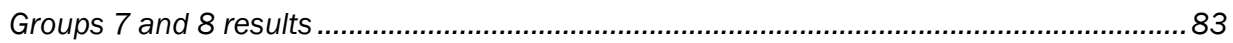

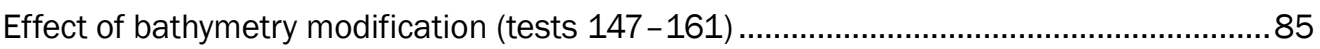



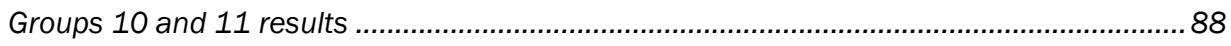

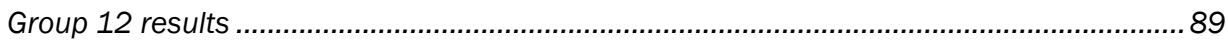

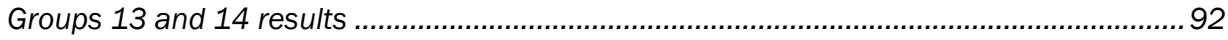

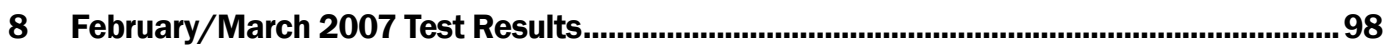

Summary of February/March 2007 tests ....................................................................... 98

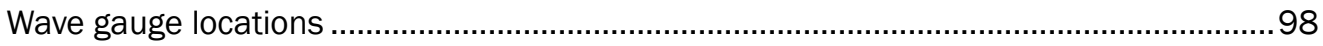

Extreme water elevation test series (tests 162-167) .................................................99

Monochromatic wave test series (test 169-175) .........................................................102

Future float plane area (tests 176-179) ...................................................................104

9 Summary and Conclusions....................................................................................... 106

Summary of physical model study ....................................................................106

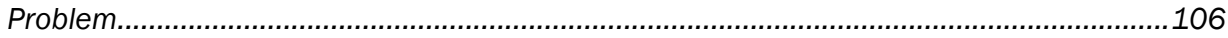

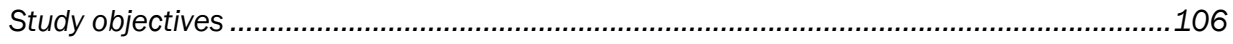

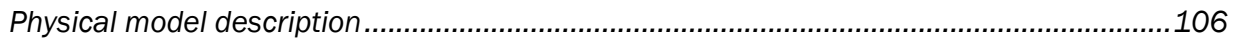

Overview of testing program ........................................................................................... 107

Study observations and conclusions .................................................................. 108

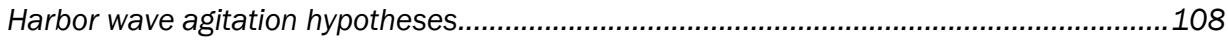

Effectiveness of engineering modifications..................................................................... 112

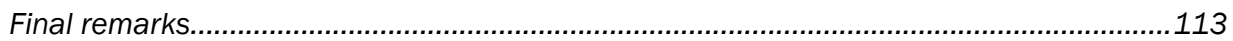





Report Documentation Page 


\section{Figures and Tables}

\section{Figures}

Figure 1. Sitka, AK, location (image from www.travelalaska.com). .......................................................... 1

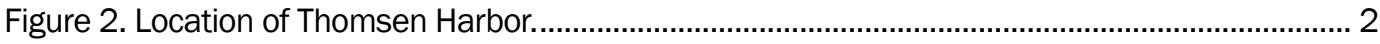

Figure 3. Aerial photograph of Western Channel and Thomsen Harbor............................................ 3

Figure 4. New Thomsen Harbor main floating dock. ............................................................................ 4

Figure 5. Region of Sitka reproduced in physical model. ............................................................... 19

Figure 6. Layout of physical model region in model shelter................................................................ 23

Figure 7. Start of model construction at southern portion of modeled area.....................................26

Figure 8. Placing of templates in Sitka model...........................................................................26

Figure 9. Model nearing completion (view from southern end of model). ..................................... 27

Figure 10. A portion of shoreline revetment reproduced in physical model....................................28

Figure 11. Sitka breakwaters replicated in physical model. .............................................................2

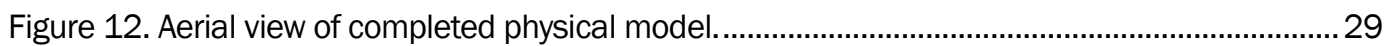

Figure 13. Aerial view showing offshore portion of physical model. ...............................................30

Figure 14. Wave gauges in vicinity of New Thomsen Harbor floating breakwater. ............................32

Figure 15. Wave board of plunger-type wave machine used in physical model................................34

Figure 16. Wave analysis output from model wave measurements. ...............................................39

Figure 17. Wave gauge locations for tests 1-34 ......................................................................... 47

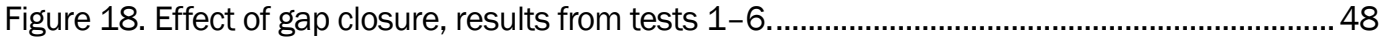

Figure 19. Effect of gap closure, results from tests $8-13$. .............................................................. 49

Figure 20. Wave energy through breakwaters, tests 6 and 14........................................................50

Figure 21. Wave energy through breakwaters, tests 13 and 15.................................................50

Figure 22. Effects of various engineering modifications, tests 17-22 …..................................... 51

Figure 23. Effect of gap closure with waves from northwest, tests 25-30....................................52

Figure 24. Effects of various engineering modifications, test 31-34 ...............................................53

Figure 25. Effect of incident wave height with northwest waves......................................................54

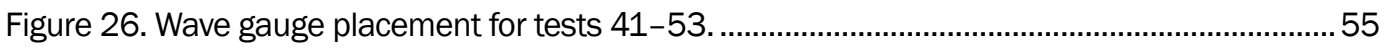

Figure 27. Effect of wave period with southwest waves, tests 41-48. .........................................56

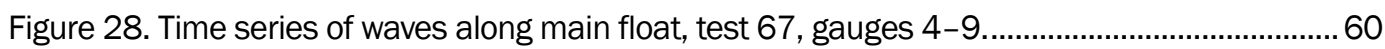

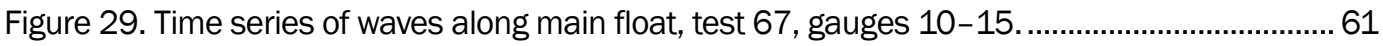

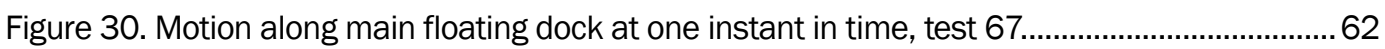

Figure 31. Distribution of vertical differential between adjacent gauges, test 67 ............................63

Figure 32. Maximum vertical difference between adjacent gauges, tests $65-70$..........................64

Figure 33. Maximum vertical difference between three adjacent gauges, tests $65-70$................. 64

Figure 34. Wave gauge array spaced at $75 \mathrm{ft}$ along main floating dock........................................6

Figure 35. Wave gauge array placed in future float plane area......................................................67 
Figure 36. Wave gauge array in lee of south breakwater........................................................... 67

Figure 37. Group 1 wave heights for 5-ft, 10-sec waves................................................................. 71

Figure 38. Group 1 wave heights for 5-ft, 12-sec waves............................................................... 71

Figure 39. Group 1 wave heights for 5 -ft, 14-sec waves............................................................. 72

Figure 40. Group 1 wave heights for 5-ft, 16-sec waves ............................................................ 72

Figure 41. Group 3 wave heights for 5-ft, 10-sec waves. .............................................................. 74

Figure 42. Group 3 wave heights for 5-ft, 12-sec waves............................................................. 74

Figure 43. Group 3 wave heights for 5 -ft, 14-sec waves............................................................. 75

Figure 44. Group 3 wave heights for 5-ft, 16-sec waves. .............................................................. 75

Figure 45. Group 4 wave heights for 5-ft, 10-sec waves.............................................................. 76

Figure 46. Group 4 wave heights for 5-ft, 12-sec waves............................................................... 76

Figure 47. Group 4 wave heights for 5-ft, 14-sec waves................................................................ 77

Figure 48. Group 4 wave heights for 5-ft, 16-sec waves............................................................... 77

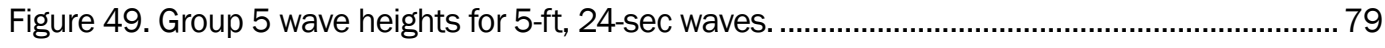

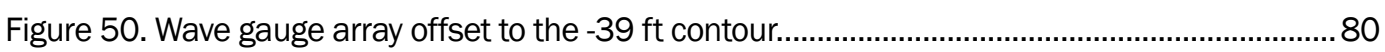

Figure 51. Group 6 wave heights for 5-ft, 10-sec waves. ................................................................ 81

Figure 52. Group 6 wave heights for 5-ft, 16-sec waves............................................................. 81

Figure 53. Group 6 wave heights for 5-ft, 24-sec waves. .............................................................. 82

Figure 54. Comparison between Group 1 and Group 6 wave heights ( $T_{p}=10$ and $16 \mathrm{sec}$ )............82

Figure 55. Comparison between Group 5 and Group 6 wave heights $\left(T_{p}=24 \mathrm{sec}\right)$........................ 83

Figure 56. Shoreline wave absorbers for Group 8 (tests 143-146).............................................. 84

Figure 57. Group 7 wave heights for 5-ft, 10-sec waves without absorber....................................... 85

Figure 58. Group 7 wave heights for 5-ft, 10-sec waves with absorber.......................................... 85

Figure 59. Pea gravel infill looking from Japonski Island toward seaward end of array. ................... 87

Figure 60. Pea gravel infill looking from shore toward Japonski Island. .......................................... 87

Figure 61.Group 9 wave heights for 5-ft, 10-sec waves with pea gravel added................................ 88

Figure 62. Effect of bathymetry and wave absorber for tests 149 and 151 .................................. 89

Figure 63. Effect of bathymetry and wave absorber for tests 150 and 152 ................................... 89

Figure 64. Second pea gravel addition; view from Japonski Island. ................................................90

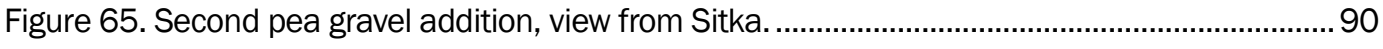

Figure 66. Effect of additional bathymetry modification, 5-ft, 10-sec wave...................................... 91

Figure 67. Effect of additional bathymetry modification, 5-ft, 24-sec wave. ...................................92

Figure 68. Sea surface elevation time series, gauges 4-9 (test 156). ........................................... 94

Figure 69. Sea surface elevation time series, gauges 10-15 (test 156).........................................95

Figure 70. Extract of sea surface elevation time series, gauges 4-9 (test 156)..............................96

Figure 71. Extract of sea surface elevation time series, gauges 10-15 (test 156)..........................97

Figure 72. Extreme water level and waves with modified bathymetry (tests 162-163)................100

Figure 73. Extreme water level and waves with bathymetry removed (tests 164-165)................. 101

Figure 74. Extreme wave condition at low water (tests 166-167)................................................ 101

Figure 75. Monochromatic tests at $+10 \mathrm{ft}$ mllw (tests 168-171) . .................................................103

Figure 76. Monochromatic tests at +0 ft mllw (tests 172-175) . ..................................................103 
Figure 77. Monochromatic tests with waves from northwest (tests 176-177).............................105

Figure 78. Breakwater extensions with waves from northwest (tests 178-179). 105

\section{Tables}

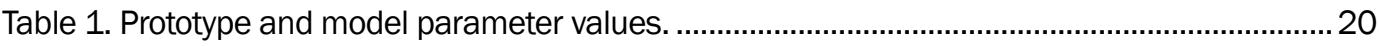

Table 2. Model scale ratios and prototype equivalence. ................................................................... 21

Table 3. Calibrated wave conditions for testing of New Thomsen Harbor model. ...............................36

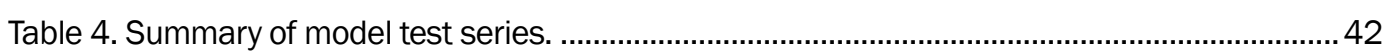

Table 5. Experiment parameters for September 2005 tests.......................................................... 45

Table 6. Experiment parameters for June/July 2006 tests..............................................................59

Table 7. Experiment parameters for November 2006 tests for Group 1.........................................68

Table 8. Experiment parameters for November 2006 tests for Group 3.........................................69

Table 9. Experiment parameters for November/December 2006 tests for Group 4.......................70

Table 10. Experiment parameters for November 2006 tests for Groups 5-8..................................78

Table 11. Experiment parameters for November 2006 tests for Groups 9-12. .............................86

Table 12. Experiment parameters for November 2006 tests for Groups 13-14 ............................92

Table 13. Experiment parameters for February 2007 tests.............................................................99 


\section{Preface}

This study was conducted by the U.S. Army Engineer Research and Development Center (ERDC), Coastal and Hydraulics Laboratory (CHL), Vicksburg, MS, for the U.S. Army Engineer District, Alaska (POA). POA provided initial funding authority on 22 February 2005, and a review draft of this report was submitted to POA on $20 \mathrm{~J}$ uly 2007. Review comments from POA Engineering Division were incorporated into the report on 18- 19 October 2007.

Deirdre M. Ginter, Hydraulics and Hydrology Section (HH), Civil Works Branch, Engineering Division, POA, was the point of contact for the sponsoring Alaska District, and she provided study oversight and review. Kenneth J . Eisses, Chief, Civil Works Branch, POA, provided advice and direction throughout the study. J ohn Oliver, Corps of Engineers, retired, provided technical advice and review through a contract with POA.

The physical model study was directed by Dr. Steven A. Hughes, Navigation Division (HN), CHL. J ulie A. Cohen, Harbors, Entrances, and Structures Branch $(\mathrm{HN}-\mathrm{H}), \mathrm{CHL}$, prepared the model design drawings, managed the day-to-day operation of the physical model, performed data analysis, and assisted in report and figure preparation. Hugh F. Acuff, $\mathrm{HN}-\mathrm{H}$, provided overall planning and operational guidance throughout the study and assured all aspects of the study proceeded as planned. The physical model was constructed by craftsmen from the ERDC Directorate of Public Works (DPW) under the supervision of Charles Brown, Construction Leadman, and FrankJ ames, Construction Supervisor. David Daily and Timothy Nisley, ERDC Information Technology Laboratory, supported the instrumentation and wave machine requirements.

This study was conducted August 2005 through March 2007 under the direct supervision of J ose E. Sanchez, Chief, HN-H, CHL. Administrative supervision was provided by Thomas W. Richardson, Director, CHL; Dr. William D. Martin, Deputy Director, CHL; and Dr. M. Rose Kress, Chief, HN, CHL.

COL Richard B. J enkins was Commander and Executive Director of ERDC. Dr. J ames R. Houston was Director. 


\section{Unit Conversion Factors}

\begin{tabular}{|l|l|l|}
\hline Multiply & By & To Obtain \\
\hline cubic yards & 0.7645549 & cubic meters \\
\hline feet & 0.3048 & meters \\
\hline inches & 2.54 & centimeters \\
\hline miles (U.S. statute) & 1.609347 & kilometers \\
\hline square miles & $2,589,998$ & square kilometers \\
\hline
\end{tabular}




\section{Introduction}

\section{Background}

Sitka is a major fishing and deep sea distribution port in southeastern Alaska for the outer island settlements of the Alexander Archipelago. Sitka was one of the first Russian settlements in Alaska, and it once served as Alaska's first capital. Sitka is on the west coast of Baranof Island fronting the Pacific Ocean on Sitka Sound as shown in Figures 1 and 2. Sitka is 95 air miles southwest of J uneau and 185 miles northwest of Ketchikan, $\mathrm{AK}$.

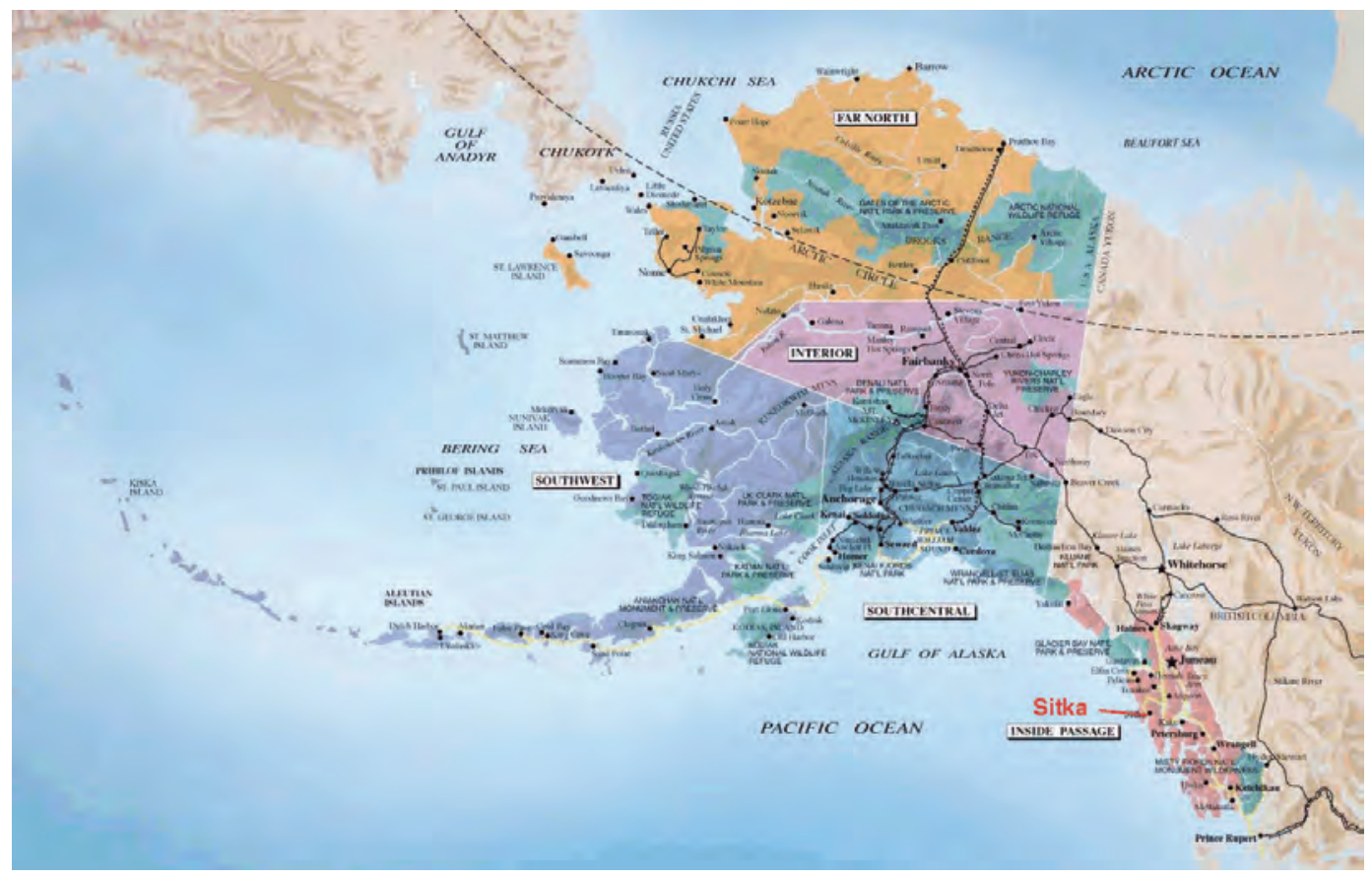

Figure 1. Sitka, AK, location (image from www.travelalaska.com).

The U.S. Army Engineer District Alaska (hereafter, the Alaska District) of the U.S. Army Corps of Engineers (USACE) is responsible for maintaining the Federal navigation project at Sitka, AK. This responsibility includes the Western Channel, Crescent Bay, and Channel Rock Breakwaters situated near Channel Rock at the northwestern entrance to Western Channel. Little dredging is anticipated at Sitka, so the primary USACE maintenance requirements are repair of the breakwaters if needed. 


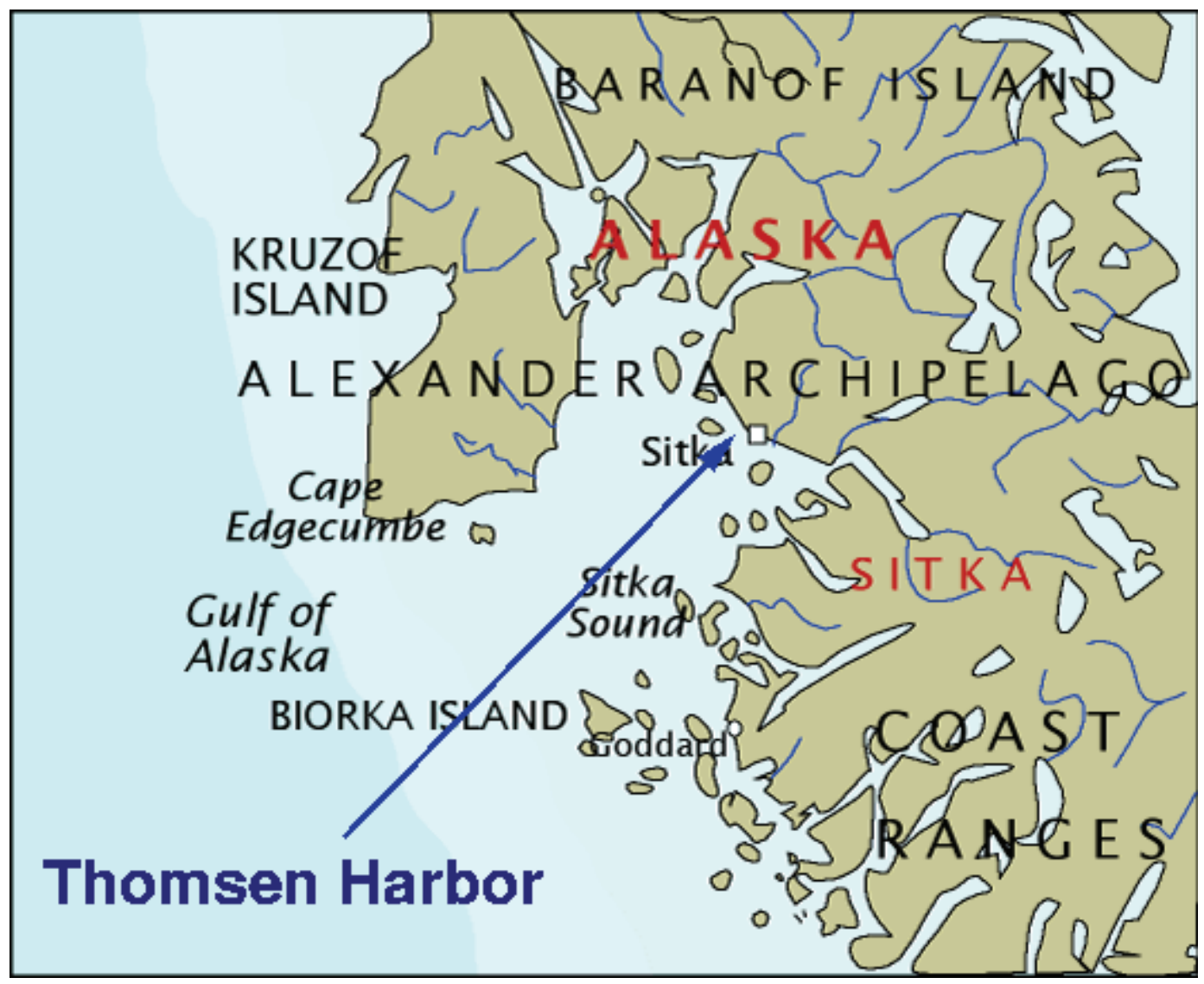

Figure 2. Location of Thomsen Harbor.

The three Channel Rock breakwaters were authorized in 1992, and construction was completed in 1995 with placement of a total of 310,500 cu yd of rock. The main purpose of the breakwaters is to provide wave protection for an expansion of Thomsen Harbor, that is located within the Western Channel. This project provided a minimum harbor capacity of 315 vessels with potential for future expansion. Figure 3 shows an aerial view of the Western Channel, Thomsen Harbor, and the three breakwaters. Breakwater lengths (left to right in Figure 3) are approximately $320 \mathrm{ft}, 1200 \mathrm{ft}$, and $480 \mathrm{ft}$, respectively. 


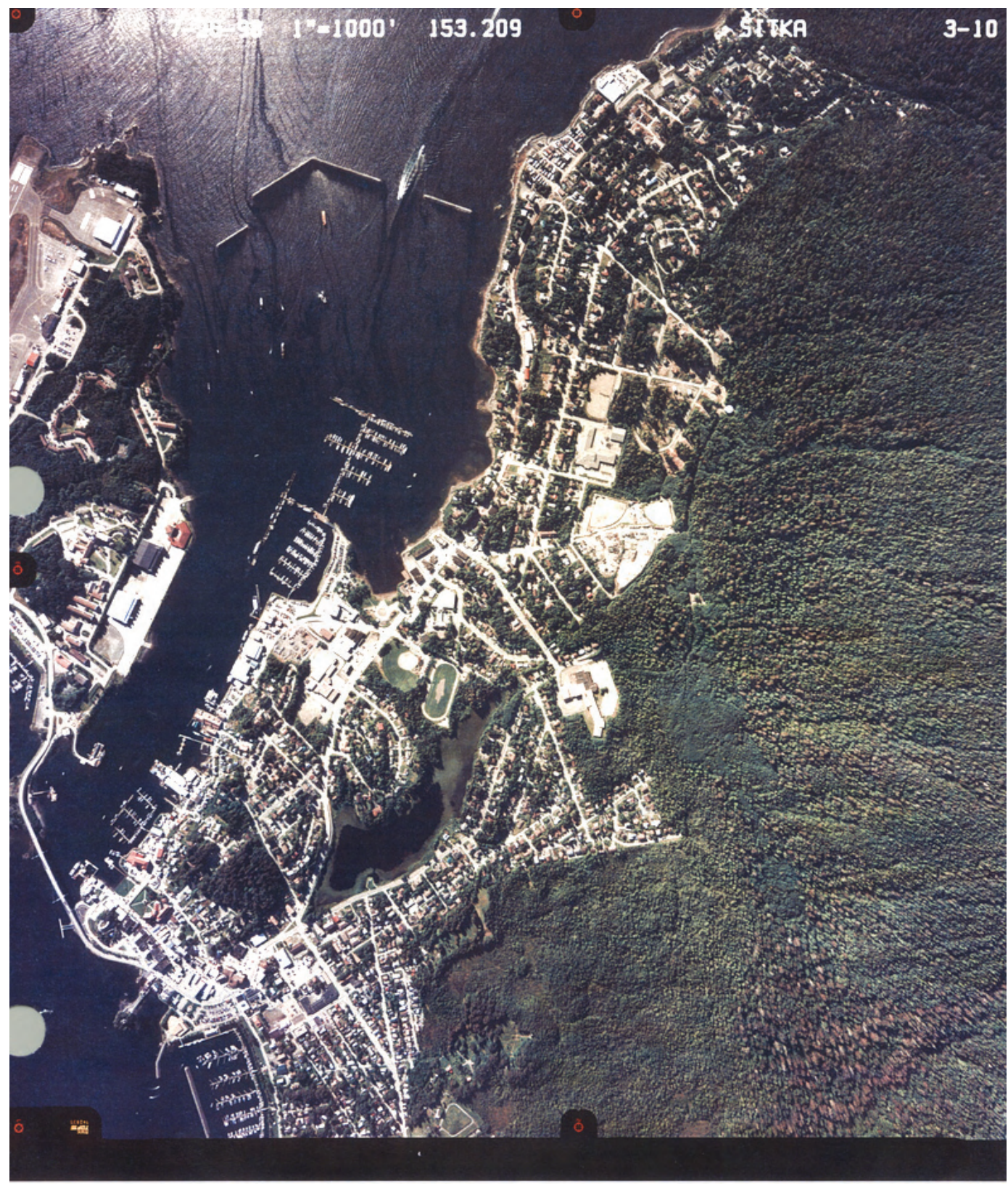

Figure 3. Aerial photograph of Western Channel and Thomsen Harbor.

The small-vessel mooring slips shown in Figure 3 are constructed of floating docks held in lateral position by vertical piles as shown in Figure 4 so the docks are free to rise and fall with the tide. The mean tide range at Sitka is $7.7 \mathrm{ft}$, and the mean higher high tide range is $9.9 \mathrm{ft}$. 




Figure 4. New Thomsen Harbor main floating dock. 


\section{Problem statement}

Local interests have reported that the floating docks sometime experience vertical wave-like motions that make walking on the docks difficult. Vessels moored to the floating dock experience similar motion. Unscientific observations estimate the period of wave motion causing problems for the slips and moored vessel to be in the range of 8 to $20 \mathrm{sec}$, and it has been reported that most episodes of increased dock motion occur during high tide.

Wave motion in Thomsen Harbor having periods in the reported range is most likely caused by wave energy propagating from the Gulf of Alaska and approaching Sitka from the west and southwest directions. Waves approaching from the north to northwest have a short fetch because of island sheltering, and wave periods from this direction are somewhat shorter than $8 \mathrm{sec}$.

It is hypothesized that storm wave energy passes through the gaps between the breakwater and into the Western Channel. This wave energy causes the increased level of wave agitation where vessels are moored in the floating slips in Thomsen Harbor. At high tide it is also possible for storm wave energy to pass over the breakwaters (crest at $+16.4 \mathrm{ft}$ mean lower low water [mllw]) or through that portion of the breakwater above the impermeable breakwater core which has a top elevation around $+9.2 \mathrm{ft} \mathrm{mllw}$.

Direct coupling of wave period to dock motion periods is not necessary to develop significant dock motion. The dock system has its own harmonic resonant frequency, and it can be excited by different forcing frequencies.

To understand the cause of wave action in Thomsen Harbor and to investigate possible solutions, the Alaska District requested the Coastal and Hydraulics Laboratory (CHL) at the U.S. Army Engineering Research and Development Center (ERDC) to construct and test a small-scale, fixed-bed physical model of Thomsen Harbor and the Western Channel at Sitka.

\section{Physical model study objectives}

The primary objectives of the studies associated with Thomsen Harbor were: (1) establish the cause for wave action within the harbor causing vertical motion of the float docks, and (2) investigate potential engineering alternatives to reduce wave action within the harbor to acceptable levels. 
During the course of the study, wave measurements were acquired at additional locations within the Western Channel to provide base information at potential sites for a float plane facility.

\section{Report organization and content}

The chapters of this report are in chronological order from initial design of the model through to interpretation of final results. Chapter 2 overviews the principles of physical modeling, points out the advantages and disadvantages of the technology, and discusses known scale and laboratory effects and how these two effects might influence model results. Chapter 3 covers design and construction of the Sitka - New Thomsen Harbor physical model in the context of physical facilities available at CHL. Chapter 4 details the experiment instrumentation, wave generation and calibration procedures, model operation procedures, data collection, and initial data analyses. Chapter 5 overviews the entire testing program and provides details of tests conducted in September 2005. Results and analysis based on tests conducted in J une 2006, November 2006, and February 2007 are presented in Chapters 6, 7, and 8, respectively. Finally, Chapter 9 presents the summary and conclusions from this study.

\section{Units of measure}

Most dimensional parameters and values cited in this report are given in non-SI units of measure. Conversion to equivalent SI units can be made using the conversion factors listed on page $\mathrm{x}$ of this report.

Usually, the values of measured model parameters have been scaled to equivalent prototype values so the reader can better understand the model response. However, in some instances values are reported in model units without specifically stating these are model units. In those cases where prototype or models are not explicitly stated for a parameter, the context will usually reveal whether the value is in model dimensions or equivalent prototype dimensions. 


\section{Principles of Physical Modeling}

This chapter overviews the principles that govern the design and operation of small-scale, fixed-bed physical models of free-surface flow phenomena. Included is a discussion of the advantages and disadvantages of physical models, along with a description of how the modeling technology can be best applied to investigate wave agitation problems in New Thomsen Harbor at Sitka, AK.

\section{Principles of similitude}

The basis of all physical modeling is the idea that the model behaves in a manner similar to the prototype it is intended to emulate. Thus, a properly validated physical model can be used to predict the prototype (real world) under a specified set of conditions. However, there is a possibility that physical model results may not be indicative of prototype behavior due to scale effects or laboratory effects. The role of the physical modeler is to minimize scale effects by understanding and applying proper similitude relationships, and to minimize laboratory effects through careful model operation.

Similarity between the real world (prototype) and a small-scale replica (model) of a coastal project area is achieved when all major factors influencing reactions are in proportion between prototype and model, while those factors that are not in proportion throughout the modeled domain are so small as to be insignificant to the process. For coastal short-wave models, three general conditions must be met to achieve model similitude:

a. Geometric similarity exists between two objects or systems if the ratios of all corresponding linear dimensions are equal. This relationship is independent of motion of any kind and involves only similarity in form (Warnock 1950). Geometrically similar models are also known as geometrically undistorted models because the horizontal and vertical length scales are the same. (Departure from geometric similarity is restricted to hydrodynamics of long waves and unidirectional flows.)

b. Kinematic similarity indicates a similarity of motion between particles in model and prototype. Kinematic similarity is achieved when the ratio between the components of all vectorial motions for the prototype and model is the same for all particles at all times (Hudson et al. 1979). In a geometrically similar model, kinematic similarity gives particles 
paths that are geometrically similar to the prototype. Kinematic similarity assures the wave motions and associated flow kinematics are correctly replicated in the physical model.

c. Dynamic similarity between two geometrically and kinematically similar systems requires that the ratios of all vectorial forces in the two systems be the same (Warnock 1950). This means that there must be constant prototype-to-model ratios of all masses and forces acting on the system. The requirement for dynamic similarity arises from Newton's second law that equates the vector sum of the external forces acting on an element to the element's mass reaction to those forces. For example, dynamic similitude is required when the model is used to simulate the damping effect of floating docks or moored vessels.

Perfect similitude requires that the prototype-to-model ratios of the inertial, gravitational, viscous, surface tension, elastic, and pressure forces be identical. In practice, perfect similitude is impossible at reduced model scale. Fortunately, many coastal problems and flow regimes are adequately modeled by an imperfect similitude where inertia and gravity forces dominate while all other forces are small in comparison.

For convenience, physical modeling similitude requirements are expressed in terms of scale ratios, defined as the ratio of a parameter in the prototype to the value of the same parameter in the model. The scale ratio is represented by the notation:

$$
N_{X}=\frac{X_{p}}{X_{m}}=\frac{\text { value of } X \text { in prototype }}{\text { value of } X \text { in model }}
$$

where $N_{X}$ is the prototype-to-model scale ratio of the parameter $X$. For example, the length scale is usually denoted as $N_{L}$ and the velocity scale is $N_{V}$.

\section{Hydraulic similitude}

Hydraulic similitude requirements for coastal hydrodynamic short-wave models can be derived (e.g., Hughes 1993) from the continuity and NavierStokes equations governing incompressible, free-surface flows. The resulting similitude conditions are listed here. In Equations 2-4, the expressions on the left side give the similitude criteria, which are also given in terms of scale ratios on the right side (Hughes 2003). 
1. The model must be geometrically undistorted, i.e., horizontal and vertical length scales are the same.

2. The Froude number, which is the ratio of inertia to gravity forces, must be the same in the model as in the prototype, i.e.,

$$
\left(\frac{V}{\sqrt{g L}}\right)_{p}=\left(\frac{V}{\sqrt{g L}}\right)_{m} \quad \text { or } \quad \frac{N_{V}}{\sqrt{N_{g} N_{L}}}=1
$$

3. The Strouhal number, which is the ratio of temporal to convective inertial forces, must be the same in the model as in the prototype, i.e.,

$$
\left(\frac{L}{V t}\right)_{p}=\left(\frac{L}{V t}\right)_{m} \quad \text { or } \quad \frac{N_{L}}{N_{V} N_{t}}=1
$$

4. The Reynolds number, which is the ratio of inertia to viscous forces, must be the same in the model as in the prototype, i.e.,

$$
\left(\frac{\rho L V}{\mu}\right)_{p}=\left(\frac{\rho L V}{\mu}\right)_{m} \quad \text { or } \quad \frac{N_{\rho} N_{L} N_{V}}{N_{\mu}}=1
$$

where

$$
\begin{aligned}
V & =\text { characteristic velocity } \\
g & =\text { gravitational acceleration } \\
L & =\text { characteristic length } \\
t & =\text { time } \\
\rho & =\text { fluid density }
\end{aligned}
$$

and the subscripts $p$ and $m$ represent prototype and model, respectively.

The geometric similarity criterion (condition 1) coupled with the Froude Criterion (condition 2) assure that all terms in the governing flow equations are in similitude with the exception of the viscous terms. Froude similarity includes the turbulent Reynolds shear stress terms; thus, macro features of turbulent dissipative processes are also in similitude.

Viscous effects can only be modeled if the Reynolds Criterion (condition 3) is met along with the Froude criterion in a geometrically similar model. In general, this is practical only at prototype scale (full-size scale). Consequently, 
coastal short-wave models can be either nondissipative where viscous and capillary effects are negligible, such as waves prior to breaking; or the model can have highly turbulent flow dissipation over a relatively short distance, such as during wave breaking on a structure or a beach (Le Méhauté 1976). In reality, there will always be a small amount of wave attenuation due to viscous frictional losses and surface tension effects, but these scale effects can be minimized to the point of insignificance.

The hydrodynamic time scale for Froude-scaled hydrodynamic models is obtained by solving Equation 2 for $\mathrm{NV}$ and substituting into Equation 3 to give:

$$
N_{t}=\sqrt{\frac{N_{L}}{N_{g}}}
$$

Because the gravitational force will be the same in the model as in the prototype, the ratio $N_{g}$ will be unity, and it is usually not included in the scaling criteria. Other scale ratios derived from Froude and Reynolds scaling are given in most similitude texts (e.g., Hughes 1993).

\section{Physical model advantages}

Small-scale physical models are essentially analog computers of all the physical processes being simulated with the model. Nonlinearities and complex physical interactions between fluid and solid boundaries are faithfully reproduced without compromise provided the model has been scaled correctly and laboratory effects are controlled. For this reason, small-scale physical models offer an opportunity to examine those processes that are beyond theoretical understanding or are too complicated to represent adequately with simplified analytical or numerical modeling tools. The following is a list of advantages associated with physical models (Hughes 1993).

a. Physical models incorporate and integrate the fully nonlinear governing equations of the modeled process without simplifying assumptions.

$b$. Complex boundaries and bathymetry can be included without difficulty.

c. The small size of the model permits easy data collection.

d. Model forcing conditions can be easily simulated and controlled. 
e. Similitude requirements for many problems are well understood and easily implemented.

$f$. Visual feedback from a physical model often reveals aspects of the physical process that had not been considered previously. Observations also help us to understand the differences that arise from changing the forcing conditions, and they often stimulate new ideas or alternative solutions.

g. Engineering solutions can be optimized in a physical model to achieve improved project functionality at minimum expense.

$h$. Often physical models are a cost-effective option relative to alternate study methods.

The benefits arising from physical model studies depend largely on the careful operation of the model coupled with a full understanding of the potential problems and shortcomings that may exist because of scale or laboratory effects.

\section{Physical model disadvantages}

The major disadvantages associated with small-scale physical models relate to either scale effects or laboratory effects.

\section{Physical model scale effects}

Scale effects in coastal hydrodynamic models result primarily from the Froude scaling assumption that gravity is the dominant physical force balancing the inertial forces. The other physical forces of viscosity, elasticity, and surface tension are incorrectly scaled with the belief that these forces contribute little to the physical processes. Scale effects in physical models are analogous to decreased accuracy that occurs in numerical models when complex physical processes are represented by simplified mathematical formulations (Kamphuis 1991).

In fixed-bed models the primary scale effect occurs wherever flows in the model become so slow that the flow regime might transition from turbulent to laminar flow conditions whereas such a transition would not occur in the prototype. In this case the viscous forces in the model would not be in similitude. An example of this scale effect is flow through the permeable core of a rubble-mound structure where the flow regime is considered to be turbulent in the prototype, but might be laminar in a small-scale physical model where the size of the core material is scaled according to the 
length scale. This scale effect is avoided by increasing the size of the core material in the model. Note that the cores of the Sitka breakwaters are considered to be impermeable.

\section{Physical model laboratory effects}

Laboratory effects in coastal physical models are primarily related to the following:

a. Physical constraints on flow in the model are caused by the need to represent a portion of the prototype in a finite amount of space. Model boundaries may exist where there is no boundary in the prototype. Waves reflect off model boundaries and introduce reflected wave trains back into the simulated wave field. This problem is partially solved using energy dissipating beaches composed of gentle slopes and rubberized horsehair mats that can minimize reflection to less than 5 percent.

$b$. Mechanical means of wave and current generation may introduce unintentional nonlinear effects. The most common example is incorrect reproduction of bound long waves that sometimes cause problems for harbor basins. The model engineer must attempt to make the mechanical waves resemble reasonably well the waves observed in nature.

c. Prototype forcing conditions are simplified and only a subset of all possible conditions can be selected for testing. A common laboratory effect in wave basins is when long-crested unidirectional waves are generated to approximate directional waves that occur in nature. This compromise is not considered serious if the testing covers multiple approach angles, but the engineer must assess the approximation to determine whether it is reasonable. Another example is simulating a storm using a constant water level as opposed to a time-varying surge hydrograph.

Laboratory effects in physical models are analogous to problems in numerical models caused by numerical approximation to the equations, roundoff and truncation errors, and computer speed, memory, and availability (Kamphuis 1991).

\section{Other physical model disadvantages}

Cost of physical model construction and operation is an important factor to consider. Construction costs increase directly with the model size, so the reduction in potential scale effects that arises from larger models will come at higher costs. Operation of a physical model requires skilled 
engineers and technicians, and significant time and effort is spent minimizing laboratory effects and assuring quality measurements. Also, time scales in physical models are determined by the similitude relationships so some time-dependent simulations make take a long time to complete (when compared to numerical modeling).

Even though data acquisition in a physical model is much easier than field data collection, there are inherent limitations. The number of measurement locations in the model is limited by available instrumentation and data channels. Therefore, careful consideration must be given about what to measure and where to place the instruments.

\section{Physical model appropriateness}

In many cases, a coastal problem can be examined by several different methods including numerical models, physical models, analytical techniques, statistical analyses, and desktop studies. Selecting which techniques are most suited to a particular problem requires the following: (a) knowledge of the primary forcing and responses that shape the coastal processes in the problem area, and (b) an understanding of how well the forcing and response are replicated by the alternative technologies. Often multiple technologies are used with each providing part of the answer.

Physical models are appropriate where the hydrodynamic physical processes are complex (wave nonlinearities, wave/ current interactions, complex bathymetry, numerous boundaries), and where the response to the hydrodynamics is not well understood or quantified. In addition, the similitude relationships for the dominant processes must be known, and the potential scale and laboratory effects are thought to be surmountable.

Wave agitation in an enclosed harbor resulting from waves entering through multiple gaps (and possibly over the breakwaters) qualifies as a complicated hydrodynamic physical process. The hydrodynamic regime for this situation is complicated by a number of physical processes. Waves are diffracted as they enter the harbor basin through the gaps, and waves entering through one gap interact with waves entering through the other gaps. Complex bottom bathymetry refracts the incident waves, and the harbor shoreline reflects wave energy back into the harbor. At higher water levels the wave crests are higher than the breakwater impermeable core, and wave energy passes over the breakwater or through the voids between the armor stones. 
Physical models have proven in the past to be reliable tools for determining wave action throughout harbors resulting from a variety of incident wave conditions. The models are particularly useful where harbor basin geometry is complex, and wave energy enters via multiple openings and through the protective breakwaters. 


\section{Physical Model Design and Construction}

This chapter describes the design and construction of the New Thomsen Harbor physical model. Included is a discussion of the dominant physical processes governing wave agitation in the vicinity of the harbor, the rationale for scale selection, and a summary of potential scale effects and how they might influence model results.

\section{Dominant physical processes in Western Channel at Sitka}

Sitka tides are semidiurnal (two high and two low tides each tidal day) with a mean range of $7.7 \mathrm{ft}$ and a diurnal range (difference in height between mean higher high water [mhhw] and mllw) of $9.9 \mathrm{ft}$. The maximum water level of $4.94 \mathrm{ft}$ above mhhw or at elevation $+14.84 \mathrm{ft}$ mllw was recorded in 1948.

The three breakwaters protecting the northern entrance of the Western Channel have an impermeable core with a top elevation estimated to be $+9.2 \mathrm{ft}$ mllw. Thus, waves arriving when the water level is at or above mhhw ( $+9.9 \mathrm{ft} \mathrm{mllw}$ ) will overtop the breakwater core and wave energy not dissipated by the breakwater armor stones will enter the basin. The gaps between the breakwaters are slightly wider at high water than low water, which also allows a little more wave energy into the protected basin. Wave reflection off the shorelines of the Western Channel is influenced by tide level. During low tide a mildly sloping beach emerges that helps dissipate wave energy. At high water, however, the waves impact directly on steep rubble-mound revetments protecting the shoreline, and more of the incident wave energy is reflected back into the basin. Local observations of troublesome events at New Thomsen Harbor indicated that high tide levels appeared to contribute to the difficulties.

Waves can approach Sitka from the northwest, west, and southwest directions. Waves from the northwest will be locally generated because of the sheltering provided by Kruzof Island. This island limits the open water fetch to the northwest of Sitka to less than 10 miles, so wind-generated wave periods will seldom exceed 3 to $5 \mathrm{sec}$. Local reports estimated the period of adverse floating dock motion to be in the range of 8 to $20 \mathrm{sec}$, and this observation implies that the problem is less likely to be caused by the shorter-period waves from the northwest. However, waves from the northwest have a direct path through the breakwater gaps, allowing a 
portion of the wave energy into the harbor that could excite dock motions at longer periods. If waves from the northwest are responsible for wave agitation in the harbor, these waves should also be accompanied by brisk winds required to generate larger waves over relatively short fetches.

Larger waves generated in the Gulf of Alaska can approach Sitka from the west and southwest. Waves from due west are partially blocked by Kruzof Island, but they can diffract around the island and continue toward Sitka. Waves from the southwest have a direct, unobstructed approach to Sitka, but they arrive with wave crests parallel to the airport runway on J aponski Island that shelters the Western Channel and New Thomsen Harbor. The waves must diffract around the northern tip of J aponski Island, go through the gap between Battery Island and J aponski Island, undergo shoaling and refraction due to the bathymetry, and finally enter the protected basin through the breakwater gaps (and potentially over the breakwaters).

Waves propagating from the Gulf of Alaska can have wave periods upwards of $20 \mathrm{sec}$ with periods in the range of 6 to $12 \mathrm{sec}$ being typical. Because this period range seems to correlate with the reported floating dock periods of oscillation, it would be logical to assume that the dock motion is being driven directly by the incident waves entering the harbor basin.

Natural and man-made basins can seich at longer wave periods (30 sec to several minutes) if excited into one of the fundamental modes corresponding to the basin geometry. This seiching is problematic for larger vessels and can hamper loading operations and stress mooring lines. Basins can be excited by the bound long-wave energy associated with incident shorter-period waves, or by free long waves generated by distant events. Basin seiching at long periods can generate horizontal currents at the nodes that could push moored vessels against the floating docks, but this would not necessarily cause vertical undulations of the floating dock system, particularly at the periods in the range of 8 to $20 \mathrm{sec}$. Because the reported dock motion does not appear to be caused by long-wave seiching within the Western Channel, no attempt was made to replicate long wave motions in the physical model. Accurate reproduction of long wave seiching in a harbor in a physical model is difficult but not impossible.

Tidal currents flowing through the Western Channel may have a minor influence on waves entering through the breakwater gaps, but this impact is minimal, particularly if the most problematic events occur at high water 
when the tidal flow is less. If tidal flow was a dominant forcing factor responsible for dock motion, then problems should occur on a monthly basis or even more often. Because of no reported problems linked to either tidal flows or the combination of tidal flow and waves, it seems likely that recreation of tidal flow in the wave agitation physical model is not needed. Of course tidal flow is a key factor in water quality throughout the entire Sitka region, and any remedial plan that potentially decreases tidal circulation must consider the impact on water quality.

In summary, the main physical processes that need to be recreated in the fixed-bed physical model are the following:

a. Elevated water levels.

$b$. Short-period waves from the northwest.

c. Longer period waves from the southwest.

d. Wave diffraction, refraction, and shoaling processes.

$e$. Wave reflection by the shoreline revetments.

$f$. Wave overtopping and flow through the three detached breakwaters.

Absent from the physical model are tidal current (thought to be small), wind-driven current (unknown influence), and other physical processes that may have some minor sway on wave action but are thought to be orders of magnitude less influential than these dominant processes.

\section{Model scale selection}

Selecting physical model scale ratios requires consideration and assessment of multiple requirements and limitations. The model must include as much of the project site area as needed to simulate the physical forcing, but this area is constrained by the size of the available space in the model facility. Those physical processes identified as being the dominant forcing in the project area must be scaled according to established similitude criteria at a scale as large as can be accommodated in the model facility in order to minimize potential scale effects. Existing wavemakers must be able to reproduce the maximum waves to be used in testing at the selected scale. If the wavemaker is insufficient in this regard, either new equipment must be sought, or the model scale must be reduced to meet the requirement. Known scale effects, laboratory effects, and other limitations must be assessed to determine possible impacts on model results. The following 
sections detail the scale section processes for the physical model of New Thomsen Harbor.

\section{Model purpose}

The physical model was constructed to support studies of the Alaska District. The primary purpose of the physical model was to establish the cause for wave action within the harbor causing vertical motion of the floating docks, and investigate potential engineering alternatives to reduce wave action within the harbor to acceptable levels.

The model design needed to accommodate a variety of possible engineering solutions including such possibilities as closing one or more breakwater gaps, raising the breakwater crest elevations, reducing shoreline reflection, and even modifying bathymetry within the Western Channel. The first aspect of model design was to consider how much of the Western Channel region needed to be included in the model in order to simulate the wave forcing for various directions while simulating accurately wave penetration into New Thomsen Harbor through the gaps between the detached breakwaters.

\section{Modeled region}

Once the determination was made that tidal current does not contribute substantially to adverse wave agitation within New Thomsen Harbor, the necessary area to be modeled consisted only of the basin inside the breakwaters and enough of the adjacent bathymetry in the Western Channel to simulate incoming storm waves from the southwest to northwest approach angles. The narrow connecting channel to the southeast of old Thomsen Harbor was not essential to the dominant physical processes so it was not necessary to include the channel in the physical model domain.

The black polygon shown in Figure 5 outlines the approximate region surrounding Sitka that needed to be reproduced by the physical model. This area measures about 7,500 ×6,500 ft, or about 1.7 square miles. Included in the modeled domain are Battery Island and Line Island that have significant impact on waves approaching from the west or southwest. Beyond the southeastern model boundary where the connecting channel exits the physical model, a small basin was added to absorb any wave energy passing this way. The basin was lined with absorbing "horsehair" mats so waves would not be reflected back into the study area. 


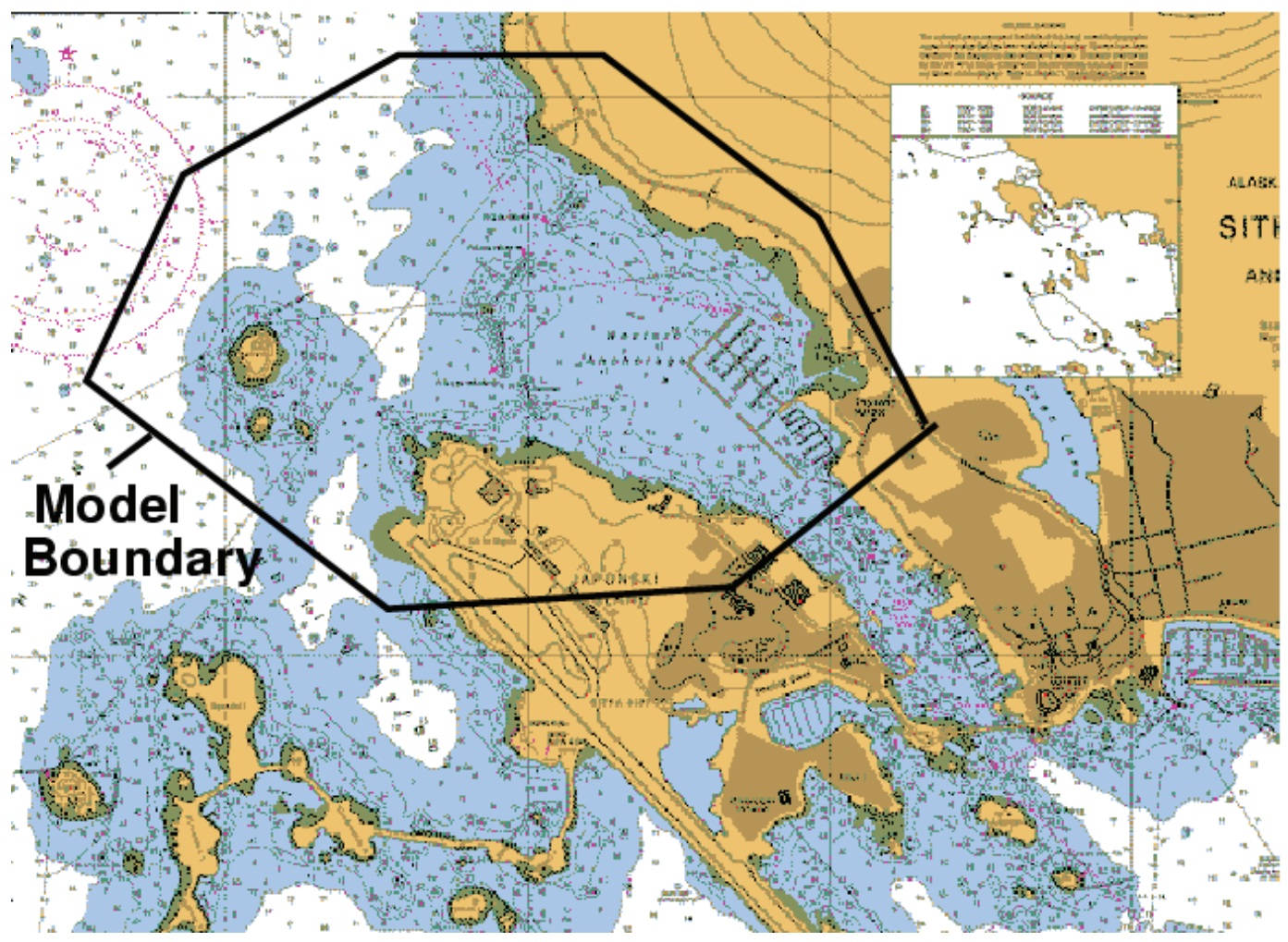

Figure 5. Region of Sitka reproduced in physical model.

The largest shelter space at CHL that was available during the time of this study measured about $160 \times 145 \mathrm{ft}$. An analysis indicated that it would be possible to fit the model area shown in Figure 5 in the shelter space using a prototype-to-model length scale of:

$$
N_{L}=\frac{L_{p}}{L_{m}}=60
$$

From experience it was known that model construction would intrude slightly into the modeled area, and extra room would be needed to accommodate the wave machine needed for this study, so the length scale was increased (model size decreased) to $N_{L}=75$. The next step was to determine the corresponding similitude criteria for waves and to evaluate the capability of available wavemakers to assure the desired conditions could be generated in the physical model.

\section{Hydrodynamic similitude criteria}

Small-scale model simulation of all free-surface flow phenomena, such as waves, must adhere to the Froude scaling, which means simply that the model must be geometrically undistorted (horizontal and vertical length 
scales are the same), and the model velocity scale and time scale must conform to the scaling relationships given by Equations 2 and 5, respectively. For a model length scale of $N_{L}=75$, the required velocity scale is given by:

$$
N_{V}=\sqrt{N_{g} N_{L}}=\sqrt{(1)(75)}=8.66
$$

and the hydrodynamic time scale (wave period scale) becomes

$$
N_{T}=\sqrt{\frac{N_{L}}{N_{g}}}=\sqrt{\frac{(75)}{(1)}}=8.66
$$

where the gravitational scale ratio, $N_{g}$, is unity.

\section{Wave generation capability}

Estimates of maximum wave height, range of wave periods, and water level elevations at New Thomsen Harbor were provided by the Alaska District. The wave estimates were based on a National Oceanic and Atmospheric Administration (NOAA) wave buoy located in deep water southwest of the Sitka region. Table 1 presents the primary wave and water elevation parameters used for model design along with model area requirements. The model equivalents of the prototype values were determined using the length scale ratio of $N_{L}=75$.

Table 1. Prototype and model parameter values.

\begin{tabular}{|l|l|l|}
\hline Parameter & Prototype Value & Model Value \\
\hline Approximate modeled area & $1.4 \mathrm{sq} \mathrm{mi}$ & $7,100 \mathrm{sq} \mathrm{ft}$ \\
\hline Minimum wave period & $4 \mathrm{sec}$ & $0.46 \mathrm{sec}$ \\
\hline Maximum wave period & $24 \mathrm{sec}$ & $2.77 \mathrm{sec}$ \\
\hline Maximum sig. wave height & $10 \mathrm{ft}$ & $0.133 \mathrm{ft}=1.6 \mathrm{in}$. \\
\hline Deepest bottom elevation & $-80 \mathrm{ft} \mathrm{mllw}$ & $-1.07 \mathrm{ft} \mathrm{mllw}$ \\
\hline Maximum tide elevation & $+11 \mathrm{ft}$ mllw & $+0.15 \mathrm{ft} \mathrm{mllw}$ \\
\hline Maximum total water depth & $91 \mathrm{ft}$ & $1.22 \mathrm{ft}$ \\
\hline
\end{tabular}

The total water depth was a limitation of the model facility, so that value was scaled up to prototype to assure it would be sufficient. Finally, the deepest bottom elevation is the depth at the wavemaker, and it is the total water depth subtracted from the elevation of the maximum water level.

An existing plunger-type wavemaker with a total length of $80 \mathrm{ft}$ was able to generate regular waves in the maximum water depth that met the maximum 
wave conditions. This wavemaker has a prismatic-shaped wave board that generates waves with an up-and-down vertical motion. The wave board can produce regular or irregular waves. Because of the irregular nature of random seas, irregular waves more closely replicate nature and are preferred in the physical model. However, it requires more capability to generate irregular significant wave heights $\left(H_{m 0}\right)$ than it does to generate regular waves of the same height.

Experience with the available wavemaker indicated that it would produce the required maximum wave height condition using irregular waves. Therefore, the wavemaker was considered adequate and appropriate for generating waves at the chosen length scale.

\section{Summary of model scaling}

The important model scale ratios (value in the prototype divided by the equivalent value in the model) are listed in Table 2. The fundamental scaling parameter is the length scale, $N_{L}=75$, which can be interpreted as $1 \mathrm{ft}$ in the model equals $75 \mathrm{ft}$ in the real world.

Table 2. Model scale ratios and prototype equivalence.

\begin{tabular}{|l|l|l|}
\hline Scale & Scale Ratio & Model Equivalence \\
\hline Length scale & $N_{x}=75$ & $1 \mathrm{ft}=75 \mathrm{ft}$ \\
\hline Area scale & $N_{A}=5,625$ & $1 \mathrm{sq} \mathrm{ft}=5,625 \mathrm{sq} \mathrm{ft}$ \\
\hline Time scale & $N_{T}=8.66$ & $1 \mathrm{sec}=8.66 \mathrm{sec}$ \\
\hline Velocity scale & $N_{V}=8.66$ & $1 \mathrm{ft} / \mathrm{sec}=8.66 \mathrm{ft} / \mathrm{sec}$ \\
\hline Wave height scale & $N_{H}=75$ & $1 \mathrm{in} .=6.25 \mathrm{ft}$ \\
\hline Wave period scale & $N_{T}=8.66$ & $1 \mathrm{sec}=8,66 \mathrm{sec}$ \\
\hline
\end{tabular}

\section{Physical model layout}

The layout of the modeled region of the Western Channel and New Thomsen Harbor in the selected model shelter is shown in Figure 6 oriented with north toward the top of the figure. The utilized portion of the model shelter measured about $145 \mathrm{ft}$ in the east-west direction and $160 \mathrm{ft}$ in the north-south direction. The red outlined boxes indicate different locations for the wave machine to simulate incident waves from the west, northwest, and north quadrants.

All bathymetry above the - $60 \mathrm{ft}$ mllw contour was reproduced in the model with a fixed bed constructed of concrete. (Note that elevations are given in 
prototype dimensions.) The - $60 \mathrm{ft}$ contour delineates the blue-colored bathymetry from the white-colored region on the map portion of Figure 6. Thus, all the bathymetry colored blue and the land masses colored brown in Figure 6 were reproduced in the physical model. The floor of the model was at an elevation equivalent to - $80 \mathrm{ft}$ mllwin the prototype, so a slope was constructed from the - $60 \mathrm{ft}$ contour to the $-80 \mathrm{ft}$ contour (3.2 in. verti$\mathrm{cal}$ in the model). Topography above mllw was reproduced to an elevation $(+20 \mathrm{ft})$ above the highest water level with additional freeboard included for wave runup.

\section{Potential scale and laboratory effects}

Scale effects and laboratory effects were summarized in general terms in Chapter 2. An assessment of how these scale and laboratory effects might influence results obtained from the New Thomsen Harbor physical model is given in the following paragraphs.

\section{Scale effects in New Thomsen Harbor physical model}

At the selected model length scale, hydrodynamics are in similitude so there is no appreciable scale effect related to the hydrodynamics. All waverelated phenomena such as wave shoaling, diffraction, reflection, and wave breaking will be in similitude with the prototype. Wave-induced current will be correct, and all nonlinear aspects of the wave motion also will be correct. Flow over and through the three detached breakwaters at high water levels will be in similitude because the rubble-mound is large enough to preclude any scale effects related to laminar flow conditions within the stone matrix. Therefore, all the important hydrodynamic processes that might be responsible for wave motions in New Thomsen Harbor were correctly simulated in the physical model.

The physical model was conducted using fresh water to simulate the salt water environment at Sitka. This is a practical compromise to avoid corrosion of laboratory facilities and delicate instrumentation. The slight difference in water density between model and prototype has virtually no impact on hydrodynamics as proven by many studies over the past 50 years (Hughes 1993). 


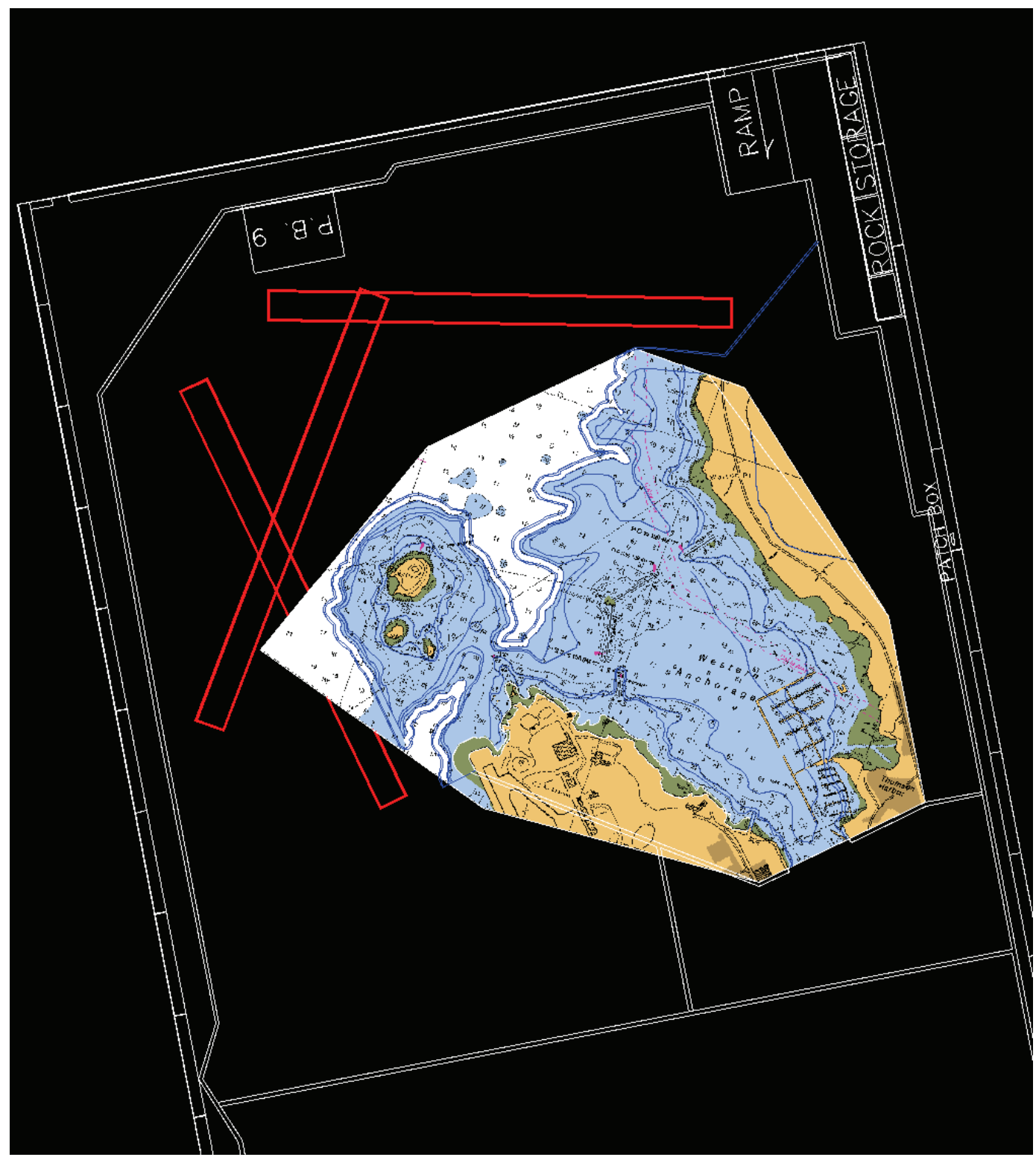

Figure 6. Layout of physical model region in model shelter.

\section{Laboratory effects in New Thomsen Harbor physical model}

The key laboratory effects in the New Thomsen Harbor physical model were related to either wave generation, water level, or model boundaries. Waves were generated by a plunger-type wavemaker that reproduced longcrested, irregular waves scaled to match wave spectra typical of those generated by storms in the Gulf of Alaska to the west and southwest of Sitka. Wave approach direction was fixed by the orientation of the wave machine within the basin. The use of long-crested waves to represent multidirectional wave conditions in the prototype was a reasonable compromise, especially at Sitka where incident storm waves are channeled by the 
surrounding land masses, and wave approach directions are somewhat limited.

Water level was identified as an important factor in harbor wave agitation at New Thomsen Harbor. Water level in the physical model was kept static at the level corresponding to maximum water level for much of the testing. This assured the maximum transmission of wave energy over and through the breakwaters into the protected harbor area.

Model boundaries are responsible for two laboratory effects: unwanted reflections and unwanted current patterns. Reflections from vertical walls in the model basin were kept to a minimum by placement of rubberized "horsehair" mats that are effective in absorbing incident wave energy. Wave guides (vertical walls) were used at the ends of the wavemaker to prevent immediate diffraction of waves before they entered into the modeled region. Diffraction would reduce wave height along the crest.

Waves passing through the Western Channel into the narrow connecting channel southeast of New Thomsen Harbor were absorbed in the small basin shown at the bottom of Figure 6 where the map ends. Wave absorbing material was placed in this small basin to minimize reflection of wave energy back into the study area.

\section{Physical model construction}

Construction costs are a large part of a physical model study. Before committing to a physical model, there should be reasonable expectation that the benefits to be derived are greater than the cost of constructing and operating the model. The New Thomsen Harbor physical model was designed and built with the goal of determining the probable cause of wave agitation within the harbor mooring area, and evaluating engineering alternatives for reducing wave agitation to manageable levels.

\section{Bathymetry}

Once the region to be modeled was scaled to fit within the available space, plan view drawings were prepared and correspondence between prototype and model coordinate systems was established. This was followed by construction of the fixed-bed bathymetry and topography.

The procedure for constructing fixed-bed models is to begin with a flat, horizontal floor, place compacted sand on the floor up to about $2 \mathrm{in}$. from 
the required elevation, then fill in the remaining elevation with mortar that sets into a hard surface. The construction technique is guided by templates that are spaced throughout the model at approximately 4-ft spacing.

Prototype-scale bathymetry and topography for the fixed-bed portion of the model between elevations $+20 \mathrm{ft}$ and $-60 \mathrm{ft}$ mllw were scaled to model dimensions and contoured on a plan view drawing in AutoCAD software. Template lines were selected based on the contours. When possible, the template lines were kept parallel and evenly spaced; but in some locations variation was needed to assure accurate molding of the bathymetry. Experience by the model designer helped establish a useful set of templates. The software produced profiles for each template along with the information necessary to position the template spatially in the model. Full-sized drawings of the templates were produced, and the model shop at ERDC cut the templates out of medium gauge sheet metal.

Fixed-bed bathymetry construction started in the model at the southern end of the Western Channel and proceeded northward through the Western Channel toward the deeper water. Each template was positioned, and the elevation was adjusted to close tolerance. After several templates had been placed, the space between adjacent templates was filled with construction-grade sand that was then wetted and compacted. Finally, readymixed concrete mortar was placed, and the surface was floated to a smooth finish level with the top of the templates. It was also necessary to handfinish the bathymetry to capture local variations between templates that had been noted on the drawings. This was especially the case for the two offshore islands included in the model, and the shorelines of the bay and J aponski Island. The construction technique is illustrated by the photographs in Figures 7-9.

Figure 7 shows the beginning of model construction at the south end of the project area. The workers are standing in the stilling basin that was used to dampen waves after they passed through the Western Channel. Figure 8 shows placing of templates, and Figure 9 is a wide-angle photograph of the model after partial completion. The vantage point of Figure 9 is from the stilling basin looking north, so J aponski Island is on the left. 


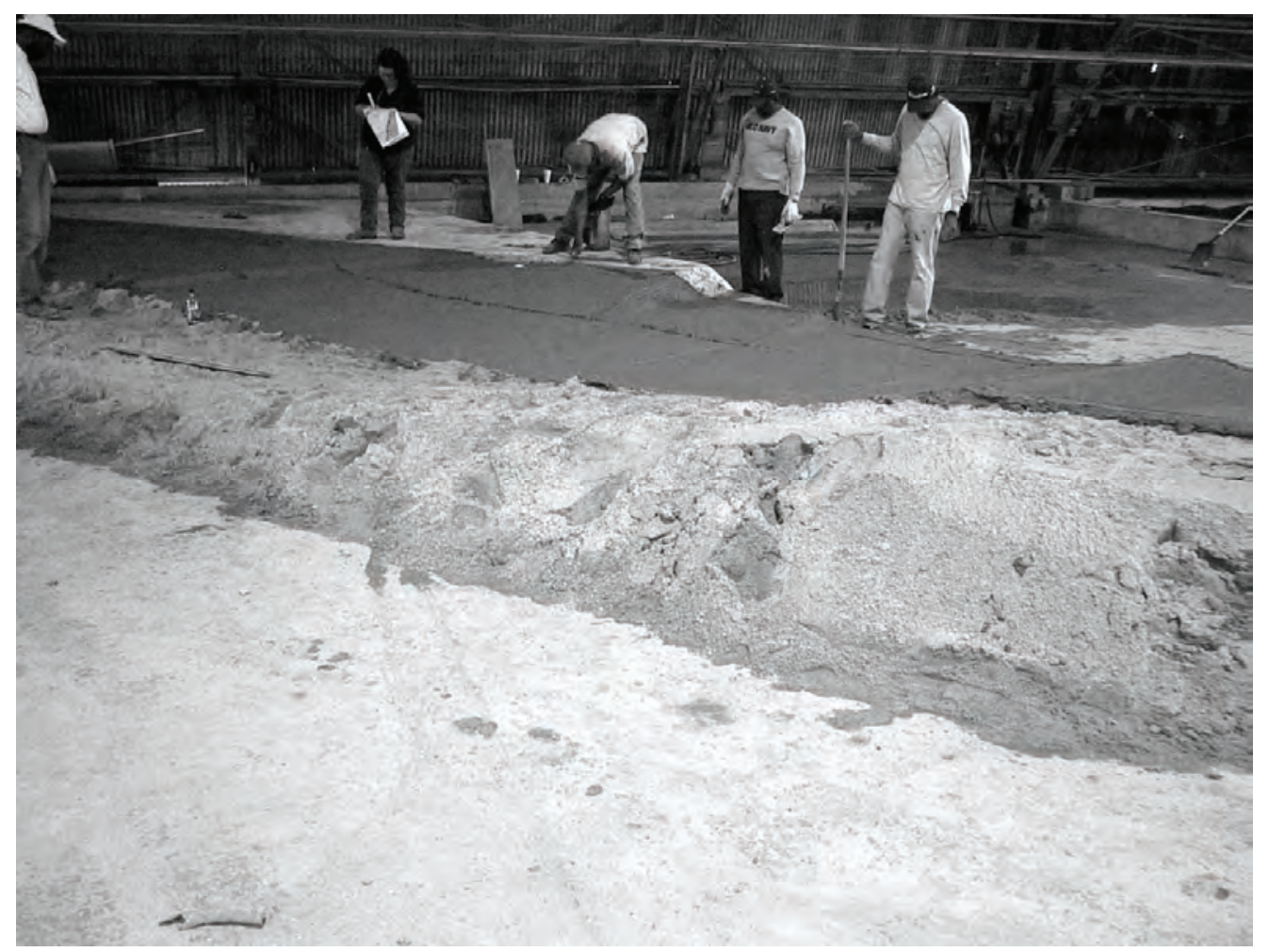

Figure 7. Start of model construction at southern portion of modeled area.



Figure 8. Placing of templates in Sitka model.

After completion of the fixed-bed bathymetry, that portion of the model below mllw was painted blue, and the portion above mllw was painted beige. This paint scheme helped visitors viewing the model to visualize the region. 


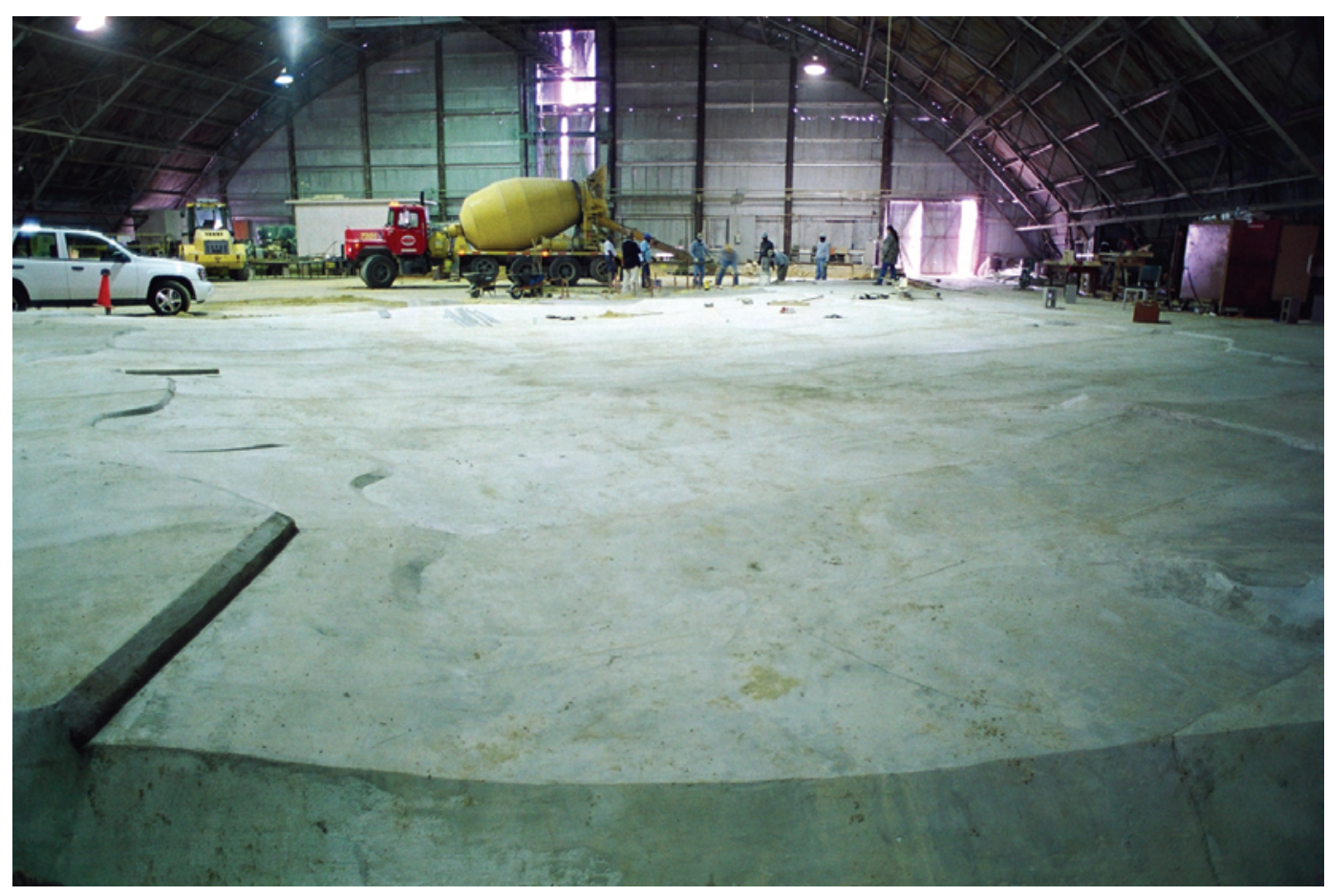

Figure 9. Model nearing completion (view from southern end of model).

\section{Shoreline revetments}

Those portions of the bay shoreline protected with stone revetments were recreated in the physical model. The general revetment slope was molded with concrete, and appropriately scaled stones were then placed on the slope to provide a reasonable representation of the revetments. At higher water levels these revetments are partially submerged, and the revetments absorb some incident wave energy and reflect the rest. Figure 10 shows a section of J aponski Island shoreline revetment just to the west of the gap between the westernmost breakwater and the shoreline.

\section{Detached breakwaters}

The three detached breakwaters play an important role in reducing wave energy entering the region of New Thomsen Harbor. The breakwaters at Sitka were constructed with an impermeable core with a top elevation estimated to be at approximately $+9.2 \mathrm{ft}$ mllw. The core was protected by an 2-ft-thick underlayer of Class B stone, and a 5-ft-thick layer of armor stone. The final crest elevation of the breakwaters was $+16.4 \mathrm{ft} \mathrm{mllw}$, and the breakwater side slopes were built at $1 \mathrm{~V}$-on-1.5H. 


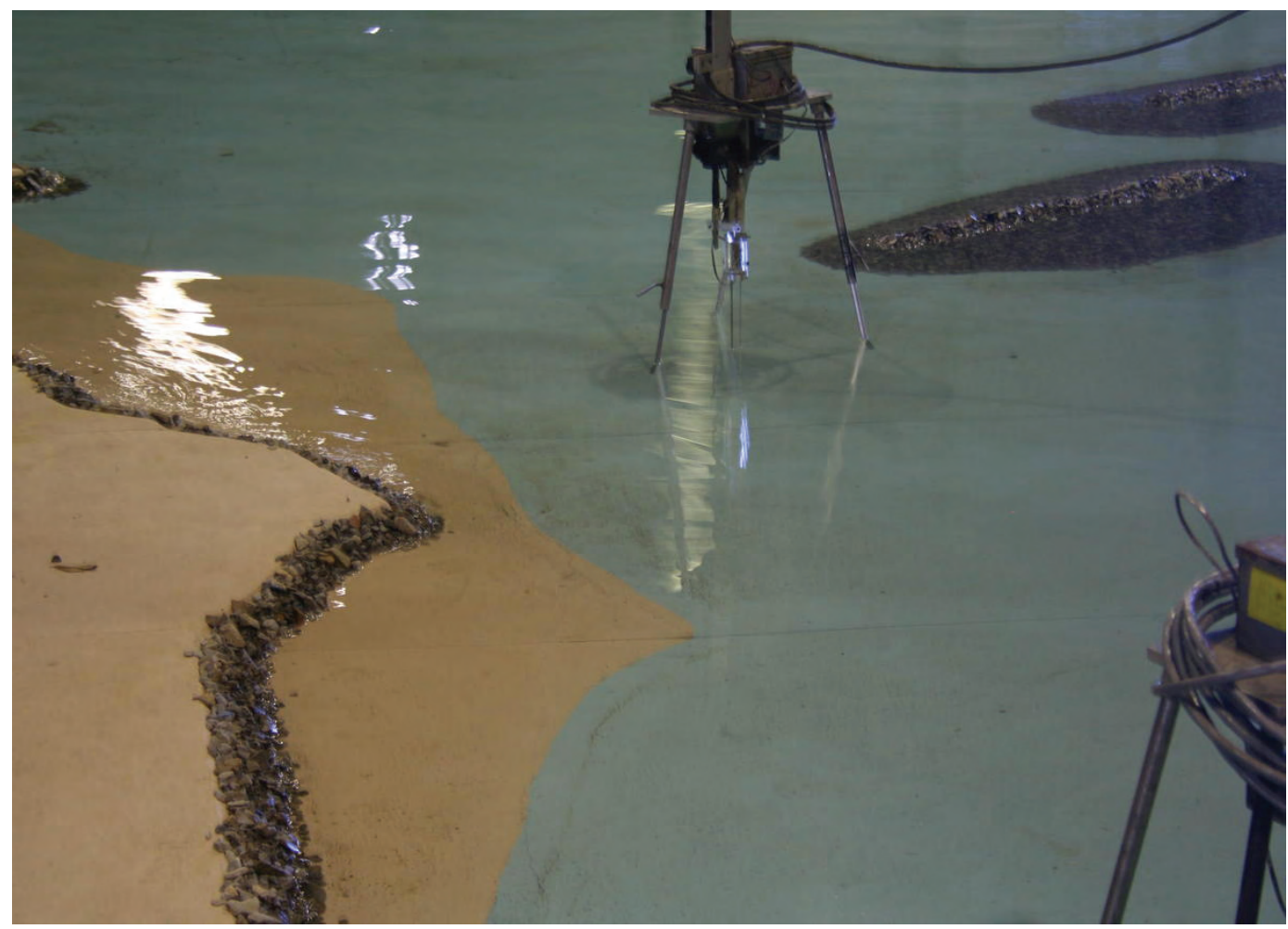

Figure 10. A portion of shoreline revetment reproduced in physical model.

In the physical model, the impermeable core was constructed with concrete mortar. Templates of the finished breakwater cross sections were cast into the core at about 2-ft spacing. Underlayer and armor stones were selected according to the same size distribution specified in the design documents (scaled to model size) and hand-placed on the breakwaters. The final breakwater elevation and cross section were checked and adjusted to assure conformance with the original design. All the armor stones on the model breakwaters remained stable throughout testing even with wave conditions greater than those anticipated by the original design. Breakwater elevation was repeatedly checked during testing to correct for any settlement or nesting of armor stones that may have occurred. Figure 11 shows a portion of the breakwater during testing.

Figures 12 and 13 are overhead views of the completed physical model. The vantage point of Figure 12 is from the north looking into the protected Western Channel and New Thomsen Harbor. The outer docks of the harbor are indicated by the black lines painted on the seafloor toward the upper left of the photograph. For a sense of scale, notice the engineers from the Alaska District standing on the right side of the image. Figure 13 includes the northern tip of J aponski Island and the two offshore islands included in the model. The unpainted portion of the model is at the $-80 \mathrm{ft}$ 
contour. The wave machine can be seen on the far left side of Figure 13. Notice the complex wave patterns around the islands and the damping effectiveness of the detached breakwaters.

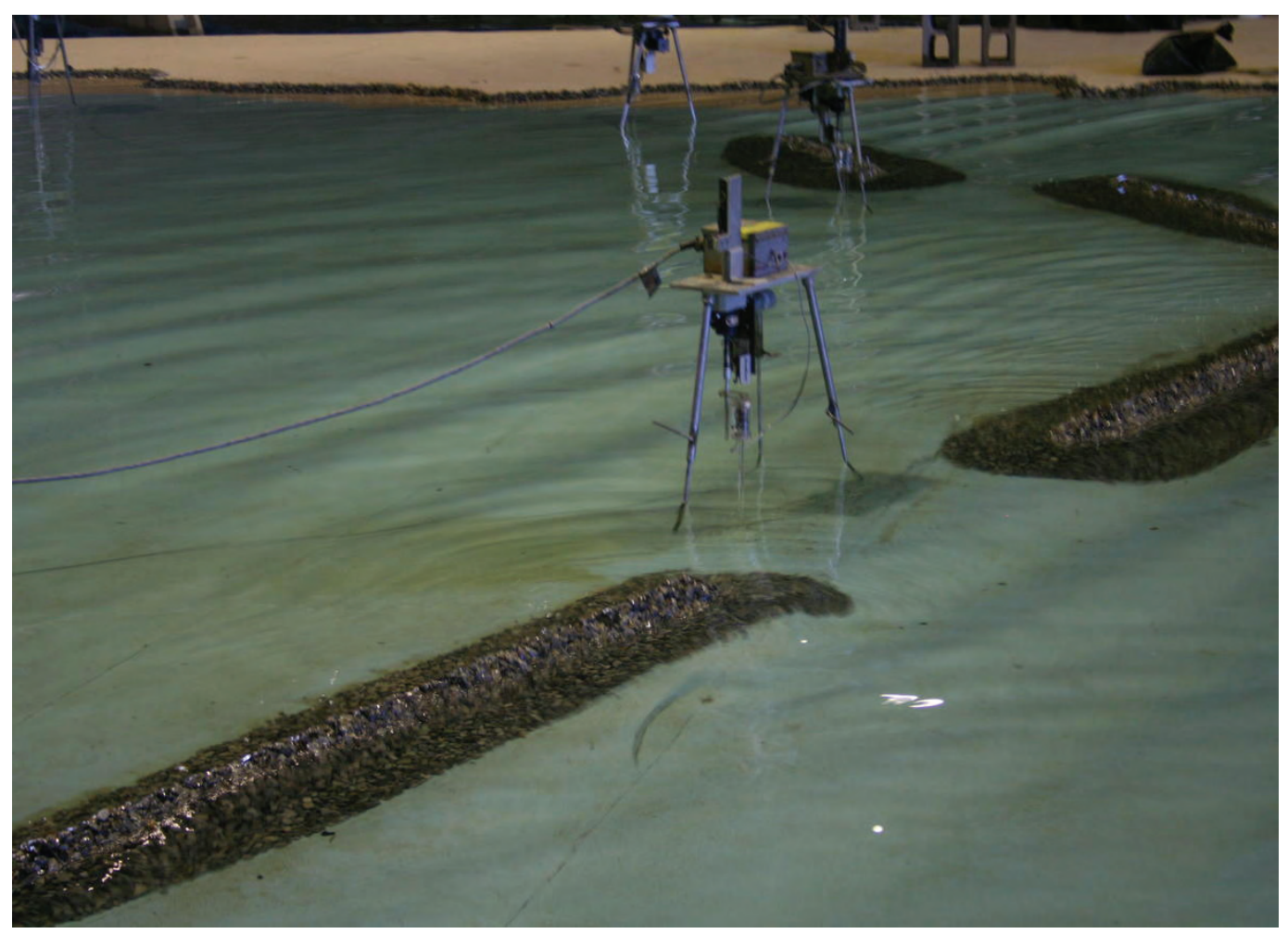

Figure 11. Sitka breakwaters replicated in physical model.

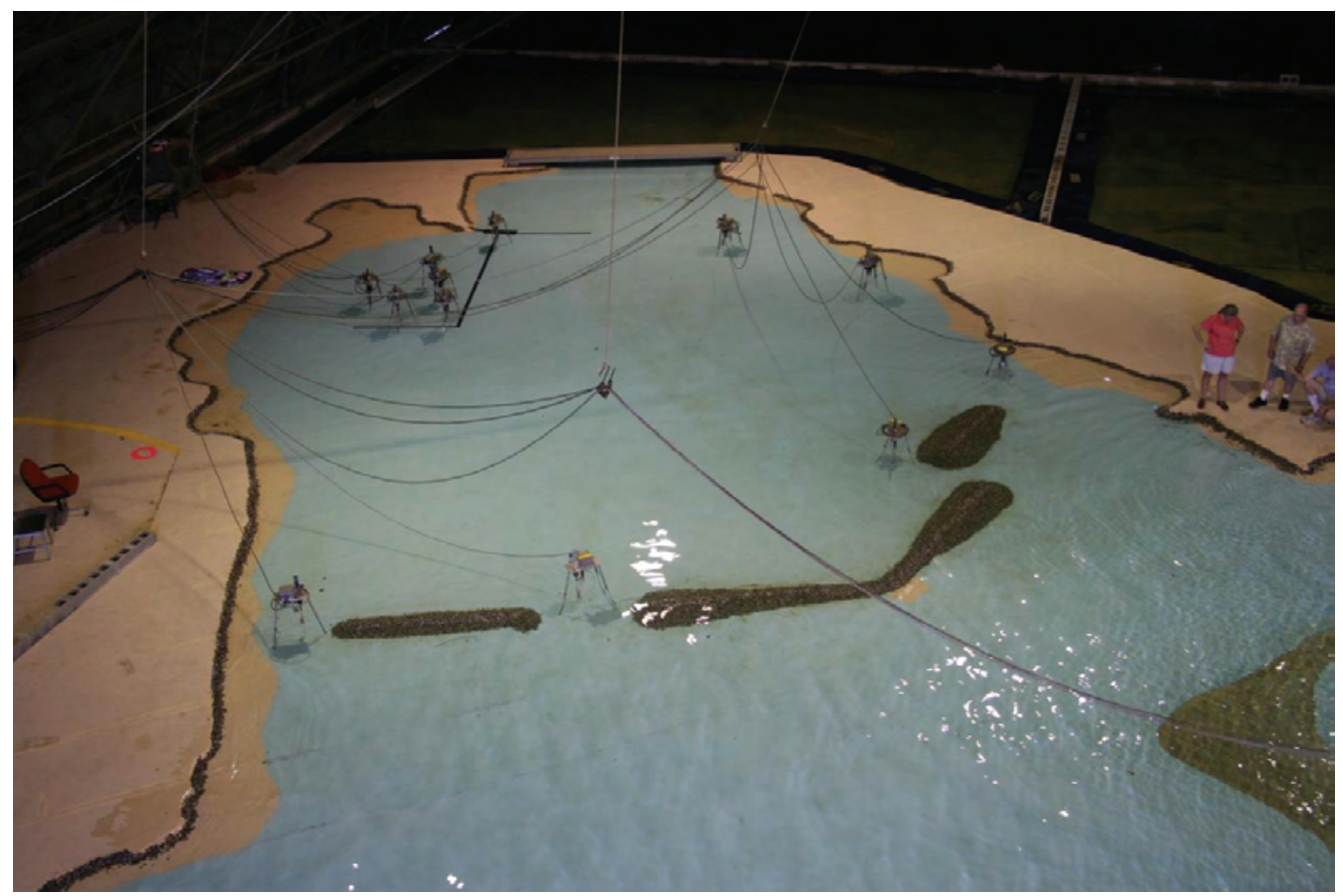

Figure 12. Aerial view of completed physical model. 


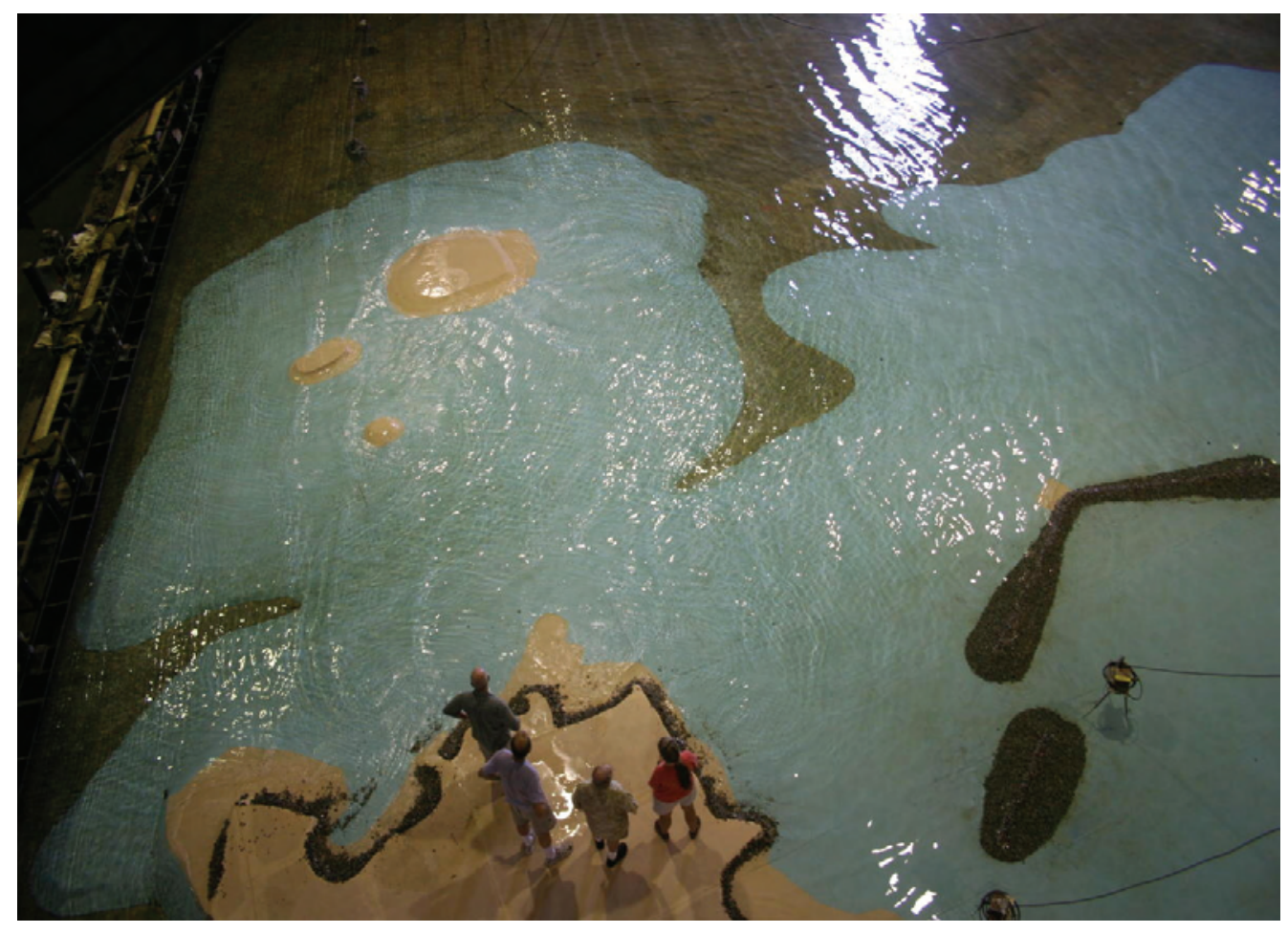

Figure 13. Aerial view showing offshore portion of physical model. 


\section{Instrumentation and Procedures}

A physical model is similar in ways to an analog computer because reactions in the model are governed by the physical forces generated by waves and flowing water. If the model is not properly configured, or if the model is not properly operated, model results can be negatively influenced or even incorrect. Thus, care is needed in setting up the experiments and assuring that correct operating procedures are followed.

This chapter describes the instrumentation used to record model response, overviews the wave calibration methodology, discusses the procedures followed when operating the physical model, and describes the data collection and initial data analyses.

\section{Experiment instrumentation}

The following sections briefly describe the instrumentation used to acquire measurements of the New Thomsen Harbor wave agitation in response to different forcing and boundary conditions.

\section{Still water level}

Throughout the duration of each test, the still water level in the physical model basin was kept at a constant elevation specified for that particular test. An automated water level monitoring and correction system was installed to counter slow leaks in the physical model. Water elevation was constantly monitored in a stilling well located at the deepwater boundary wall of the physical model, and any drop in water elevation triggered opening of an automated water line valve. The inflow of water to the basin continued until the correct water level was restored.

Before the start of each experiment, the water level was checked using a point gauge mounted in the vicinity of the shoreline close to the northernmost detached breakwater. Vertical positioning of this point gauge was related to the primary model benchmark.

\section{Waves}

The key physical parameter measured during the New Thomsen Harbor wave agitation tests was variation of the sea surface water elevation as a function of time at selected locations throughout the physical model. 
Waves were measured in the Sitka physical model using capacitance-type wave gauges mounted on tripods at fixed locations. Figure 14 shows several wave gauges located near the floating breakwater (designated by black line on bottom) that protects New Thomsen Harbor. Wave gauges can also be seen in Figures 10 and 11 in Chapter 3.

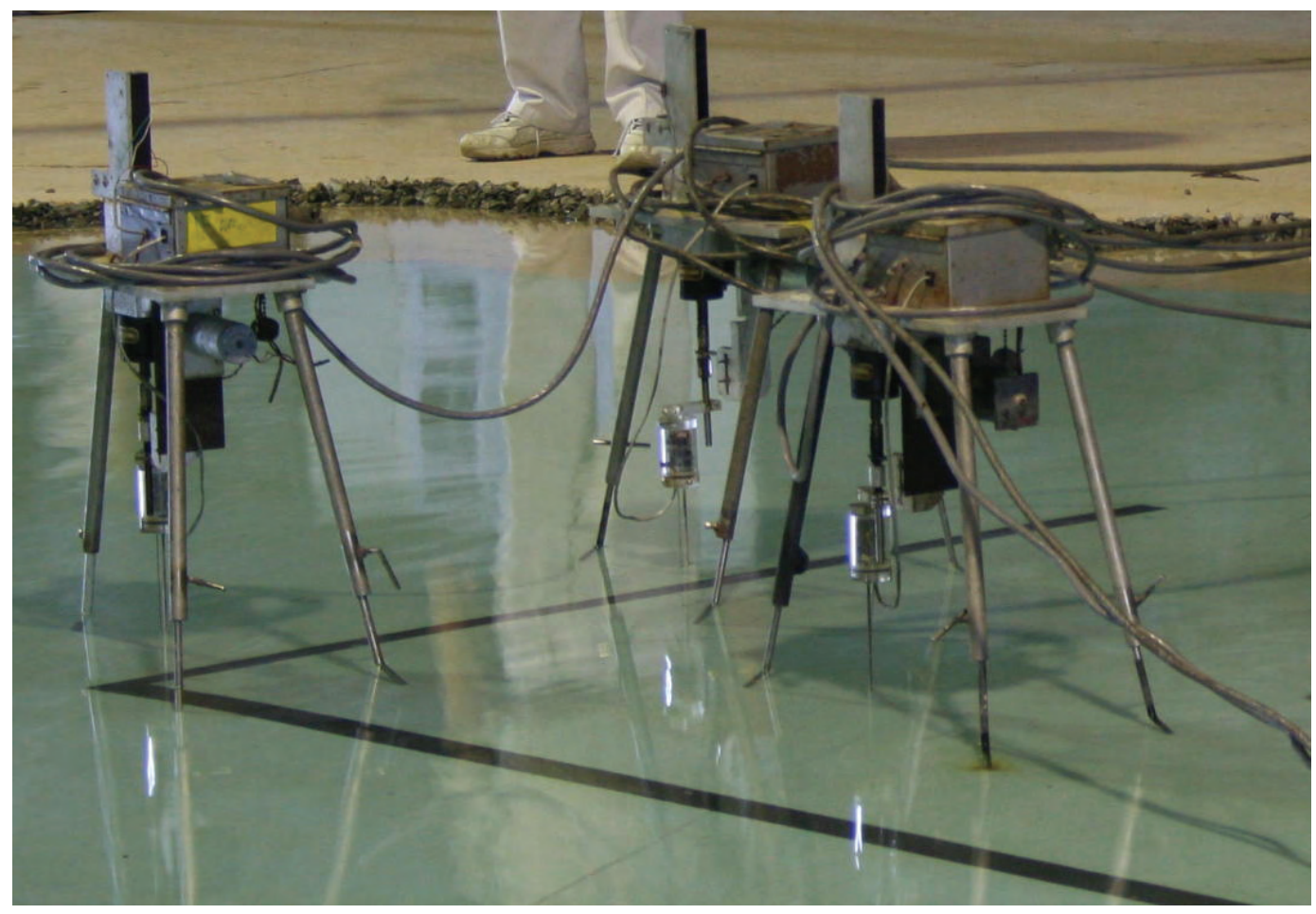

Figure 14. Wave gauges in vicinity of New Thomsen Harbor floating breakwater.

As many as 19 wave gauges were used during some experiments, and the wave gauge locations were varied over the course of the study according to the measurement needs of each experiment. Details of gauge layouts are given in Chapter 5 for all experiments.

The capacitance gauges measured the vertical variation of the water surface as the waves moved past the gauge position. The gauges work by sensing the change in capacitance in a thin insulated vertical wire as the water elevation varies on the wire. Each gauge captures a time series of information that can be converted into water surface elevations at that location. The time series can then be analyzed to obtain wave information.

All wave gauges were mounted on remotely controlled stepping motors that permit the gauges to be raised and lowered precise vertical distances for calibration. The range of calibration was estimated for the largest waves expected to be generated in the model. Wave gauges were calibrated 
daily with the water at test level and motionless. The gauges were first raised 10 equal increments, then lowered 20 equal increments, and finally raised 10 equal increments to bring the gauges back to their original vertical positions. Data collected at each stopping point were analyzed to establish the relationship (usually linear) between water elevation at the gauge and frequency output by the gauge. Provided all gauges exhibited the expected calibration, the calibration relationship was saved in a file for later application to the measured raw wave data collected the same day as the calibration.

For all experiments, wave data collection started at the same instant the wavemaker was activated, and continued through the duration of the experiment (until the wave board stopped). Time series sea surface elevation data were collected at a $20-\mathrm{Hz}$ rate. Wave data were transmitted into the main control room and recorded on a computer for post-experiment processing. At the selected model scale, wave heights of $1 \mathrm{ft}$ in Thomsen Harbor would be 0.16 in. ( $4 \mathrm{~mm}$ ) at model scale, and the wave gauges are capable of measuring these small variations in sea surface elevation.

\section{Wave generation and calibration}

\section{Wave machine}

Waves in the New Thomsen Harbor physical model were generated with a computer-controlled, vertical displacement plunger-type wave machine. Figure 15 shows a side view of the plunger wave board. The trapezoidal section moves up and down in the water to create waves by displacing a volume of water. This type of wavemaker produces long-crested, regular or irregular waves, but it cannot generate waves having directional spreading in the wave spectra. However, the wave approach directions to Sitka are limited somewhat by the adjacent land masses, so waves reaching the study area will not exhibit a large amount of directional variability. It was concluded that representation of directional wave trains in nature by longcrested waves propagating in a single direction in the model was a reasonable compromise. 


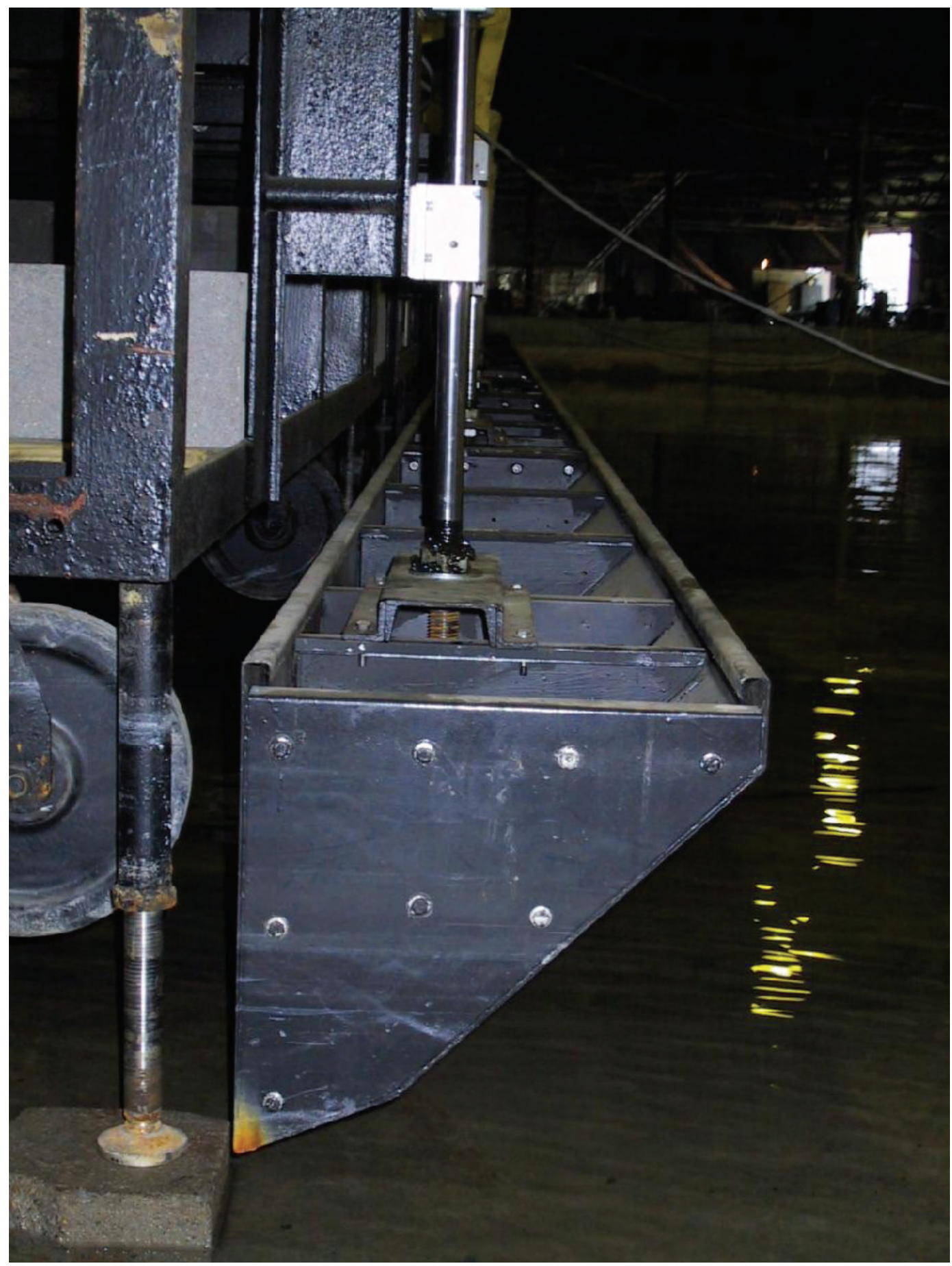

Figure 15. Wave board of plunger-type wave machine used in physical model. 


\section{Wave calibration}

For model testing, waves can be either irregular or regular (monochromatic) wave. Irregular waves are preferred because they are more realistic, but there are instances in which regular waves can provide insight into the physical processes. Creating irregular waves in the model basin requires specification of the wave board up-and-down motion as a function of time. The wave board motion generates a time series of corresponding wave motions.

Several steps were required in order to assure the generated wave time series represented a scaled version of the target wave conditions. First, spectral representations of wave conditions typical of storm waves with wave height and periods in the range specified by the Alaska District were scaled to model-size spectra. A computer program then created a time-series realization of sea surface elevations that matched the spectral description given by spectral shape (idealized TMA spectrum), significant wave height $\left(H_{m 0}\right)$, and peak spectral period $\left(T_{p}\right)$. The next step was to apply a relationship that converted the wave time series to an appropriate wave board stroke time series.

Whereas mathematical formulas are available for specifying wave motions for piston-type and flapper-type wave machines, there is no practical relationship for converting from sea surface elevation time series to equivalent wave board stroke time series for plunging-type wavemakers. Therefore, it was necessary to calibrate the wave machine following a standard procedure used at CHL.

Based on past experience with this wave machine, an approximate wave board stroke time series with correct spectral shape and peak wave period was generated to command the wave machine. This signal was run in the basin at the specified water level, and measurements were made at three wave gauges positioned in a line parallel to the wave machine and in the same water depth. These measurements were analyzed and averaged, and a gain factor was calculated that would uniformly increase or decrease the wave board stroke signal to match the target spectrum. Then the test was repeated with the new board signal. Once the measured spectra matched the target spectra, the command signals were saved for future use in tests specifying that particular combination of wave parameters and water depth. This procedure was repeated for each unique combination of $H_{m 0}$, $T_{p}$, and water depth. 


\section{Range of wave conditions}

The initial wave machine calibration was for irregular waves with the water elevation at $+11 \mathrm{ft}$ mllw (prototype-scale units) for all conditions. Wave signals were calibrated for two significant wave heights $\left(H_{m 0}=5,10 \mathrm{ft}\right)$, and seven peak wave periods $\left(T_{p}=4,6,8,10,12,14,16 \mathrm{sec}\right)$ for a total of 17 unique wave conditions. Wave calibration does not depend on wave direction because the calibration is for waves near the wave board before any transformation due to shoaling or wave refraction/ diffraction. Therefore, orientation of the wave machine was immaterial to the calibration. With plunger-type wavemakers it is possible to run these wave board signals at higher and lower water levels without too much difference in resulting wave height. However, it is best to calibrate at each water level if possible.

Toward the end of model testing ERDC and the Alaska District engineers decided to test several wave conditions for which no previously calibrated wave board signals existed. These additional wave conditions are listed in Table 3 along with the original calibration set described above. In Table 3 all values are given in prototype-scale units. Wave height and period for irregular wave conditions refer to $H_{m 0}$ and $T_{p}$, respectively. For monochromatic waves, wave height is the actual height of the wave and not the value of $H_{m 0}$ estimated from the measured spectrum. Equivalent modelscale units can be found using the scale ratios summarized in Table 2, Chapter 3.

Table 3. Calibrated wave conditions for testing of New Thomsen Harbor model.

\begin{tabular}{|l|l|l|l|}
\hline Wave Type & $\begin{array}{l}\text { Water Level } \\
\text { (Prototype Units) }\end{array}$ & $\begin{array}{l}\text { Wave Height } \\
\text { (Prototype Units) }\end{array}$ & $\begin{array}{l}\text { Wave Period } \\
\text { (Prototype Units) }\end{array}$ \\
\hline Irregular & $+11 \mathrm{ft} \mathrm{mllw}$ & $5 \mathrm{ft}$ and $10 \mathrm{ft}$ & $4,6,8,10,12,14$, and $16 \mathrm{sec}$ \\
\hline Irregular & $+11 \mathrm{ft} \mathrm{mllw}$ & $5 \mathrm{ft}$ & $24 \mathrm{sec}$ \\
\hline Irregular & $+13 \mathrm{ft} \mathrm{mllw}$ & $10 \mathrm{ft}$ & 12 and $20 \mathrm{sec}$ \\
\hline Monochromatic & $\begin{array}{l}+0 \mathrm{ft} \text { mllw and } \\
+10 \mathrm{ft} \mathrm{mllw}\end{array}$ & $6 \mathrm{ft}$ & $3.5,5,12$, and $15 \mathrm{sec}$ \\
\hline
\end{tabular}

The $3.5 \mathrm{sec}$ wave period ( $0.4 \mathrm{sec}$ model scale) was the shortest wave period that could be generated in the model with the specified significant wave height.

\section{Model operation procedures}

Generally, the following standard procedures were followed during the conduct of a test in the New Thomsen Harbor physical model. 
a. The model was flooded to the elevation for the test, and an automatic system was started that monitored the water level, adding water when needed. Water slowly leaked out of the basin overnight, so each morning it was necessary to add water to return the water level to the correct elevation. Throughout the day manual checks of water level using the point gauge were also performed.

$b$. If necessary, wave gauges were moved to locations specified for the experiment or set of experiments being conducted.

c. Every day before starting any experiments, the wave gauges were calibrated while the water elevation was motionless. Typically, the calibration procedure took $30 \mathrm{~min}$. On rare occasions a gauge would fail calibration and have to be repaired or replaced. On several days during the testing, the wave gauge calibration was repeated at the end of the day to check whether temperature changes in the shelter during the day had affected the capacitance wave gauge response.

d. Some experiments looked at differences in harbor wave agitation for different engineering modifications, such as closing one or more gaps, placing wave absorbers, etc. These modifications were made prior to the start of the run by ERDC staff, who waded into the model to make the adjustments.

e. After all disturbances in the water surface had dissipated, the command was given to start the wave machine. Data collection from the wave gauges started at the same time. Waves were run continuously for a total of $10 \mathrm{~min}(600 \mathrm{sec})$. Wave data collection stopped at the same time the wave machine stopped, even though waves continue to arrive at the harbor for about $30 \mathrm{sec}$ after the wave machine stopped.

$f$. At the conclusion of each run, the collected wave data were immediately processed as described in the following section and saved. On many occasions, resulting wave parameters were summarized and printed so ERDC and Alaska District engineers could review the results of particular modifications and develop additional variations based on these results. In other words, testing was an interactive process with immediate feedback being used to guide the testing program.

g. Approximately 10 to $15 \mathrm{~min}$ were allowed for the basin water motions to settle before initiating another test. During settling, basin motion was monitored on selected wave gauges. Allowing $30 \mathrm{~min}$ for calibration and 15 min settling time between runs, it was possible to conduct a maximum of 14 experiments in the model during an 8-hr working day. 
Of course, engineering modifications, data assessment, etc., reduced this maximum on most days.

\section{Data collection and initial analyses}

Wave measurements were acquired at a minimum of 15 locations throughout the New Thomsen Harbor physical model. Three gauges were permanently located on a line parallel with and near to the wavemaker. These gauges were used to calibrate the waves and to provide the nominal wave parameters before waves underwent shoaling, refraction by the bathymetry, and diffraction around the islands. The only time these gauges were moved was in conjunction with relocation of the wavemaker. Details of wave gauge layouts for specific tests are given in Chapter 5 .

At the completion of each experiment, the collected data were immediately converted into engineering units and stored in a computer file containing the necessary identifying information. Data channels from the wave gauges were converted into model units of meters by applying the calibration factors determined at the start of testing for that day. Subsequent analyses typically expressed results in customary English units scaled up to prototype size. This allowed engineers to have a better understanding of the measurements.

As mentioned, sea surface elevation data were collected for a total of $10 \mathrm{~min}(600 \mathrm{sec})$ at a $20-\mathrm{Hz}$ rate giving time series of 12,000 points for each data channel. It took about $30 \mathrm{sec}$ for the first generated waves to reach the wave gauges located in the vicinity of New Thomsen harbor, and prior to wave arrival the water surface was stationary. Therefore, the first $30 \mathrm{sec}$ of data collection (600 data points) were discarded from the time series for subsequent analyses. (Note that the time of wave arrival depends on wave period, and the 30 -sec value cited corresponded to the shortest period waves used in the study.)

Standard post-test analysis of the recorded wave gauge signal included time series analysis for representative statistics such as significant wave height $\left(H_{1 / 3}\right)$ and mean wave period $\left(T_{m}\right)$, and the wave height distribution. Frequency-domain analysis decomposed the measured irregular wave time series under the assumption that the measurement can be represented by the summation of many sine waves of differing amplitudes and periods. The main result from frequency-domain analysis was a wave energy spectrum that indicated the distribution of wave energy over the range of wave frequencies (inverse period). The square root of the area 
under the spectrum times four is known as the "zeroth-moment" wave height, or $H_{m 0}$. This parameter is often called significant wave height because, for narrow-banded spectra in deep water, $H_{m 0}$ is approximately equal to $H_{1 / 3}$. The other key parameter taken from frequency-domain analysis is the wave period associated with the spectral peak, $T_{p}$. Various representations of the analyzed wave parameters were prepared in the form of line or bar charts for comparison purposes.

Figure 16 illustrates a typical output plot from the Generalized Experiment Control and Data Acquisition Package (GEDAPTM) analysis package. The figure shows the plotted time series in model-scale engineering units, analyzed wave spectrum, and both frequency- and time-domain representative parameters in model units. This standard analysis gave engineering values for comparison of wave agitation between different gauges and different engineering alternatives. The visual output provided a means to judge the quality of the data just recorded.

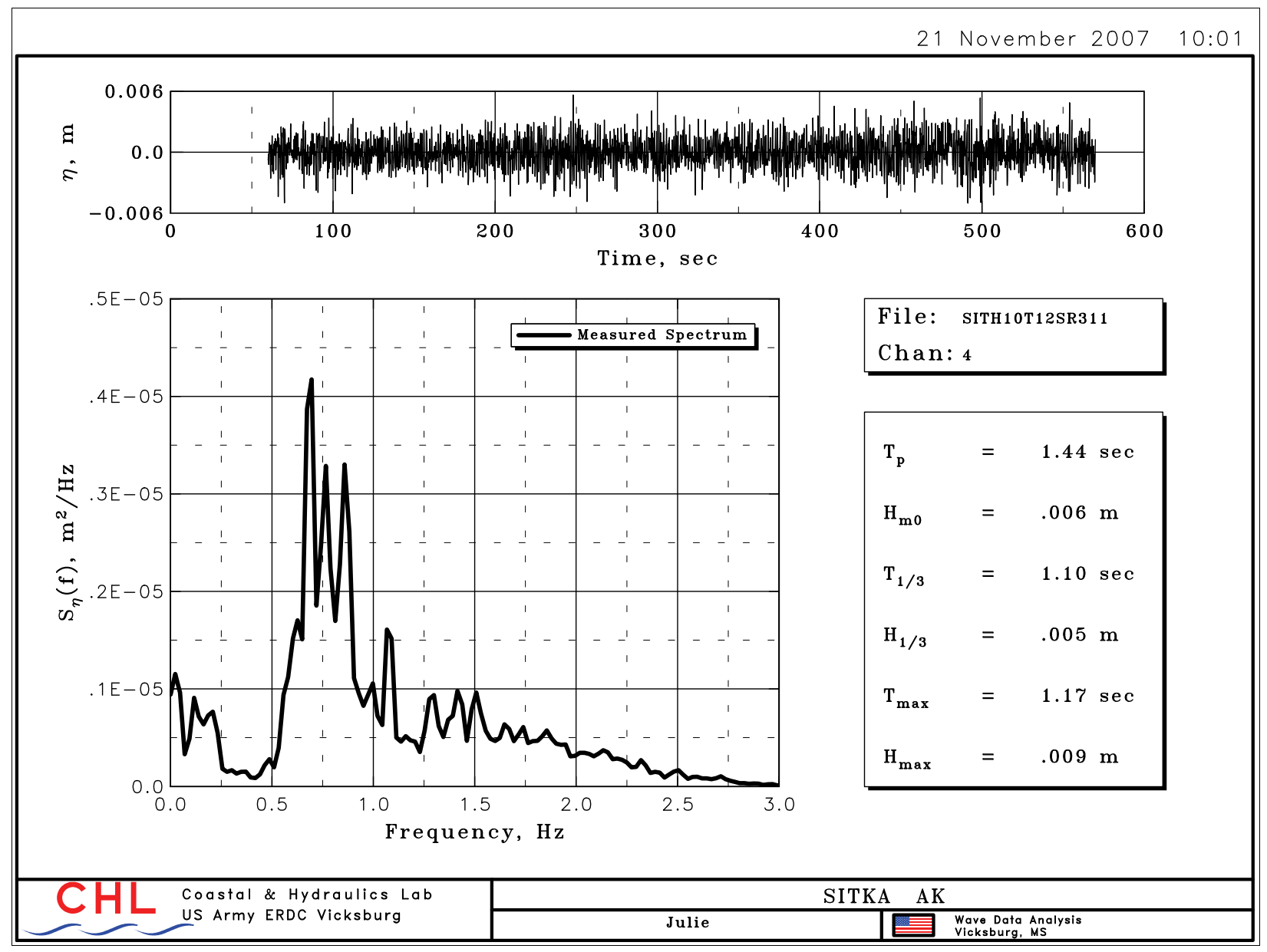

Figure 16. Wave analysis output from model wave measurements. 
Wave heights for monochromatic waves were determined strictly from the time-domain analysis as the average of the highest one-third waves $\left(H_{1 / 3}\right)$. This parameter is a closer match to the actual wave height than the frequency-domain parameter $H_{m 0}$. Wave period was determined as the average wave period, $T_{m}$, found from time-domain upcrossing analysis.

Several custom MatLab ${ }^{\circledR}$ scripts were written to display time series data in unique ways and to compare vertical differences between adjacent wave gauges as a function of time. For some of the experiments, 12 wave gauges were arranged in an equally spaced array along the location of the main floating dock in New Thomsen Harbor. Separation distance between gauges was $100 \mathrm{ft}$ ( $16 \mathrm{in}$. model scale) for some tests and $75 \mathrm{ft}$ (12 in. model scale) for other tests.

The MatLab ${ }^{\circledR}$ script read in all 12 wave gauge time series and processed the information to determine the vertical differences due to wave passage between adjacent locations at each instance of time. The code also plotted distributions of the differences and determined the maximum difference at each location. This information was used to assess excessive wave motion along the main floating dock. An optional routine created animations of the vertical differences along the entire floating dock. The time series at each gauge location was plotted to identify any locations that might have experienced unusually large wave heights due to focusing of wave energy or interaction between two wave trains. 


\section{Overview and September 2005 Results}

This chapter provides a brief overview of all the experiments conducted as part of the New Thomsen Harbor physical model study, followed by a presentation of engineering results for the tests conducted in September 2005. Chapters 6, 7, and 8 give results for tests conducted in J une 2006, November 2006, and February 2007, respectively.

\section{Overview of testing program}

A total of 179 experiments were conducted using the Sitka physical model during four time periods spanning from the completion of the model in September 2005 to February 2007. Each testing session or series had one or more specific purposes related to understanding the cause for unacceptable wave action in New Thomsen Harbor and finding one or more possible engineering solutions to reduce wave action.

Table 4 summarizes all testing and gives nominal values of the incident wave parameters. The nominal values of wave height and period were the target values for those experiments. For most experiments these values were not precisely achieved. Actual wave heights and periods obtained from analysis of the measured wave data are given in tables included in the detailed discussions of the tests. The following is a brief description of each distinct testing period:

a. September 2005. The initial model test series consisted of 53 tests. The main purposes of the testing were to determine the cause for excessive wave action in the harbor, to examine the effect of closing one or more gaps between the breakwaters, and to look at several proposed engineering modifications. Details of the testing and test results are provided later in this chapter.

b. June 2006. These 17 tests looked at the instantaneous vertical differential between wave gauges aligned at $100-\mathrm{ft}$ spacing along the main floating dock. The purpose was to see if waves passing through the harbor could cause enough vertical difference between gauges to create uncomfortable conditions. (See Chapter 6 for details.) 
Table 4. Summary of model test series.

\begin{tabular}{|c|c|c|c|c|c|c|}
\hline $\begin{array}{l}\text { No. } \\
\text { Tests }\end{array}$ & $\begin{array}{l}\text { Wave } \\
\text { Type }\end{array}$ & $\begin{array}{l}\text { Water } \\
\text { Level } \\
\text { (ft mllw) }\end{array}$ & $\begin{array}{l}\text { Wave } \\
\text { Height } \\
\text { (ft) }\end{array}$ & $\begin{array}{l}\text { Wave } \\
\text { Period } \\
\text { (sec) }\end{array}$ & $\begin{array}{l}\text { Wave } \\
\text { Dir. }\end{array}$ & Objectives \\
\hline \multicolumn{7}{|c|}{ September 2005} \\
\hline 13 & Irreg & +11 & 5,10 & 4,12 & SW & Effect of gap closure \\
\hline 9 & Irreg & +0 & 5,10 & 4,12 & SW & Effect of gap closure, other engr. options \\
\hline 12 & Irreg & +11 & 5 & 4,6 & NW & Effect of gap closure, other engr. options \\
\hline 19 & Irreg & +11 & 5 & $4-24$ & SW & Effect of gap closure and period, other engr. options \\
\hline \multicolumn{7}{|c|}{ June 2006} \\
\hline 5 & Irreg & +11 & 10 & 8-14 & SW & Float array at 100-ft spacing, differential along dock \\
\hline 12 & Irreg & +11 & 5,10 & $6-16$ & SW & Float array at 100 -ft spacing, differential along dock \\
\hline \multicolumn{7}{|c|}{ November 2006 - Groups 1, 3, and 4} \\
\hline 24 & Irreg & +11 & 5 & $10-16$ & SW & Gap closure effect on float array, Float plane gauges \\
\hline 16 & Irreg & +11 & 5 & $10-16$ & SW & Gap closure effect on float array, SW break. gauges \\
\hline 20 & Irreg & +11 & 5 & $10-16$ & SW & Gap closure effect on float array, SW break. gauges \\
\hline \multicolumn{7}{|c|}{ November 2006 - Groups 5, 6, 7, and 8} \\
\hline 2 & Irreg & +11 & 5 & 24 & SW & Wave penetration through/over breakwaters \\
\hline 6 & Irreg & +11 & 5 & $10,16,24$ & SW & Wave focusing by bathymetry, array to $-39 \mathrm{ft}$ contour \\
\hline 4 & Irreg & +11 & 5 & 10 & SW & Effect of shoreline wave absorption \\
\hline 4 & Irreg & +11 & 5 & 10 & SW & Effect of shoreline wave absorption \\
\hline \multicolumn{7}{|c|}{ November 2006 - Groups 9, 10, 11, and 12} \\
\hline 2 & Irreg & +11 & 5 & 10 & SW & Effect of first bathymetry modification \\
\hline 2 & Irreg & +11 & 5 & 10,24 & SW & Effect of first bathymetry modification, no absorber \\
\hline 2 & Irreg & +11 & 5 & 10,24 & SW & Effect of first bathymetry modification with absorber \\
\hline 2 & Irreg & +11 & 5 & 10,24 & SW & Effect of second bathymetry modification \\
\hline \multicolumn{7}{|c|}{ November 2006 - Groups 13 and 14} \\
\hline 2 & Mono & +11 & 5 & 10,24 & SW & Monochromatic waves with modified bathymetry \\
\hline 5 & Mono & +11 & 5 & 10,24 & SW & Effect of shoreline wave absorber, monochromatic \\
\hline \multicolumn{7}{|c|}{ February 2007} \\
\hline 6 & Irreg & $+13,+0$ & 10 & 12,20 & SW & Extreme water level wave effect \\
\hline 8 & Mono & $+10,+0$ & 6 & $3-15$ & SW & Effect of monochromatic waves \\
\hline 4 & Mono & +11 & 5 & 3,5 & NW & Waves at proposed future float plane facility \\
\hline
\end{tabular}


c. November 2006. Ninety-one tests were conducted during November and December 2006. In Table 4, these tests have been placed into four sections based on purpose of testing. Groups 1, 3, and 4 examined the effects of gap closure on waves along the main floating dock and wave action at areas suggested for a new float plane facility. Groups 5- 8 looked for evidence of wave focusing that appeared to cause increased wave heights at a particular location along the floating dock. Groups 912 examined the impact of modifying bathymetry that was thought to cause wave focusing, and Groups 13 and 14 used monochromatic waves in an attempt to clarify the wave action. (See Chapter 7 for details.)

d. February 2007. The final test series consisted of 18 tests. Additional testing variations were tried with the purpose of determining more definitively the cause for the excessive wave action reported at New Thomsen Harbor and documenting waves at the proposed future float plan facility. Test variations included higher water levels, lower water level with monochromatic waves, and waves from the northwest impacting the float plane facility location. Breakwater extensions were installed to decrease waves at the float plane facility location. (See Chapter 8 for details.)

Generally, variations between tests and test series included gauge placement, installed engineering modifications, incident wave height, wave period, wave direction, water elevation, and bathymetry modifications. Details are given in each chapter related to the specific test series. The primary results are given in terms of measured significant wave height at each gauge location. Measured wave heights are plotted and compared for individual tests and between different tests. The comparisons provide insight into possible causes of excessive wave motion and quantification of the relative effectiveness of different engineering alternatives. Where possible, hypotheses are offered to explain observed variations between different wave gauges and between different tests.

\section{Summary of September 2005 tests}

The 53 tests conducted 26- 29 September 2005 were aimed at understanding wave action within and around New Thomsen Harbor, and examining differences in the waves caused by a variety of engineering modifications. These tests were the first run in the model, and engineers from the Alaska District traveled to Vicksburg, MS, to participate fully in the testing by analyzing physical model response and recommending modifications. 
Table 5 summarizes the tests for this grouping with given values converted to prototype scale. All tests were run with irregular waves, and the values of significant wave height $\left(H_{m 0}\right)$ and peak spectral period $\left(T_{p}\right)$ given in Table 5 were obtained from measurements acquired at the three wave gauges directly in front of the wavemaker. The column labeled "Dir" is the direction from which waves came. The notations in the column labeled "Gaps" indicate which gaps were open (O) or closed (C). Gaps were numbered 1 through 4 starting with the southernmost gap near J aponski Island and ending with the gap between the breakwater and shoreline near Halibut Point Road (see Figure 36 in Chapter 7). Thus, the notation COCC for test 3 would indicate that only gap 2 was open for that experiment.

\section{Wave gauge locations for tests 1-34}

Locations of the 15 wave gauges used in tests 1 through 34 are given on Figure 17. Gauges 1- 3 were located offshore adjacent to the wavemaker to record the incident reference wave condition. (The locations shown in Figure 17 for the offshore gauges are not the actual gauge locations. These locations are just for illustration purposes.) Gauges 4, 5, 6, and 7 were placed in gaps 1, 2, 3, and 4, respectively. Gauges 8 and 9 were situated as shown in Figure 17 in areas that might be considered for float plane operations. Finally, gauges 10- 15 were placed inside New Thomsen Harbor at the locations shown in the figure. The harbor floating docks were not reproduced in the physical model, so measured wave heights inside the harbor do not include any wave reduction benefits from the floating docks. 
Table 5. Experiment parameters for September 2005 tests.

\begin{tabular}{|c|c|c|c|c|c|c|}
\hline \# & $\begin{array}{l}\text { Water } \\
\text { Level } \\
\text { (ft) }\end{array}$ & $\begin{array}{l}H_{m 0} \\
(\mathrm{ft})\end{array}$ & $\begin{array}{l}T_{p} \\
\text { (sec) }\end{array}$ & Dir & Gaps & Notes \\
\hline 1 & +11 & 5.0 & 12.0 & SW & All open & \\
\hline 2 & +11 & 5.0 & 12.0 & SW & OCCC & \\
\hline 3 & +11 & 5.0 & 12.0 & SW & cocc & \\
\hline 4 & +11 & 5.0 & 12.0 & SW & $\operatorname{ccoc}$ & \\
\hline 5 & +11 & 4.9 & 12.0 & SW & CCco & \\
\hline 6 & +11 & 4.7 & 12.0 & SW & All closed & \\
\hline 7 & +11 & 3.3 & 4.4 & SW & All open & \\
\hline 8 & +11 & 7.5 & 4.0 & SW & All open & \\
\hline 9 & +11 & 7.0 & 5.0 & SW & OCCC & \\
\hline 10 & +11 & 7.0 & 5.0 & SW & cocc & \\
\hline 11 & +11 & 7.0 & 5.0 & SW & $\operatorname{ccoc}$ & \\
\hline 12 & +11 & 7.5 & 4.0 & SW & ccco & \\
\hline 13 & +11 & 7.5 & 4.9 & SW & All closed & \\
\hline 14 & +0 & 5.0 & 12.0 & SW & All closed & \\
\hline 15 & +0 & 7.5 & 4.6 & SW & All closed & \\
\hline 16 & +0 & 5.1 & 12.0 & SW & occc & \\
\hline 17 & +11 & 6.2 & 11.6 & SW & All open & Airport extension, gauges 1 and 10 suspect \\
\hline 18 & +11 & 6.2 & 12.0 & SW & All open & City expansion plan, gauges 1 and 10 suspect \\
\hline 19 & +11 & 6.2 & 12.0 & SW & All open & City expansion plan, main entrance narrowed to $150 \mathrm{ft}$ \\
\hline 20 & +11 & 6.2 & 12.0 & SW & All open & As above with shore extension removed, 1 and 10 suspect \\
\hline 21 & +11 & 6.2 & 12.0 & SW & All open & Main entrance at $150 \mathrm{ft}$, shore extension/city plan remove \\
\hline 22 & +11 & 6.3 & 12.0 & SW & All open & As above with main breakwater rehabilitated \\
\hline
\end{tabular}


Table 5 (concluded).

\begin{tabular}{|c|c|c|c|c|c|c|}
\hline \# & $\begin{array}{l}\text { Water } \\
\text { Level } \\
\text { (ft) }\end{array}$ & $\begin{array}{l}H_{m 0} \\
(\mathrm{ft})\end{array}$ & $\begin{array}{l}T_{p} \\
\text { (sec) }\end{array}$ & Dir & Gaps & Notes \\
\hline 23 & +11 & 10.9 & 4.4 & NW & All open & \\
\hline 24 & +11 & 6.5 & 6.0 & NW & All open & \\
\hline 25 & +11 & 4.7 & 4.4 & NW & All open & \\
\hline 26 & +11 & 5.0 & 4.4 & NW & All closed & \\
\hline 27 & +11 & 5.1 & 4.4 & NW & occc & \\
\hline 28 & +11 & 5.0 & 4.4 & NW & $\operatorname{cocc}$ & \\
\hline 29 & +11 & 4.7 & 4.4 & NW & $\mathrm{ccoc}$ & \\
\hline 30 & +11 & 4.9 & 4.4 & NW & ccco & \\
\hline 31 & +11 & 4.8 & 4.4 & NW & All open & City expansion plan \\
\hline 32 & +11 & 4.8 & 4.4 & NW & All open & City expansion plan, Main breakwater narrowed to $150 \mathrm{ft}$ \\
\hline 33 & +11 & 4.7 & 4.4 & NW & All open & Main breakwater narrowed to $150 \mathrm{ft}$ \\
\hline 34 & +11 & 4.7 & 4.4 & NW & All open & Main breakwater narrowed to $100 \mathrm{ft}$ \\
\hline 35 & +11 & 16.0 & 4.4 & SW & All open & Gauges 7 and 9 moved \\
\hline 36 & +11 & 5.5 & 7.9 & SW & All open & Gauges 7 and 9 moved \\
\hline 37 & +11 & 4.9 & 4.4 & SW & All open & Gauges 7 and 9 moved \\
\hline 38 & +11 & 4.7 & 4.4 & SW & All open & City expansion plan, gauges 7 and 9 moved \\
\hline 39 & +11 & 4.9 & 4.4 & SW & All open & Entrance channel to $100 \mathrm{ft}$, gauges 7 and 9 moved \\
\hline 40 & +11 & 5.4 & 7.9 & SW & All open & With wind-generated waves, gauges 7 and 9 moved \\
\hline 41 & +11 & 4.7 & 4.4 & SW & All open & Gauges 7,9 , and 15 moved \\
\hline 42 & +11 & 8.1 & 7.9 & SW & All open & Gauges 7,9 , and 15 moved \\
\hline 43 & +11 & 5.1 & 12.0 & SW & All open & Gauges 7,9 , and 15 moved \\
\hline 44 & +11 & 5.4 & 7.9 & SW & All open & Gauges 7,9 , and 15 moved \\
\hline 45 & +11 & 6.3 & 6.0 & SW & All open & Gauges 7, 9, and 15 moved \\
\hline 46 & +11 & 5.4 & 9.3 & SW & All open & Gauges 7,9 , and 15 moved \\
\hline 47 & +11 & 5.5 & 13.5 & SW & All open & Gauges 7,9 , and 15 moved \\
\hline 48 & +11 & 5.0 & 16.5 & SW & All open & Gauges 7,9 , and 15 moved \\
\hline 49 & +11 & 5.0 & 18.7 & SW & All open & Gauges 7,9 , and 15 moved \\
\hline 50 & +11 & 4.8 & 20.0 & SW & All open & Gauges 7,9 , and 15 moved \\
\hline 51 & +11 & 4.4 & 22.0 & SW & All open & Gauges 7, 9, and 15 moved \\
\hline 52 & +11 & 5.5 & 7.9 & SW & All open & Gauges 7,9 , and 15 moved \\
\hline 53 & +11 & 4.4 & 23.3 & SW & All open & Gauges 7,9 , and 15 moved \\
\hline
\end{tabular}




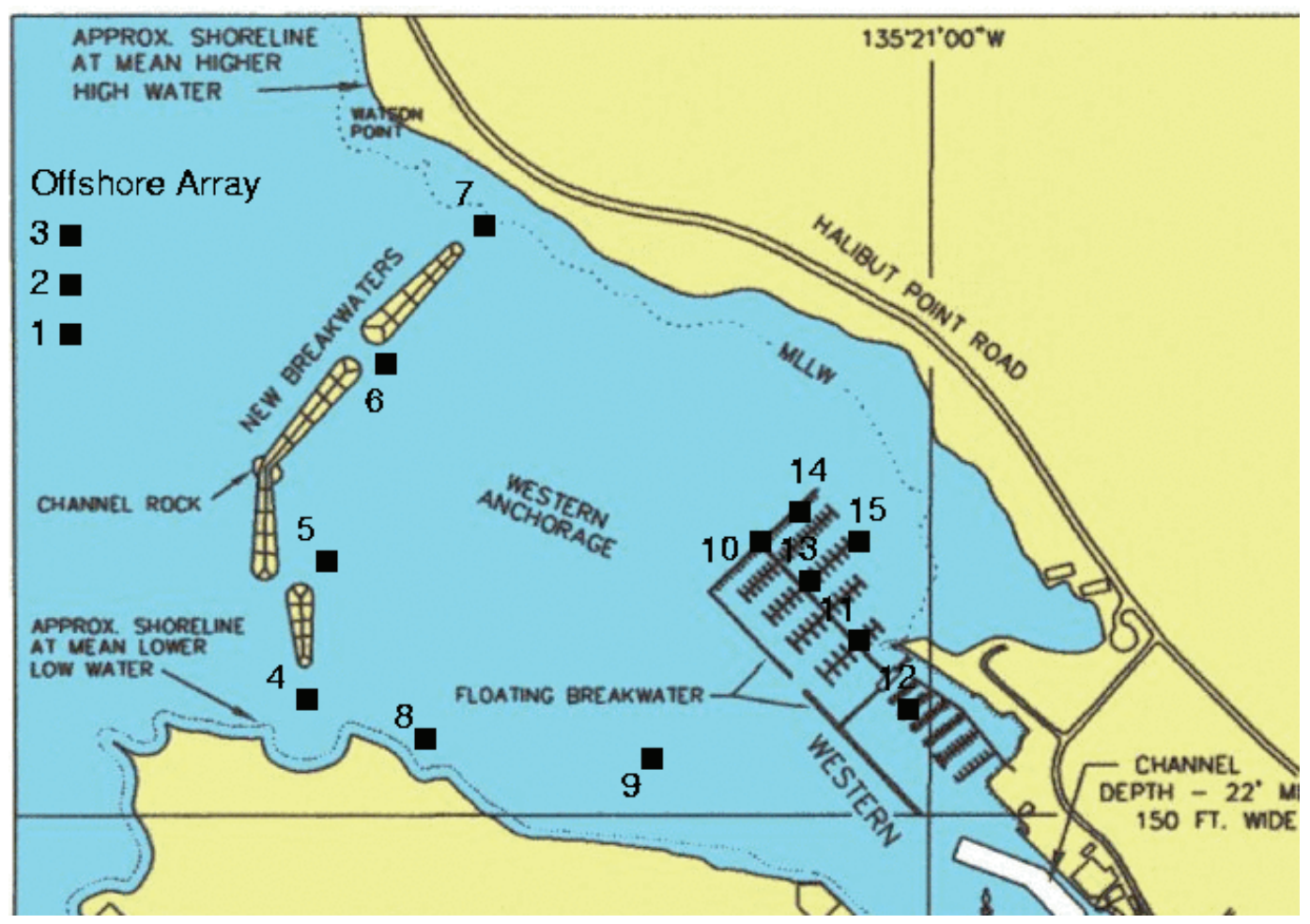

Figure 17. Wave gauge locations for tests 1-34.

\section{Effect of gap closure (tests 1-13)}

Figure 18 summarizes results from tests 1- 6 . Waves were from the southwest, and the same wave condition $\left(H_{m 0}=5 \mathrm{ft}, T_{p}=12 \mathrm{sec}\right.$ ) was generated for all tests. These tests shows the effect of leaving only one of the four gaps between breakwater/ shore open while blocking the rest of the gaps. For reference, tests with all gaps open and all gaps closed are included in the plot.

The high values shown for gauges 4- 7 simply indicate when each of those gaps was open. For this wave condition at the $+11 \mathrm{ft}$ mllw elevation, significant wave heights in the float plane area and inside New Thomsen Harbor did not exceed $0.5 \mathrm{ft}$ (prototype scale) even with all gaps open. When all gaps were closed, a low level of wave energy was still recorded inside the protected region indicating that some wave energy was passing over the breakwater and through the porous armor layer above the impermeable breakwater core. Generally, closing off all but one gap succeeded in reducing wave energy within the harbor (gauges 10-15), but the reduction was not dramatic compared with the case with all gaps open. 


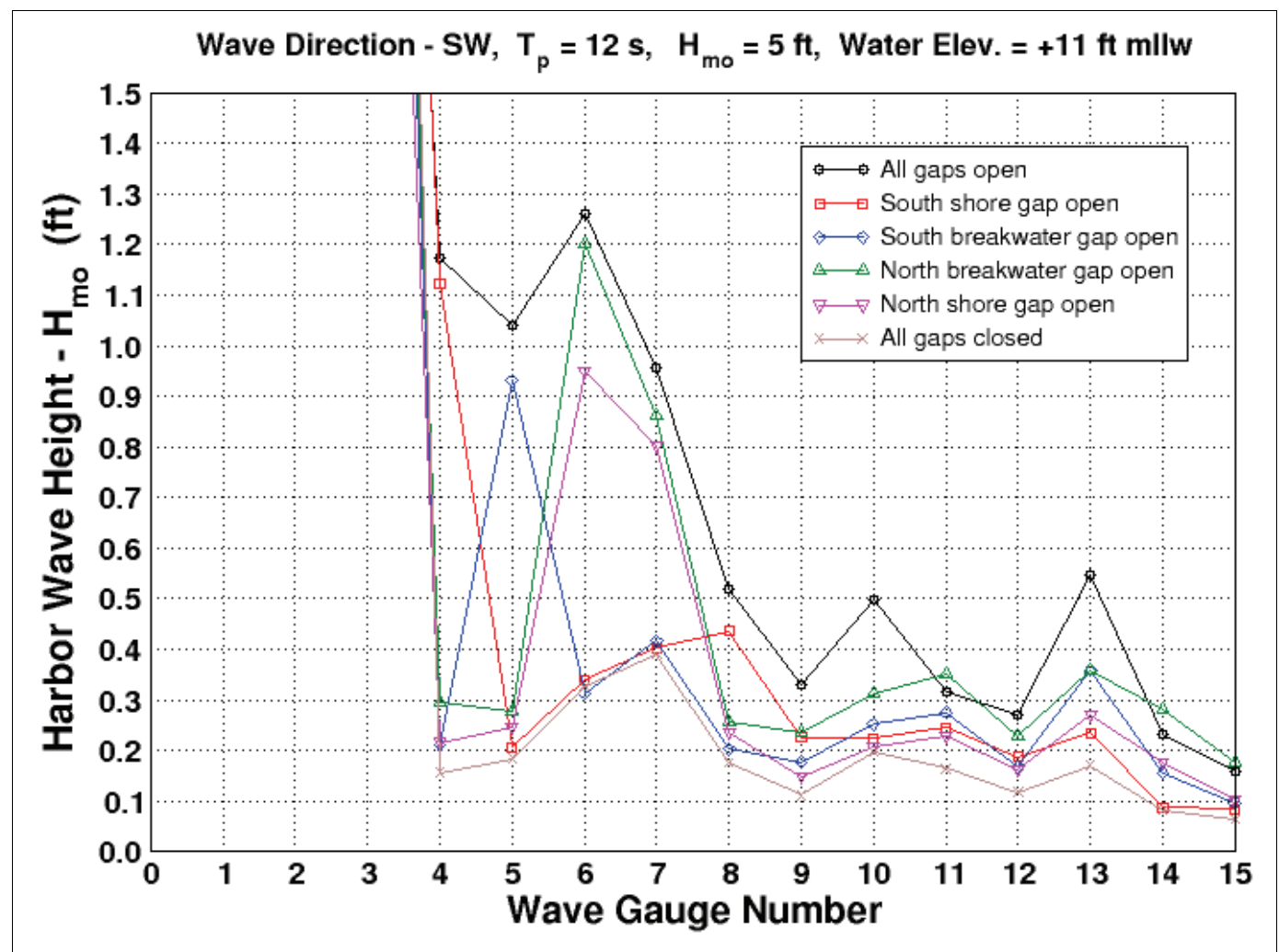

Figure 18. Effect of gap closure, results from tests 1-6.

Figure 19 presents measured results for tests 8-13. This test series was the same as the previous test series with the only difference being increased incident wave height $\left(H_{m 0}=7.5 \mathrm{ft}\right.$ ) and shorter wave period ( $T_{p}=5 \mathrm{sec}$ ). These tests gave similar results (i.e., closing all but one gap will reduce the amount of wave energy reaching New Thomsen Harbor), but for this wave condition and water level, the measured wave agitation at New Thomsen Harbor was about half of the usual 1-ft maximum criterion for small boat harbors.

\section{Wave energy over and through breakwaters (tests 6, 13-15)}

To get a better understanding of the wave energy passing over and through the detached breakwaters, tests 14 and 15 were conducted with all breakwater gaps closed and the water level reduced to +0 mllw. Less wave energy was anticipated because the breakwater impermeable cores have an elevation of $+9.2 \mathrm{ft}$ mllw. 


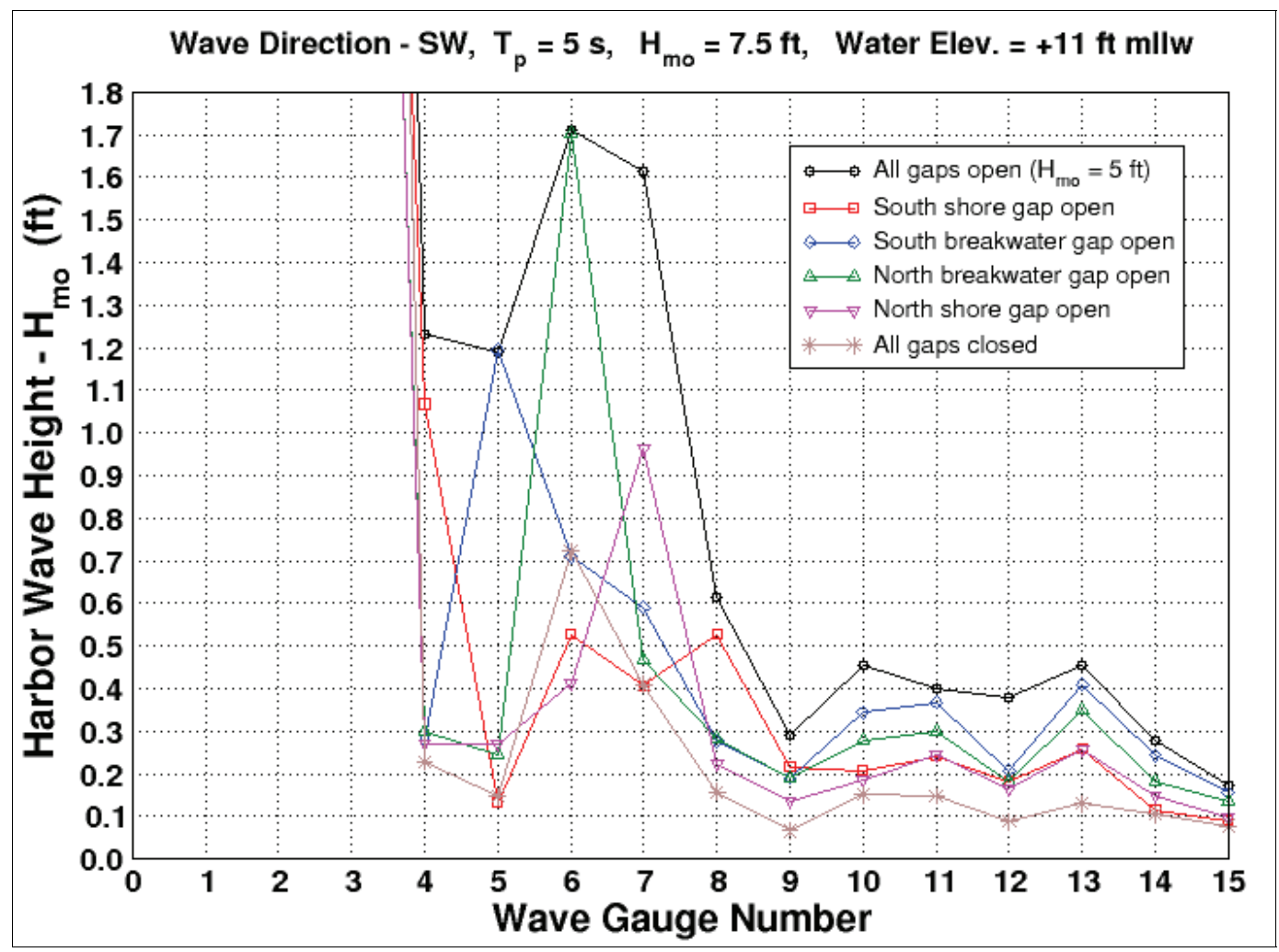

Figure 19. Effect of gap closure, results from tests 8-13.

Figure 20 plots wave height results for the 12-sec, 5-ft wave condition for all gaps closed when the water level was a $+11 \mathrm{ft}$ mllw (test 6) and $+0 \mathrm{ft}$ mllw (test 14). Figure 21 gives similar comparisons for the 5-sec, 7.5- $\mathrm{ft}$ wave conditions (tests 13 and 15). The peaks around gauges 6 and 7 were caused by leakage through the temporary barriers blocking the gaps. For gauges 10-15 in the harbor, the maximum increase of wave motion due to breakwater overtopping appears to be between 0.1 and $0.15 \mathrm{ft}$. The shorter period waves had less increase. As water level rises above $+11 \mathrm{ft} \mathrm{mllw}$, the overtopping wave energy is expected to increase. 


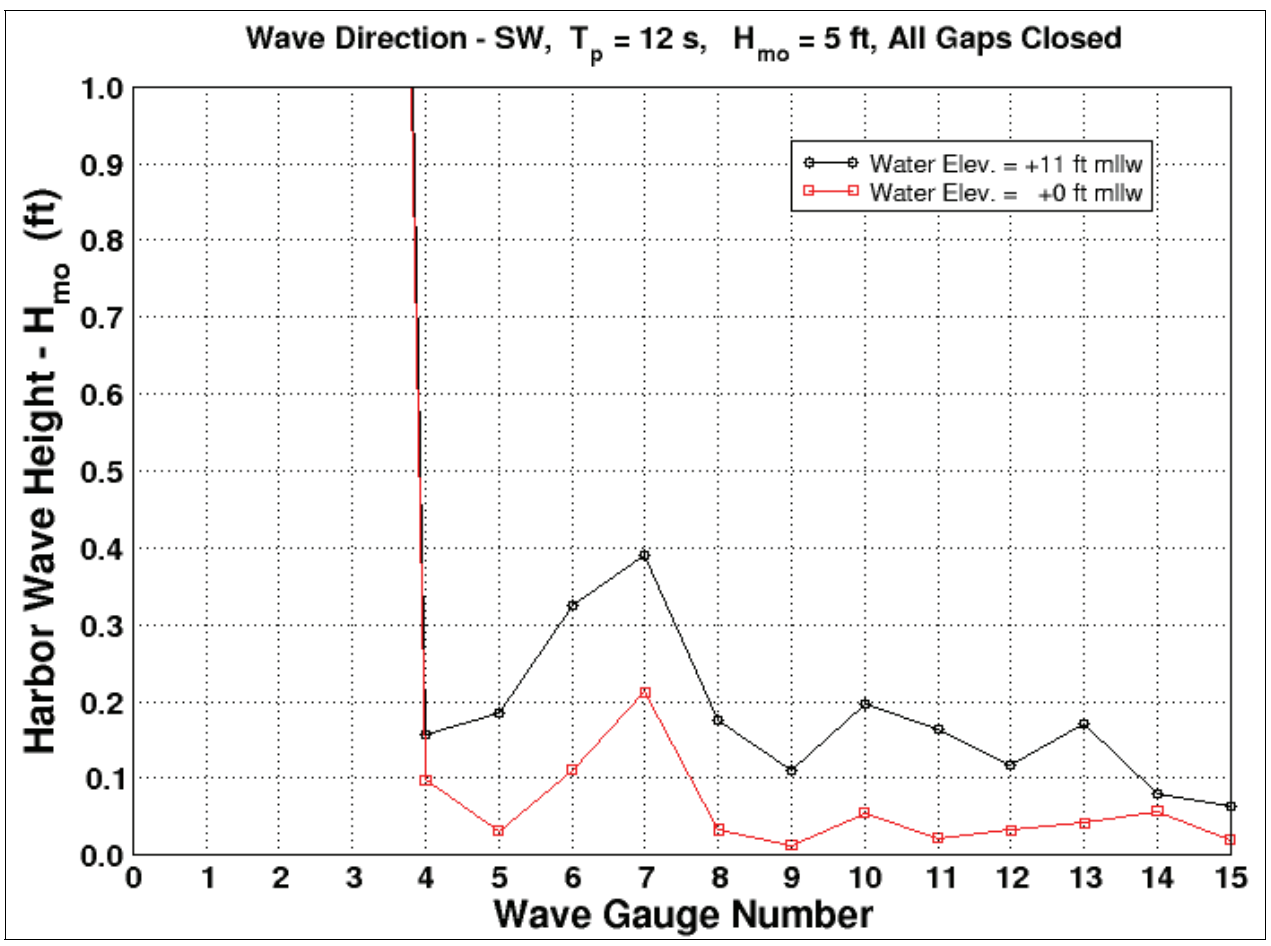

Figure 20. Wave energy through breakwaters, tests 6 and 14 .



Figure 21. Wave energy through breakwaters, tests 13 and 15. 


\section{Effects of engineering modifications (tests 17-22)}

The Alaska District engineers directed placement of several engineering modifications to assess the effectiveness of these changes in reducing wave agitation within the Western Channel and New Thomsen Harbor. Figure 22 presents wave measurements for these variations obtained from tests 17 through 22. Data post-processing indicated that wave gauges 1 and 10 were not functioning correctly during these tests, which is evident for gauge 10 on Figure 22. All breakwater gaps were open for these tests, and the incident wave condition $\left(H_{m 0}=6.2 \mathrm{ft}, T_{p}=12 \mathrm{sec}\right)$ and $+11 \mathrm{ft} \mathrm{mllw}$ water elevation were kept the same for all tests.



Figure 22. Effects of various engineering modifications, tests 17-22.

The possible expansion of the runway on J aponski Island by 1,600 ft (20 ft in the model) to the northwest would block wave energy approaching Sitka from the southwest. This runway expansion was roughly simulated with a row of concrete blocks to get a first impression of potential wave reduction. Other modifications included lengthening the southern end of the central breakwater to reduce Gap 2, reducing the main Gap 3 from approximately $300 \mathrm{ft}$ to $150 \mathrm{ft}$, and combinations of these schemes. With the exception of extending the runway, the engineering modifications did not appear to make much difference to the wave heights measured in the 
vicinity of New Thomsen Harbor. The runway expansion, however, reduced significant wave heights from about $0.6 \mathrm{ft}$ to $0.3 \mathrm{ft}$ and even lower. Therefore, one unintended consequence of the proposed runway expansion would be decreased wave heights in the harbor.

\section{Effects related to waves from northwest (tests 25-34)}

At this point in the testing the wavemaker was moved to an orientation that created waves coming toward the breakwaters from the northwest. Because of the limited fetch, these waves will have shorter periods, and the higher wave heights would be possible only during strong northwest winds. For tests $25-30$ wave conditions were constant $\left(H_{m 0}=5 \mathrm{ft}\right.$, $T_{p}=4.4 \mathrm{sec}$ ) and water level was at $+11 \mathrm{ft}$ mllw. Tests were run with only one of the gaps open at a time. Wave height results are plotted on Figure 23.

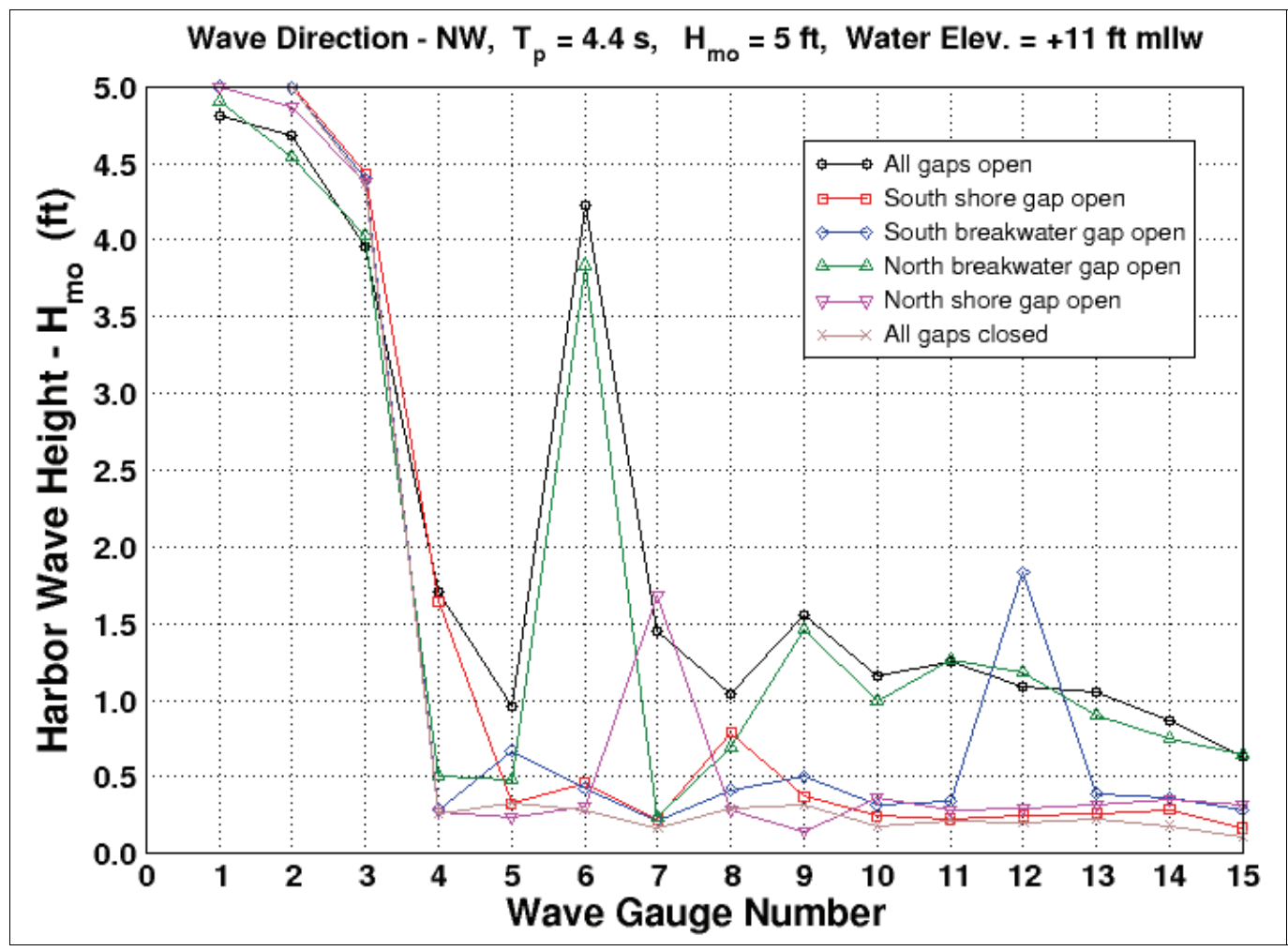

Figure 23. Effect of gap closure with waves from northwest, tests 25-30.

This wave condition resulted in maximum wave heights in the New Thomsen Harbor area between 1.0 and $1.3 \mathrm{ft}$. This was caused by wave energy entering the harbor area directly through the gap between the center and north breakwater (Gap 3). Closing Gap 3 and opening other gaps caused a significant reduction in wave height by about $1 \mathrm{ft}$ from about $1.3 \mathrm{ft}$ to around $0.3 \mathrm{ft}$. (Note the gauge 12 value for "South breakwater gap open" 
is an obvious error because it should be similar to the other nearby gauges in the cluster.) The measured waves in the harbor with Gap 3 open exceeded the usual wave height criterion for small boat harbors; but keep two facts in mind. First, this is a large wave height for fetch-limited waves from the northwest, and second, the floating breakwater protecting New Thomsen Harbor should be effective in reducing the heights of these short period waves to heights below the criterion. Nevertheless, episodes of unacceptable wave agitation caused by waves from the northwest could occur, but they will be accompanied by high winds without exception.

While the wavemaker was situated to the northwest, Alaska District engineers examined similar engineering modification as shown in Figure 22. Results from tests 31- 34 are shown in Figure 24. The "All gaps open" and "All gaps closed" wave heights came from tests 25 and 26, respectively. Incident wave height and period remained the same $\left(H_{m 0}=5 \mathrm{ft}\right.$, $T_{p}=4.4 \mathrm{sec}$ ), and water level was at $+11 \mathrm{ft} \mathrm{mllw}$.

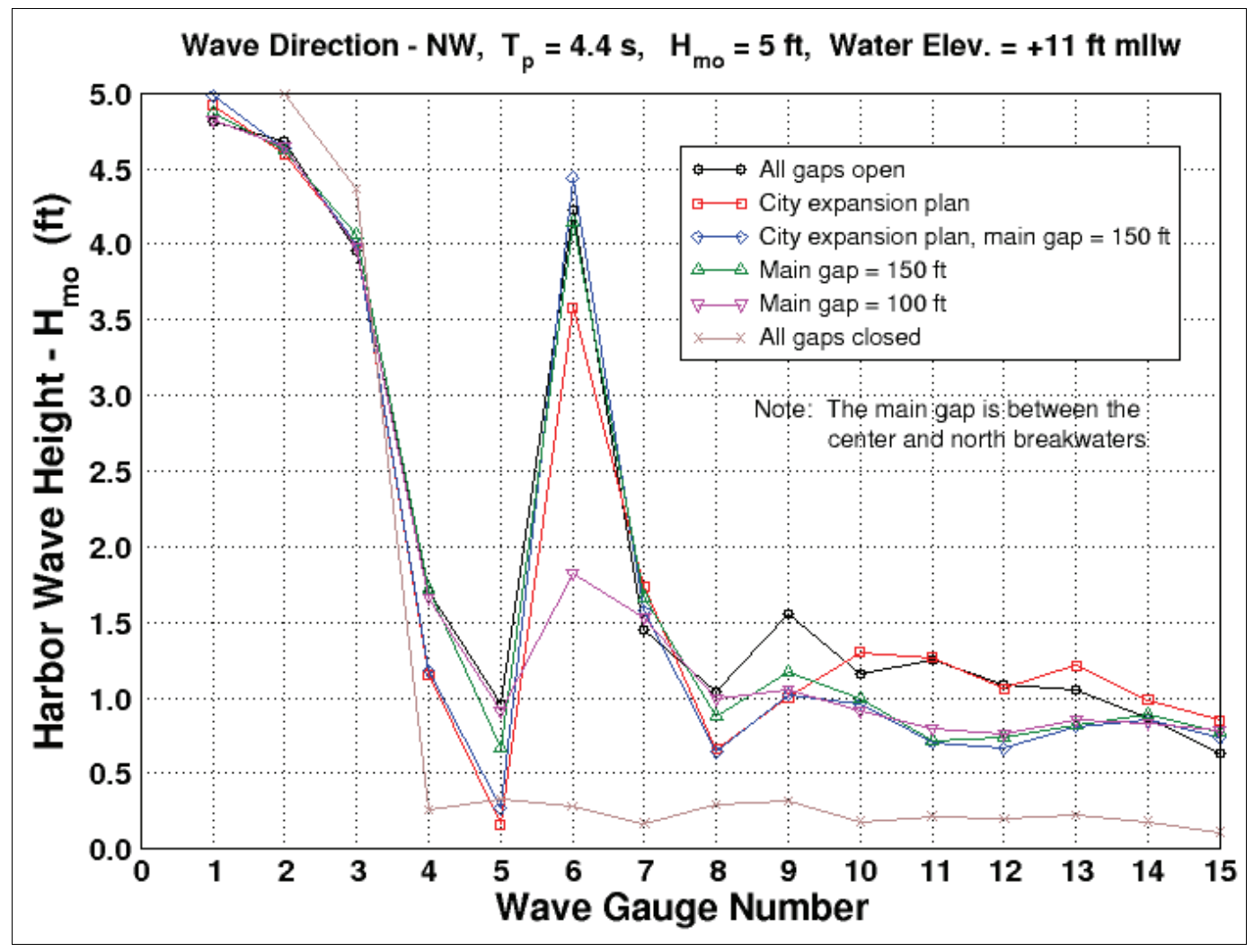

Figure 24. Effects of various engineering modifications, test 31-34. 
Lengthening the southern end of the center breakwater (City of Sitka expansion plan) had no effect on reducing wave energy from the northwest, but the three options that reduced Gap 3 from $300 \mathrm{ft}$ to $150 \mathrm{ft}$ or $100 \mathrm{ft}$ resulted in wave height reduction in New Thomsen Harbor of up to $0.5 \mathrm{ft}$.

After the wave machine was moved to the northwest orientation, calibration was performed for the $4.4 \mathrm{sec}$ wave condition used to represent shortperiod wind waves. These tests are not listed in Table 5, but the measured response during calibration did provide an opportunity to examine the effect incident wave height has on wave energy penetration from the northwest when water elevation is at $+11 \mathrm{ft}$ mllw. Measurements from the calibration tests are shown in Figure 25.

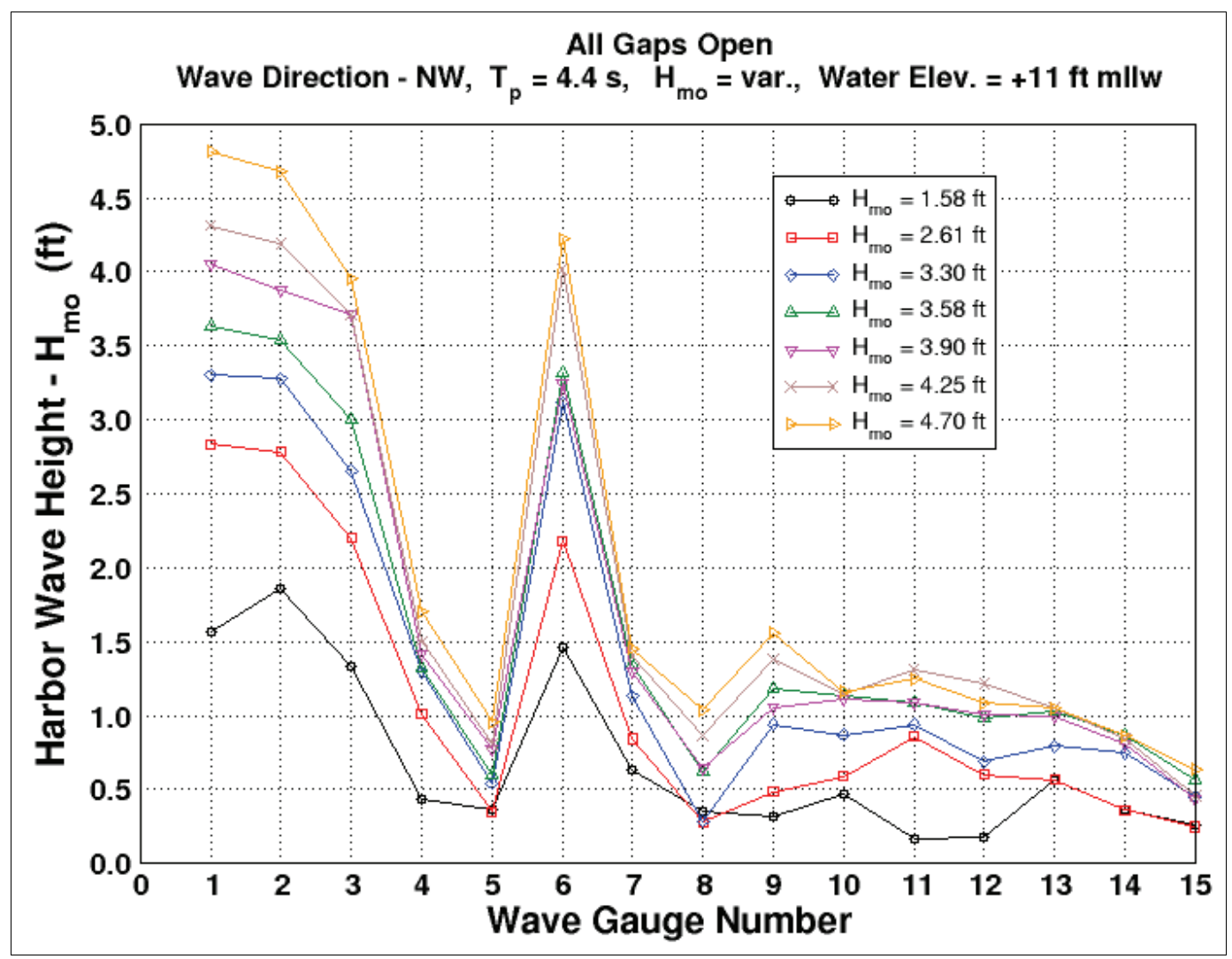

Figure 25. Effect of incident wave height with northwest waves.

As would be expected, smaller incident wave heights produce smaller response within the protected Western Channel and New Thomsen Harbor. However, incident waves of about $3.5 \mathrm{ft}$ still produce wave heights in the harbor right at the $1 \mathrm{ft}$ recommended maximum criterion. Once again, the floating breakwater system protecting the docks will help reduce the wave heights by some amount. 


\section{Wave gauge locations for tests 35-53}

After completion of tests from the northwest direction, the wave machine was moved back to the original location and orientation to produce waves from the southwest. At the same time wave gauges 7 and 9 were moved from their positions shown in Figure 17 to new locations given in Figure 26. The intent was to capture wave data directly behind the center breakwater (gauge 7) and at the corner of the floating breakwater protecting the harbor (gauge 9).

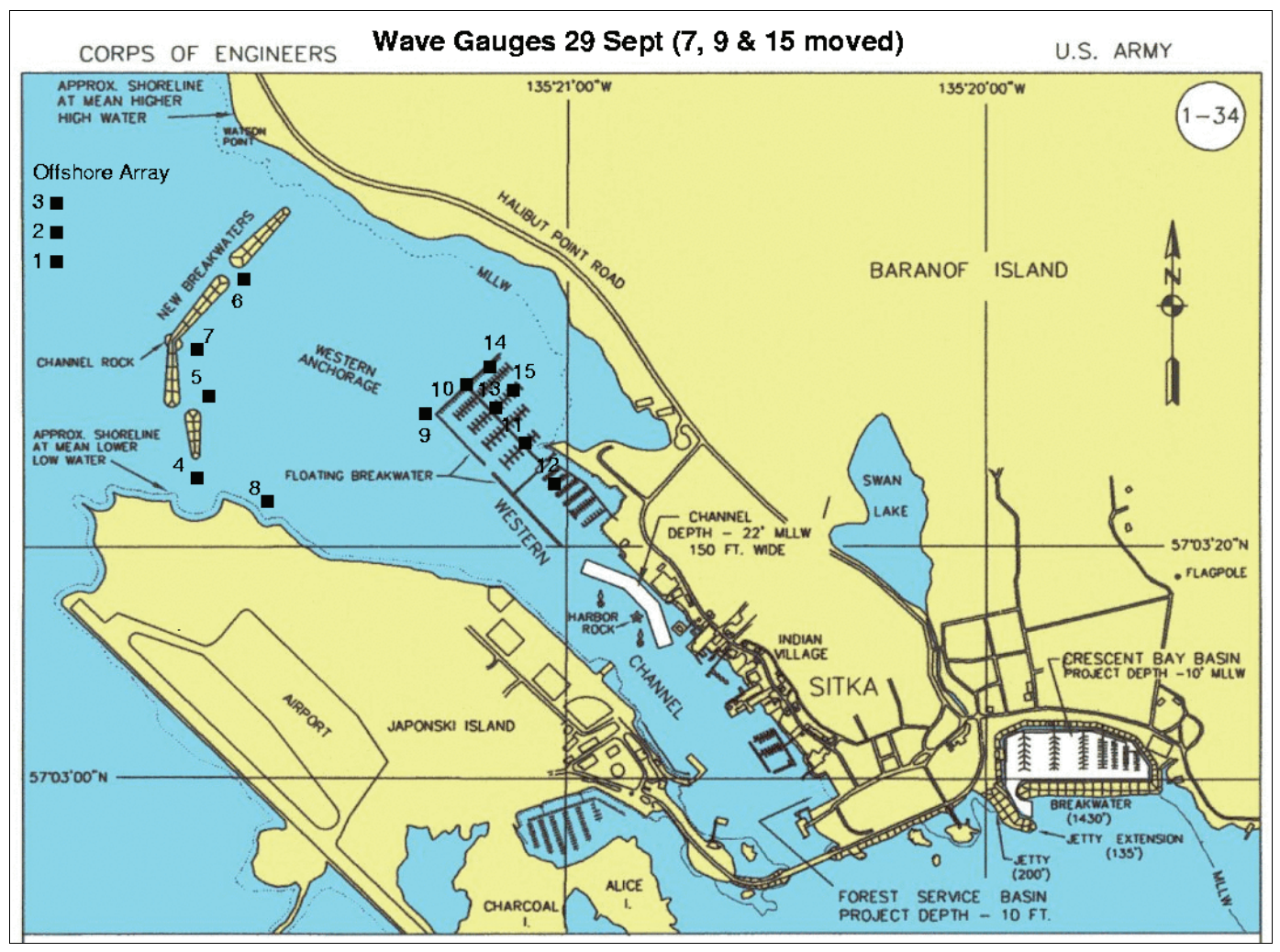

Figure 26. Wave gauge placement for tests 41-53.

Tests 35- 39 were run using the parameters listed in Table 5, but results have not been included in this report because they are similar to previous test results. However, the tests did demonstrate a reasonable degree of repeatability.

\section{Effect of wave period (tests 41-48)}

Finally, wave gauge 15 was shifted a short distance to situate it directly on top of a circular-shaped shoal to see if the shoal was influencing wave response in the harbor. Test 40 was an experiment where a large fan was used to generate wind waves from the northwest at the same time longer 
period waves came from the southwest. The experiment was not considered successful.

Tests 41- 53 varied peak spectral wave period for southwest waves having a significant wave height of $H_{m 0}=5 \mathrm{ft}$ and water level at $+11 \mathrm{ft} \mathrm{mllw}$. All breakwater gaps were open for these tests. Figure 27 displays results for periods ranging from $4 \mathrm{sec}$ up to $16 \mathrm{sec}$ (tests 41 and 43-48). The period values shown in the figure legend are nominal; actual peak periods from the data analyses are given in Table 5. Results from tests 49-53 were not included on the plot.

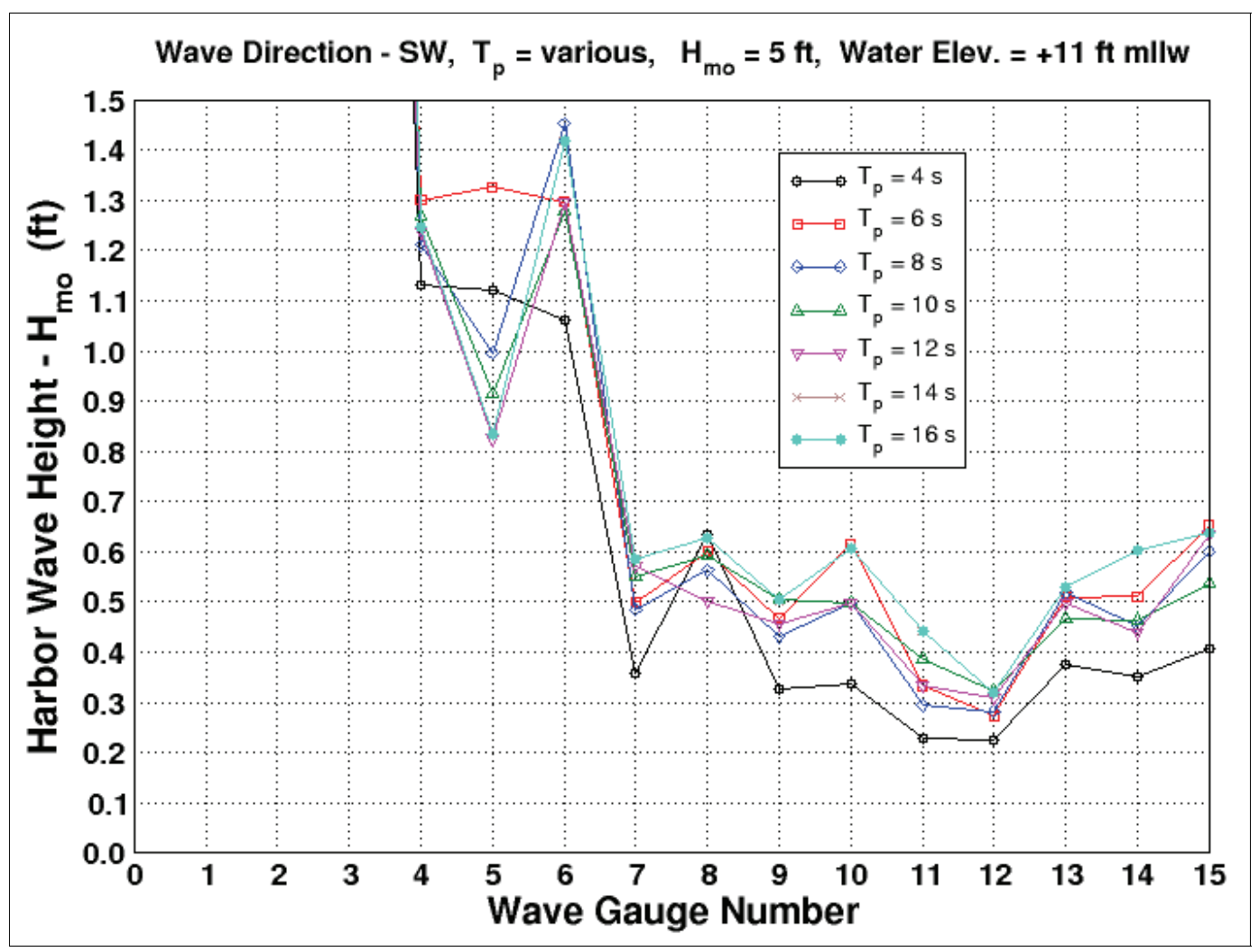

Figure 27. Effect of wave period with southwest waves, tests 41-48.

The general trend of the data in Figure 27 is increasing wave agitation in the vicinity of New Thomsen Harbor with increasing wave period. The highest wave heights in the harbor were about $0.6 \mathrm{ft}$ at gauge 10 and just over $0.6 \mathrm{ft}$ at gauge 15 . The gauge 15 result was interesting because it demonstrated a focusing effect of the shoal located within New Thomsen Harbor. Wave heights measured by gauge 15 at its previous location (see Figures 24 and 25, for example) were always lower than nearby gauge 14 . 
This concluded the initial phase of testing in the New Thomsen Harbor physical model. Alaska District engineers were hoping to make field measurements at Sitka during the winter of 2005-2006 to capture one or more wave agitation events similar to those reported previously. These measurements would be used to confirm the responses documented in the physical model, and perhaps provide additional physical insight. Unfortunately, no notable events occurred during that winter season. 


\section{June/July 2006 Test Results}

This chapter describes 17 experiments conducted during J une and J uly 2006, as part of the New Thomsen Harbor physical model study. Although testing was in both J une and J uly, it is referred to as J une 2006 for brevity in tables and figures.

\section{Summary of June/July 2006 tests}

Tests 54- 70 were conducted during J une and J uly 2006. The purpose of these 17 tests was to examine the vertical differences at each moment in time between evenly spaced locations along the line of the main float in New Thomsen Harbor. Alaska District engineers did not travel to Vicksburg for these tests. The hypothesis for these tests was that, as the larger waves pass through New Thomsen Harbor, one portion of the floating dock will be in a wave trough while another portion will be riding on a wave crest. This vertical differential might be enough to create difficult conditions on the floating dock.

Table 6 summarizes the tests for this grouping with given values converted to prototype scale. All tests were run with irregular waves, and the values of significant wave height $\left(H_{m 0}\right)$ and peak spectral period $\left(T_{p}\right)$ given in Table 6 were obtained from measurements acquired at the three wave gauges directly in front of the wavemaker. The column labeled "Dir" is the direction from which waves came. All gaps between adjacent breakwaters and between the breakwaters and shore were open for all tests.

\section{Wave gauge locations}

The 12 wave gauges numbered 4- 15 were arranged as a linear array positioned directly over the location of the main floating dock of New Thomsen Harbor. The gauges were spaced at 100-ft intervals (16 in. in the model) with gauge 4 located at the seaward end of the main floating dock and gauge 15 nearest the landward end. Wave gauges 1- 3 remained in deeper wave near the wave machine. All other aspects of the data collection were as described in Chapter 4. 
Table 6. Experiment parameters for June/July 2006 tests.

\begin{tabular}{|c|c|c|c|c|c|c|}
\hline \# & $\begin{array}{l}\text { Water } \\
\text { Level } \\
\text { (ft) }\end{array}$ & $\begin{array}{l}H_{m 0} \\
\mathrm{ft})\end{array}$ & $\begin{array}{l}T_{p} \\
(\mathrm{sec})\end{array}$ & Dir & Gaps & Notes \\
\hline 54 & +11 & 11.6 & 8.0 & SW & All open & Main float wave gauge array at $100-\mathrm{ft}$ spacing \\
\hline 55 & +11 & 10.7 & 10.9 & SW & All open & Main float wave gauge array at $100-\mathrm{ft}$ spacing \\
\hline 56 & +11 & 9.7 & 12.2 & SW & All open & Main float wave gauge array at $100-\mathrm{ft}$ spacing \\
\hline 57 & +11 & 10.0 & 14.0 & SW & All open & Main float wave gauge array at $100-\mathrm{ft}$ spacing \\
\hline 58 & +11 & 10.9 & 16.0 & SW & All open & Main float wave gauge array at $100-\mathrm{ft}$ spacing \\
\hline 59 & +11 & 10.0 & 6.0 & SW & All open & Main float wave gauge array at $100-\mathrm{ft}$ spacing \\
\hline 60 & +11 & 10.0 & 8.0 & SW & All open & Main float wave gauge array at $100-\mathrm{ft}$ spacing \\
\hline 61 & +11 & 10.0 & 10.0 & SW & All open & Main float wave gauge array at $100-\mathrm{ft}$ spacing \\
\hline 62 & +11 & 10.0 & 12.0 & SW & All open & Main float wave gauge array at $100-\mathrm{ft}$ spacing \\
\hline 63 & +11 & 10.0 & 14.0 & SW & All open & Main float wave gauge array at $100-\mathrm{ft}$ spacing \\
\hline 64 & +11 & 10.0 & 16.0 & SW & All open & Main float wave gauge array at $100-\mathrm{ft}$ spacing \\
\hline 65 & +11 & 5.0 & 6.0 & SW & All open & Main float wave gauge array at $100-\mathrm{ft}$ spacing \\
\hline 66 & +11 & 5.0 & 8.0 & SW & All open & Main float wave gauge array at $100-\mathrm{ft}$ spacing \\
\hline 67 & +11 & 5.0 & 10.0 & SW & All open & Main float wave gauge array at $100-\mathrm{ft}$ spacing \\
\hline 68 & +11 & 5.0 & 12.0 & SW & All open & Main float wave gauge array at $100-\mathrm{ft}$ spacing \\
\hline 69 & +11 & 5.0 & 14.0 & SW & All open & Main float wave gauge array at $100-\mathrm{ft}$ spacing \\
\hline 70 & +11 & 5.0 & 16.0 & SW & All open & Main float wave gauge array at $100-\mathrm{ft}$ spacing \\
\hline
\end{tabular}

\section{Maximum elevation differences along floating dock (tests 59-70)}

Tests 54- 58 were conducted primarily to provide data sets for use in developing analysis code for examining the synoptic vertical differences between all adjacent wave gauge pairs. The procedure involved analyzing the 12 measured wave gauge time series for an experiment at each instance in time.

Examination of the time series of all the gauges in the array revealed that some locations experience more wave energy than others. This finding suggested some type of wave focusing due to bathymetry or interacting wave trains. For example, Figures 28 and 29 show the time series for a nominal 5-ft, 10-sec incident wave train (test 67). 


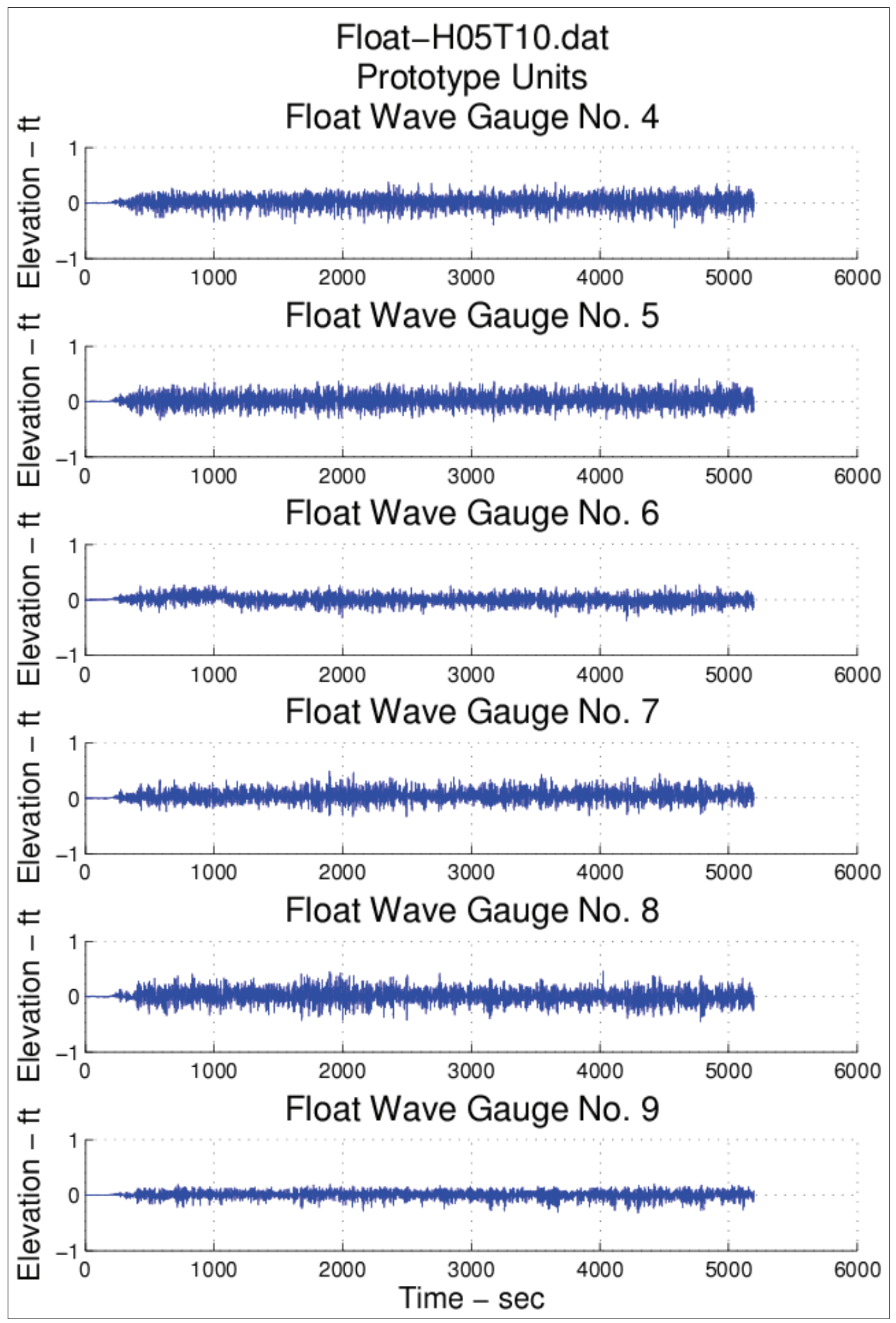

Figure 28. Time series of waves along main float, test 67 , gauges 4-9. 


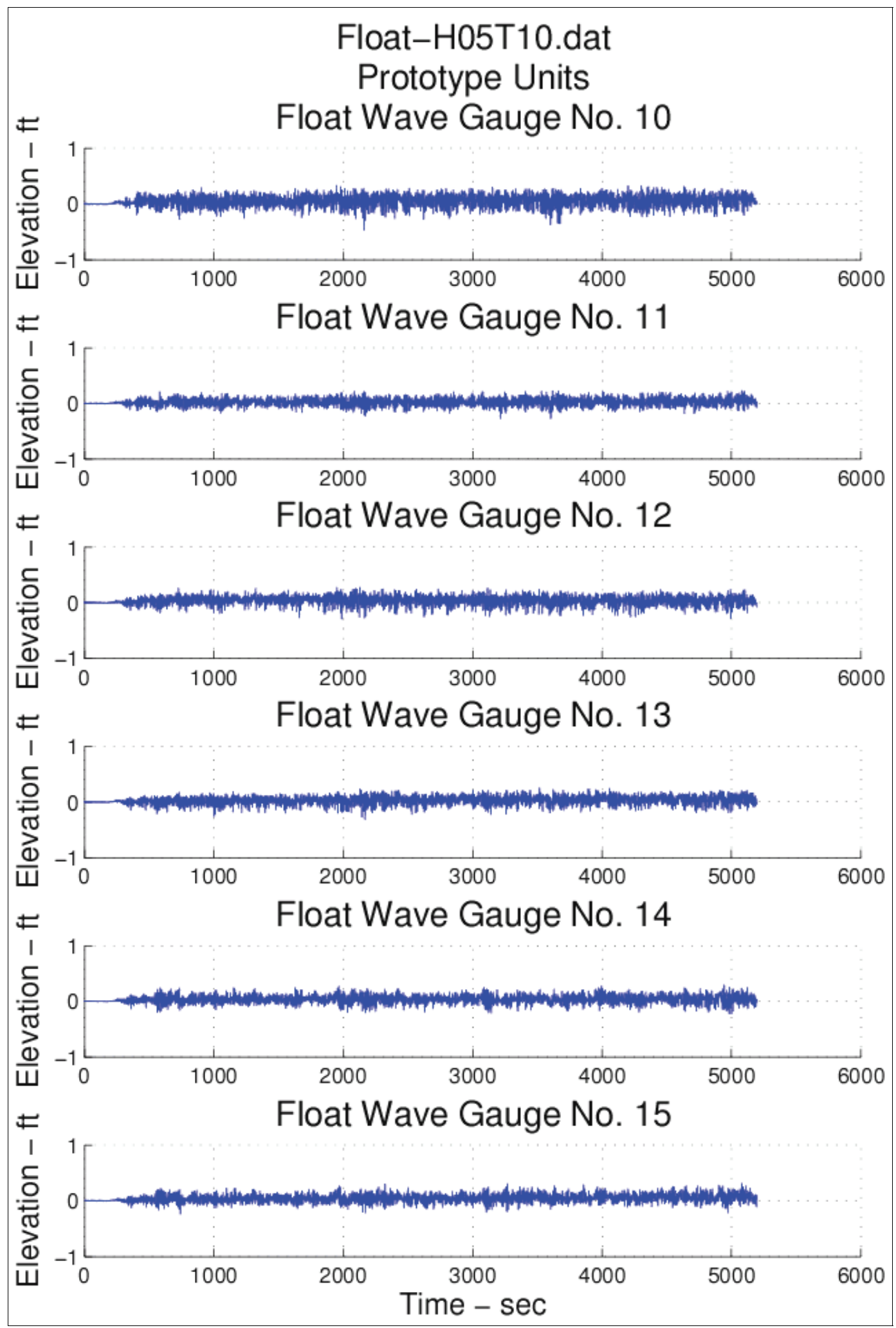

Figure 29. Time series of waves along main float, test 67 , gauges $10-15$. 
In Figure 28 notice that the waves at the gauge 7 and 8 locations appear to be higher than at adjacent gauge locations. This observation was fully explored in subsequent tests described in Chapters 7 and 8.

Figure 30 is an example of the instantaneous water elevations at all 12 main floating dock wave gauges at one instant during a test for a 5-ft, 10-sec irregular wave. This image was taken from an animation, so axis labeling was not included. Each division along the horizontal axis is a wave gauge location with gauge 4 on the left and gauge 15 on the right. Divisions on the vertical axis are at $0.5 \mathrm{ft}$ intervals. At this particular moment, the vertical difference between gauges 7 and 8 is slightly greater than $0.5 \mathrm{ft}$ over the 100 - $\mathrm{ft}$ horizontal separation distance. A similar difference is seen between gauges 8 and 9 . This wave was obviously a larger one in the wave train propagating through the harbor.



Figure 30. Motion along main floating dock at one instant in time, test 67.

Tests 65- 70 all had a significant wave height of $H_{m 0}=5 \mathrm{ft}$ and a water elevation of $+11 \mathrm{ft}$ mllw. Peak spectral wave periods $\left(T_{p}\right)$ varied between 6 and $16 \mathrm{sec}$. For each test the analysis code determined the vertical differential between adjacent wave gauges, printed out the maximum value for each gauge pair, and calculated the distribution of differences. For example, the distribution for the 5-ft, 10-sec test is given in Figure 31. This distribution includes all vertical differences between all wave gauge pairs. Notice that large differences do not occur frequently, and this might indicate that occasional waves could momentarily create uncomfortable conditions on the dock, but these difficult conditions would not be continuous.

Figure 32 plots the maximum vertical difference for each experiment between adjacent wave gauges for different wave periods. The trend is for greater vertical differentials toward the seaward end of the main floating dock with the maximum values close to $0.9 \mathrm{ft}$. The 6 -sec wave period appears to have an influence in the vicinity of gauges $10-12$. 


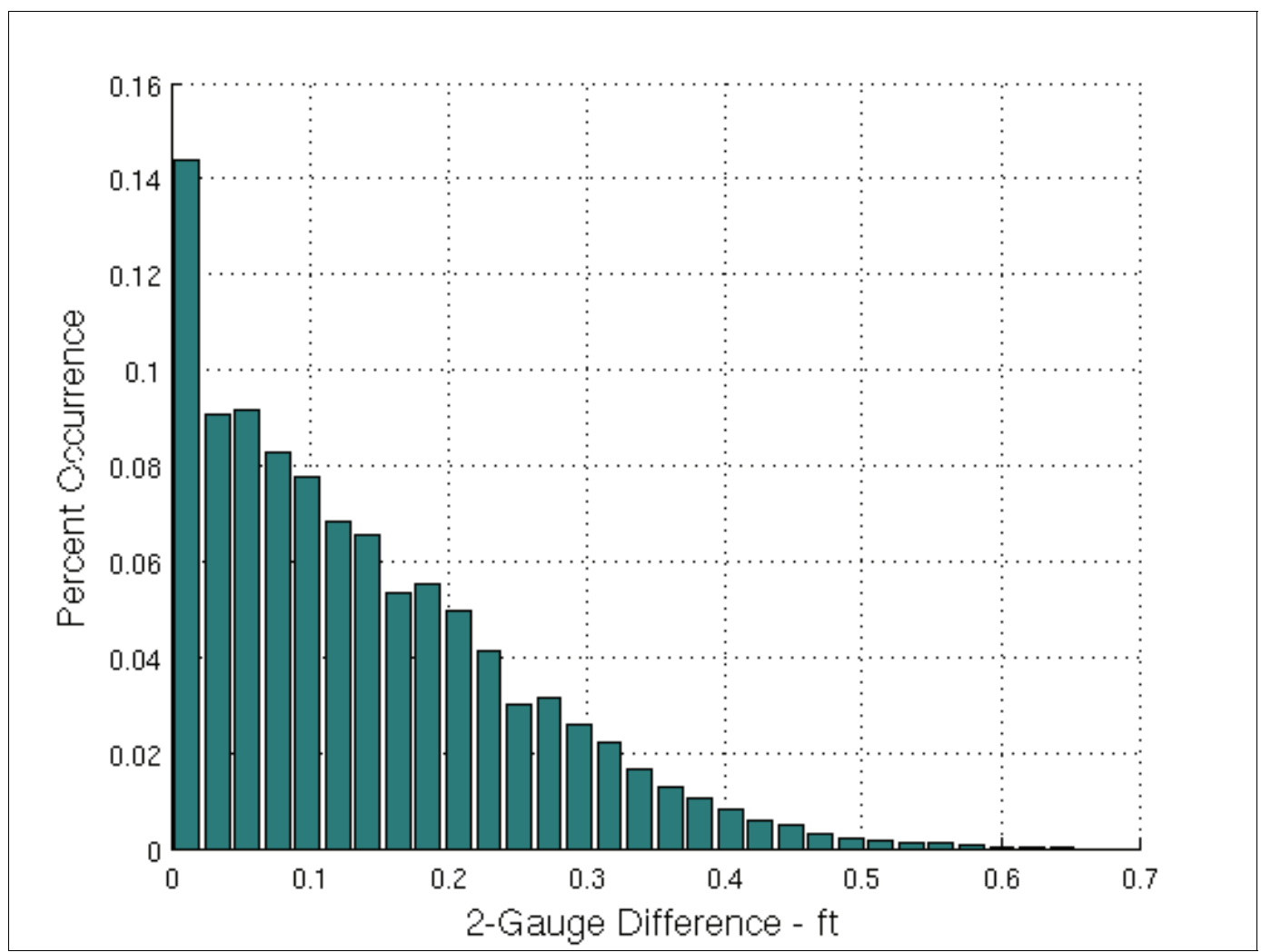

Figure 31. Distribution of vertical differential between adjacent gauges, test 67 .

The longer waves (larger wave period) have wave lengths such that the distance between wave crest and trough could be more on the order of $200 \mathrm{ft}$ or greater, depending on the wave approach direction. The analysis code was augmented to look at the maximum vertical differential between wave gauge pairs separated by $200 \mathrm{ft}$ (e.g., gauges 4 and 6).

Figure 33 shows the maximum differences over the length of the main floating dock. Vertical differences over $1 \mathrm{ft}$ are seen for the longer period waves, as was expected. The gauge pair 8-10 also exhibits an increase over neighboring pairs.

These results are only for water elevation differences, and they do not include any effects of the actual floating dock and moored vessels. Straight lines were drawn between points on Figures 30, 32, and 33. These lines should not be interpreted as rigid floating dock sections. The floating dock was not constructed in 100-ft-long rigid sections. In addition, the docks will likely have a damped response to the wave motions that would decrease the differences indicated in the figures. Finally, vessels moored to the dock will contribute to the damping or even induce additional motions as the vessels move in response to wave action. 


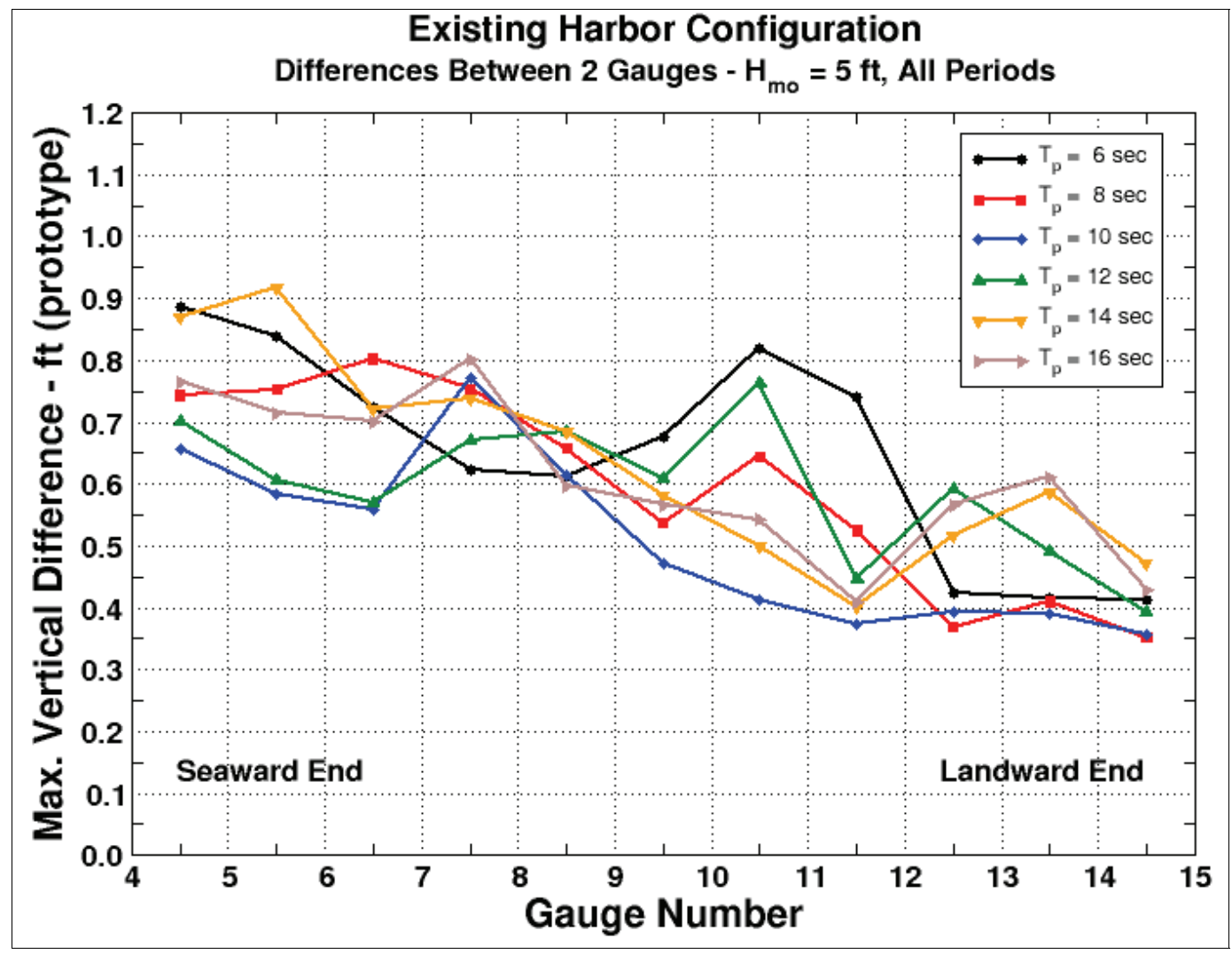

Figure 32. Maximum vertical difference between adjacent gauges, tests 65-70.

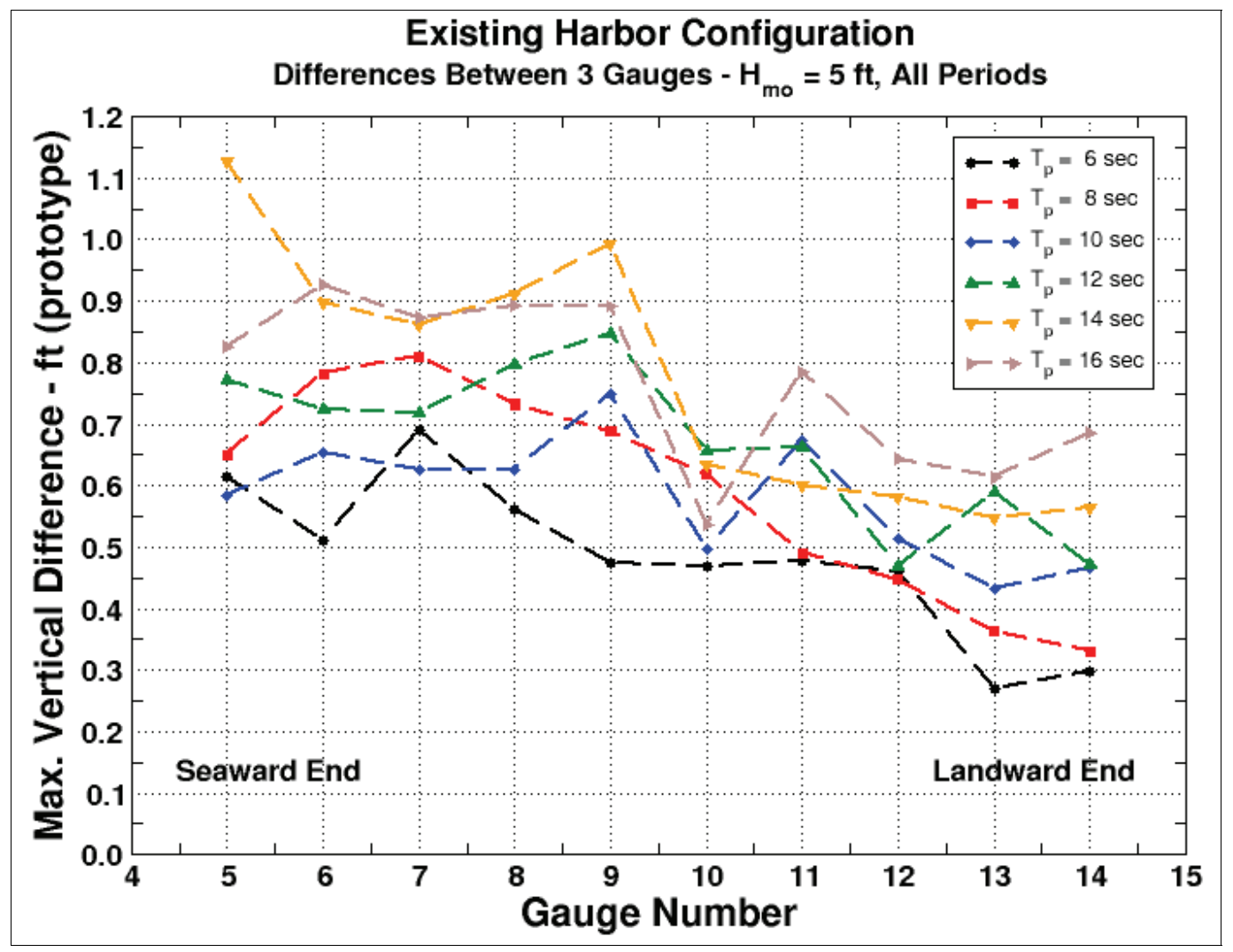

Figure 33. Maximum vertical difference between three adjacent gauges, tests 65-70. 


\section{November/December 2006 Test Results}

This chapter describes 91 experiments conducted during November and December 2006 as part of the New Thomsen Harbor physical model study.

\section{Summary of November/December 2006 tests}

Tests 71- 161 were conducted during November and December 2006. The purpose of these 91 tests was two-fold. Tests 71- 130 measured wave reduction caused by closing of different gaps between the breakwaters at an array of gauges evenly spaced along the main floating dock and at two potential locations for a future float plane facility. Tests 131-161 were aimed at better understanding the cause of observed excessive wave agitation at New Thomsen Harbor.

Rather than showing details about all 91 tests on a single table, the tests have been separated into four distinct chapter sections based on purpose of the testing. Each section has logical groupings of tests that focused on a specific objective. Groups 1, 3, and 4 examined the effects of gap closure on waves along the main floating dock and waves at areas suggested for a new float plane facility. Groups 5- 8 looked for evidence of wave focusing that appeared to cause increased wave heights at a particular location along the floating dock. Groups 9- 12 examined the impact of modifying bathymetry that was thought to cause wave focusing, and Groups 13 and 14 used monochromatic waves in an attempt to clarify the harbor wave response. Separate tables in each section discuss those particular tests.

\section{Wave gauge locations for November 2006 tests}

For all the November 2006 tests, a total of 19 wave gauges were used in the physical model. Gauges 1- 3 remained in deeper water near the wave machine. The 12 wave gauges $4-15$ were arranged as a linear array positioned directly over the location of the main floating dock of New Thomsen Harbor as shown in Figure 34. The spacing between gauges was decreased to 75 -ft intervals ( $12 \mathrm{in}$. in the model) with gauge 4 located at the seaward end of the main floating dock and gauge 15 nearest the landward end. Figure 34 includes depth contours in the vicinity of the main floating dock. 




Figure 34. Wave gauge array spaced at $75 \mathrm{ft}$ along main floating dock.

Wave gauges 16- 19 were placed as a group in one of two locations for the November 2006 testing. The first location was adjacent to J aponski Island across the Western Channel from New Thomsen Harbor as shown in Figure 35. This location was in the vicinity of a proposed future float plane facility, and the purpose of the wave gauge array was to measure wave conditions at this location for the different engineering modifications that were tested. The gauges were in this location for Group 1.

After completion of the Group 1 tests, the wave gauge array containing gauges 16- 19 was moved to a location on the lee side of the south breakwater as shown in Figure 36. These measurements provided information about wave energy levels at this location for the different engineering options. Gauges 16- 19 were eventually moved back to the future float plane facility after completion of the Group 4 tests. All other aspects of the data collection and analyses were as described in Chapter 4. 


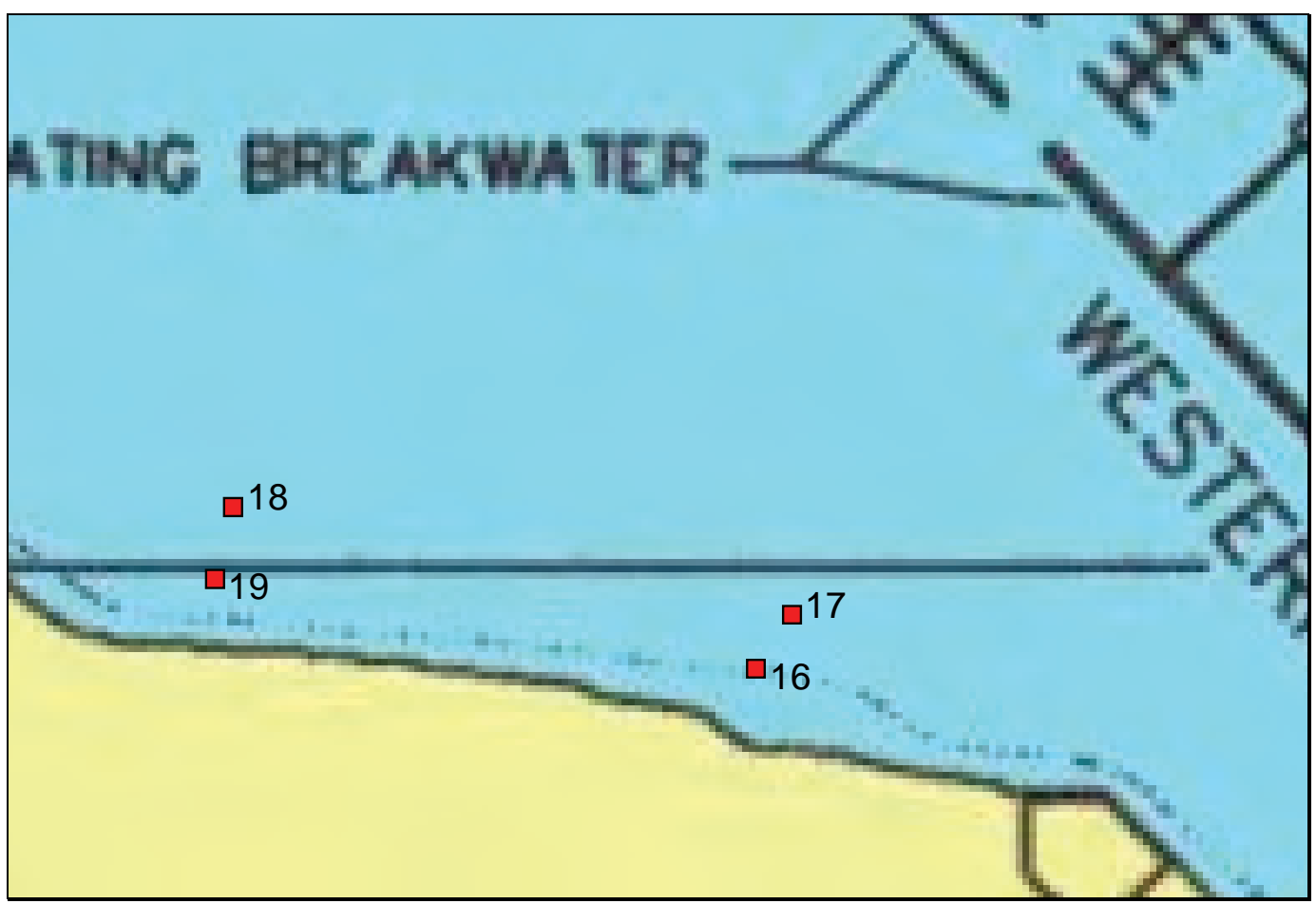

Figure 35. Wave gauge array placed in future float plane area.

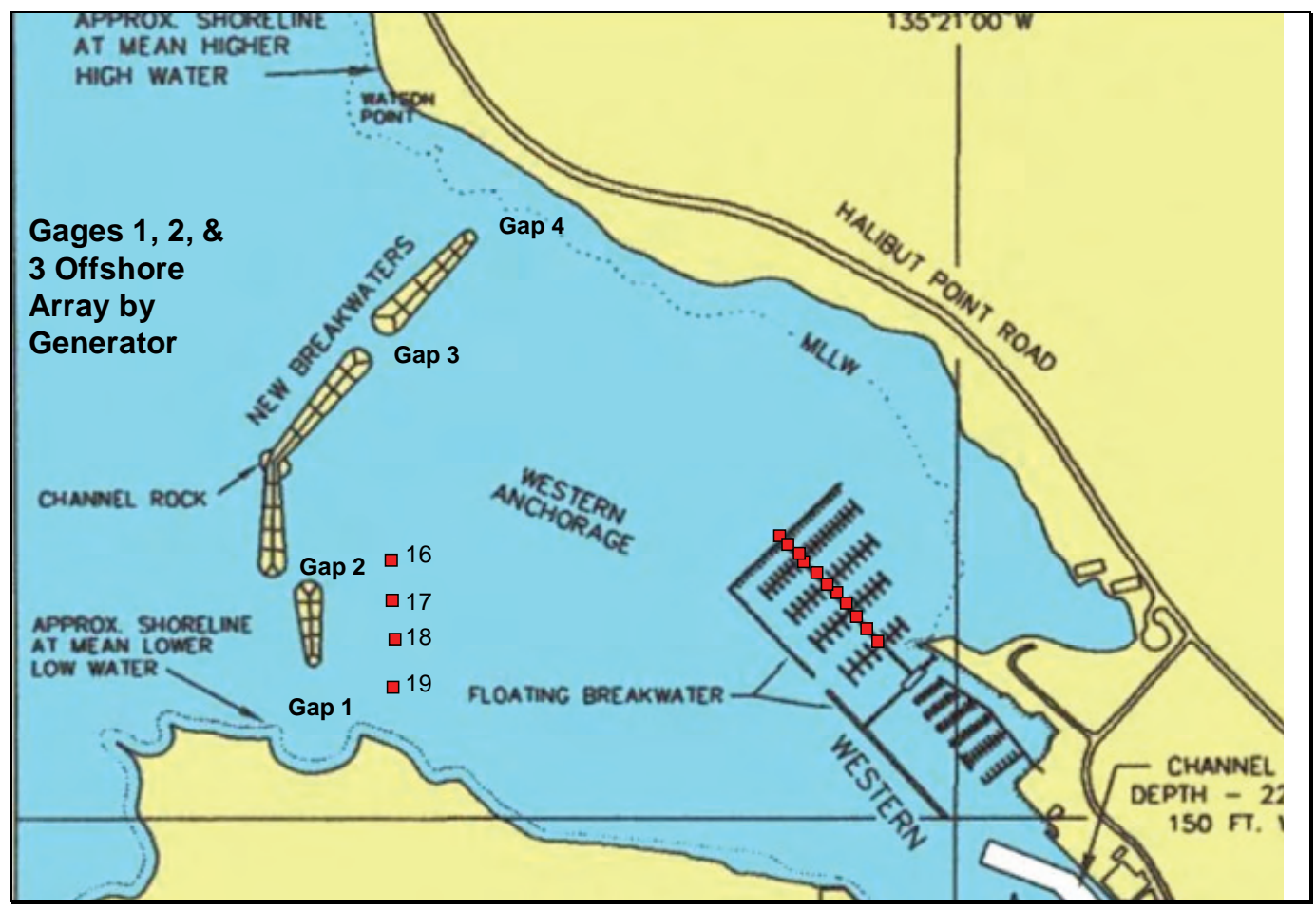

Figure 36 . Wave gauge array in lee of south breakwater. 


\section{Effect of gap closure (tests 71-130)}

Groups 1, 3, and 4 examined the differences in wave height caused by closing one or more of the gaps between breakwaters or between a breakwater and the shore. Tables 7, 8, and 9 summarize the tests for Groups 1, 3, and 4 , respectively.

Table 7. Experiment parameters for November 2006 tests for Group 1.

\begin{tabular}{|c|c|c|c|c|c|c|}
\hline \# & $\begin{array}{l}\text { Water } \\
\text { Level } \\
\text { (ft) }\end{array}$ & $\begin{array}{l}H_{m 0} \\
\text { (ft) }\end{array}$ & $\begin{array}{l}T_{p} \\
(\sec )\end{array}$ & Dir & Gaps & Notes \\
\hline \multicolumn{7}{|r|}{ Group 1} \\
\hline 71 & +11 & 5.5 & 9.5 & SW & All closed & Gauges $16-19$ in future float plane area \\
\hline 72 & +11 & 5.1 & 11.0 & SW & All closed & Gauges $16-19$ in future float plane area \\
\hline 73 & +11 & 4.9 & 13.5 & SW & All closed & Gauges $16-19$ in future float plane area \\
\hline 74 & +11 & 4.9 & 16.2 & SW & All closed & Gauges $16-19$ in future float plane area \\
\hline 75 & +11 & 5.5 & 9.3 & SW & Ooco & Gauges $16-19$ in future float plane area \\
\hline 76 & +11 & 5.1 & 11.3 & SW & OOCO & Gauges $16-19$ in future float plane area \\
\hline 77 & +11 & 4.9 & 13.5 & SW & ooco & Gauges $16-19$ in future float plane area \\
\hline 78 & +11 & 4.9 & 16.0 & SW & OOCO & Gauges $16-19$ in future float plane area \\
\hline 79 & +11 & 5.4 & 9.3 & SW & OOOC & Gauges 16-19 in future float plane area \\
\hline 80 & +11 & 5.1 & 11.3 & SW & OOOC & Gauges $16-19$ in future float plane area \\
\hline 81 & +11 & 4.8 & 13.8 & SW & OOOC & Gauges $16-19$ in future float plane area \\
\hline 82 & +11 & 4.9 & 16.5 & SW & $\mathrm{OOOC}$ & Gauges $16-19$ in future float plane area \\
\hline 83 & +11 & 5.4 & 9.3 & SW & $\mathrm{COOO}$ & Gauges $16-19$ in future float plane area \\
\hline 84 & +11 & 5.2 & 11.3 & SW & $\mathrm{COOO}$ & Gauges $16-19$ in future float plane area \\
\hline 85 & +11 & 4.9 & 13.8 & SW & $\mathrm{COOO}$ & Gauges $16-19$ in future float plane area \\
\hline 86 & +11 & 5.0 & 16.2 & SW & $\mathrm{COOO}$ & Gauges $16-19$ in future float plane area \\
\hline 87 & +11 & 5.6 & 9.3 & SW & OcOO & Gauges $16-19$ in future float plane area \\
\hline 88 & +11 & 5.2 & 11.3 & SW & OCOO & Gauges $16-19$ in future float plane area \\
\hline 89 & +11 & 5.0 & 13.5 & SW & OCOO & Gauges $16-19$ in future float plane area \\
\hline 90 & +11 & 5.0 & 16.5 & SW & OCOO & Gauges $16-19$ in future float plane area \\
\hline 91 & +11 & 5.6 & 9.3 & SW & All open & Gauges $16-19$ in future float plane area \\
\hline 92 & +11 & 5.2 & 11.3 & SW & All open & Gauges $16-19$ in future float plane area \\
\hline 93 & +11 & 5.0 & 13.8 & SW & All open & Gauges $16-19$ in future float plane area \\
\hline 94 & +11 & 5.0 & 16.5 & SW & All open & Gauges $16-19$ in future float plane area \\
\hline
\end{tabular}


Table 8. Experiment parameters for November 2006 tests for Group 3.

\begin{tabular}{|c|c|c|c|c|c|c|}
\hline \# & $\begin{array}{l}\text { Water } \\
\text { Level } \\
\text { (ft) }\end{array}$ & $\begin{array}{l}H_{m 0} \\
\text { (ft) }\end{array}$ & \begin{tabular}{|l}
$T_{p}$ \\
(sec)
\end{tabular} & Dir & Gaps & Notes \\
\hline \multicolumn{7}{|r|}{ Group 3} \\
\hline 95 & +11 & 5.5 & 9.3 & SW & OCCC & Gauges $16-19$ near south breakwater \\
\hline 96 & +11 & 5.1 & 11.3 & SW & occC & Gauges $16-19$ near south breakwater \\
\hline 97 & +11 & 4.8 & 14.0 & SW & occc & Gauges $16-19$ near south breakwater \\
\hline 98 & +11 & 4.8 & 16.5 & SW & occc & Gauges $16-19$ near south breakwater \\
\hline 99 & +11 & 5.5 & 9.3 & SW & $\operatorname{cocc}$ & Gauges $16-19$ near south breakwater \\
\hline 100 & +11 & 5.1 & 11.3 & SW & $\operatorname{cocc}$ & Gauges $16-19$ near south breakwater \\
\hline 101 & +11 & 4.9 & 13.8 & SW & $\operatorname{cocc}$ & Gauges $16-19$ near south breakwater \\
\hline 102 & +11 & 4.9 & 16.5 & SW & $\operatorname{cocc}$ & Gauges $16-19$ near south breakwater \\
\hline 103 & +11 & 5.8 & 9.3 & SW & $\operatorname{ccoc}$ & Gauges $16-19$ near south breakwater \\
\hline 104 & +11 & 5.1 & 11.3 & SW & $\operatorname{ccoc}$ & Gauges $16-19$ near south breakwater \\
\hline 105 & +11 & 4.9 & 13.8 & SW & $\mathrm{ccOC}$ & Gauges $16-19$ near south breakwater \\
\hline 106 & +11 & 4.9 & 16.5 & SW & $\mathrm{ccOC}$ & Gauges $16-19$ near south breakwater \\
\hline 107 & +11 & 5.6 & 9.3 & SW & $\mathrm{CCCO}$ & Gauges $16-19$ near south breakwater \\
\hline 108 & +11 & 5.2 & 11.3 & SW & $\mathrm{CCCO}$ & Gauges $16-19$ near south breakwater \\
\hline 109 & +11 & 4.9 & 13.8 & SW & $\mathrm{CCCO}$ & Gauges $16-19$ near south breakwater \\
\hline 110 & +11 & 4.6 & 16.5 & SW & $\mathrm{CCCO}$ & Gauges $16-19$ near south breakwater \\
\hline
\end{tabular}

Measured parameter values in Tables 7, 8, and 9 have been converted to prototype scale. All tests were run with irregular waves, and the values of significant wave height $\left(H_{m 0}\right)$ and peak spectral period $\left(T_{p}\right)$ given in the tables were obtained from measurements acquired at the three wave gauges directly in front of the wavemaker. The column labeled "Dir" is the direction from which waves came. All tests in the three groups had a nominal significant wave height of $H_{m 0}=5 \mathrm{ft}$, and nominal peak spectral wave periods of $T_{p}=10,12,14$, or $16 \mathrm{sec}$. Actual measured values are given in the tables. The notations in the column labeled "Gaps" indicate which gaps were open (O) or closed (C). Gaps were numbered 1 through 4 starting with the southernmost gap near J aponski Island and ending with the gap between the breakwater and shoreline near Halibut Point Road (see Figure 36). Thus, the notation COCC would indicate that only gap 2 was open for that experiment. 
Table 9. Experiment parameters for November/December 2006 tests for Group 4.

\begin{tabular}{|c|c|c|c|c|c|c|}
\hline \# & $\begin{array}{l}\text { Water } \\
\text { Level } \\
\text { (ft) }\end{array}$ & $\begin{array}{l}H_{m 0} \\
(\mathrm{ft})\end{array}$ & $\begin{array}{l}T_{p} \\
(\mathrm{sec})\end{array}$ & Dir & Gaps & Notes \\
\hline \multicolumn{7}{|r|}{ Group 4} \\
\hline 111 & +11 & 5.5 & 9.3 & SW & All closed & Gauges 16-19 near south breakwater \\
\hline 112 & +11 & 5.1 & 11.3 & SW & All closed & Gauges $16-19$ near south breakwater \\
\hline 113 & +11 & 5.0 & 13.5 & SW & All closed & Gauges $16-19$ near south breakwater \\
\hline 114 & +11 & 5.0 & 16.2 & SW & All closed & Gauges 16-19 near south breakwater \\
\hline 115 & +11 & 5.5 & 9.3 & SW & $\mathrm{COOO}$ & Gauges $16-19$ near south breakwater \\
\hline 116 & +11 & 5.2 & 11.3 & SW & $\mathrm{COOO}$ & Gauges 16-19 near south breakwater \\
\hline 117 & +11 & 5.0 & 13.5 & SW & $\mathrm{COOO}$ & Gauges 16-19 near south breakwater \\
\hline 118 & +11 & 4.7 & 16.2 & SW & $\mathrm{COOO}$ & Gauges 16-19 near south breakwater \\
\hline 119 & +11 & 5.5 & 9.3 & SW & OcOO & Gauges 16-19 near south breakwater \\
\hline 120 & +11 & 5.2 & 11.3 & SW & OcOO & Gauges 16-19 near south breakwater \\
\hline 121 & +11 & 5.0 & 13.3 & SW & OcOO & Gauges 16-19 near south breakwater \\
\hline 122 & +11 & 5.0 & 16.2 & SW & OcOO & Gauges 16-19 near south breakwater \\
\hline 123 & +11 & 5.6 & 9.3 & SW & OOCO & Gauges 16-19 near south breakwater \\
\hline 124 & +11 & 5.2 & 11.3 & SW & OOCO & Gauges 16-19 near south breakwater \\
\hline 125 & +11 & 5.0 & 13.3 & SW & OOCO & Gauges 16-19 near south breakwater \\
\hline 126 & +11 & 5.0 & 16.2 & SW & OOCO & Gauges 16-19 near south breakwater \\
\hline 127 & +11 & 5.7 & 9.3 & SW & OOOC & Gauges 16-19 near south breakwater \\
\hline 128 & +11 & 5.3 & 11.3 & SW & OOOC & Gauges 16-19 near south breakwater \\
\hline 129 & +11 & 5.0 & 13.3 & SW & OOOC & Gauges $16-19$ near south breakwater \\
\hline 130 & +11 & 5.0 & 16.2 & SW & OOOC & Gauges $16-19$ near south breakwater \\
\hline
\end{tabular}

\section{Group 1 results}

Group 1 (tests 71-94) looked at the differences in wave height caused by closing only one of the gaps between breakwaters or between a breakwater and the shore. Figures 37- 40 present the measured wave heights at each gauge location for nominal peak spectral wave periods of 10, 12, 14, and $16 \mathrm{sec}$, respectively. Gauges $4-15$ were along the main floating dock while gauges 16- 19 were in the future float plane area. 


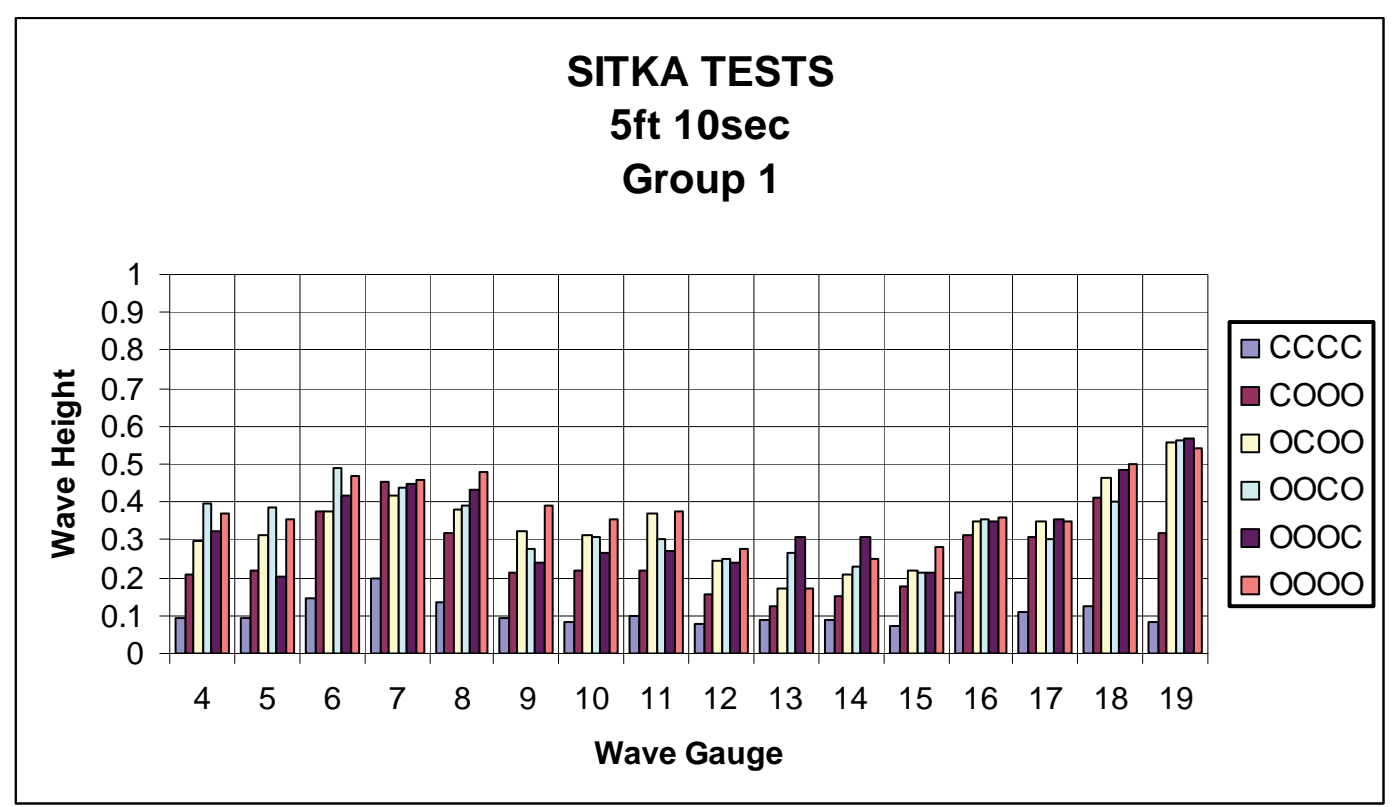

Figure 37. Group 1 wave heights for 5-ft, 10-sec waves.

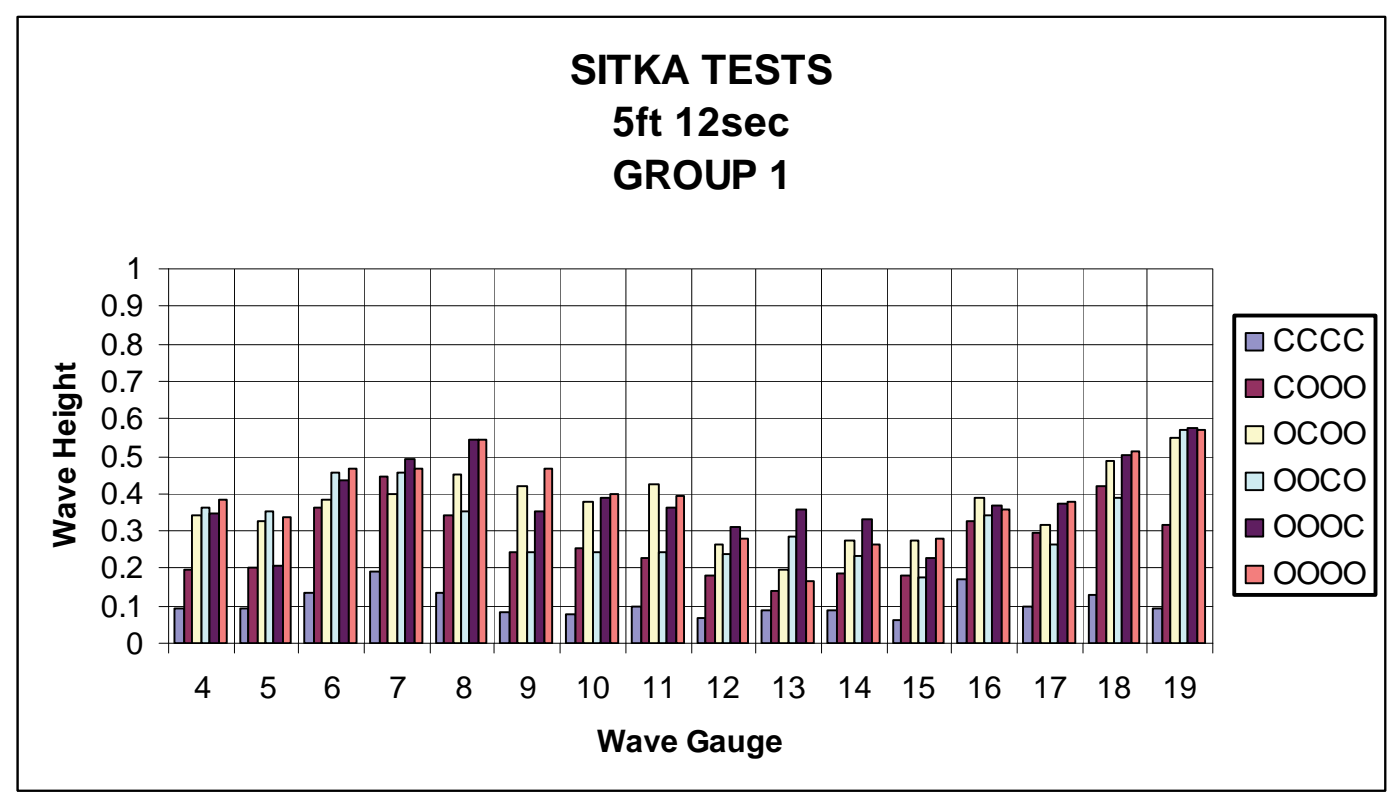

Figure 38. Group 1 wave heights for 5-ft, 12-sec waves. 




Figure 39. Group 1 wave heights for 5-ft, 14-sec waves.

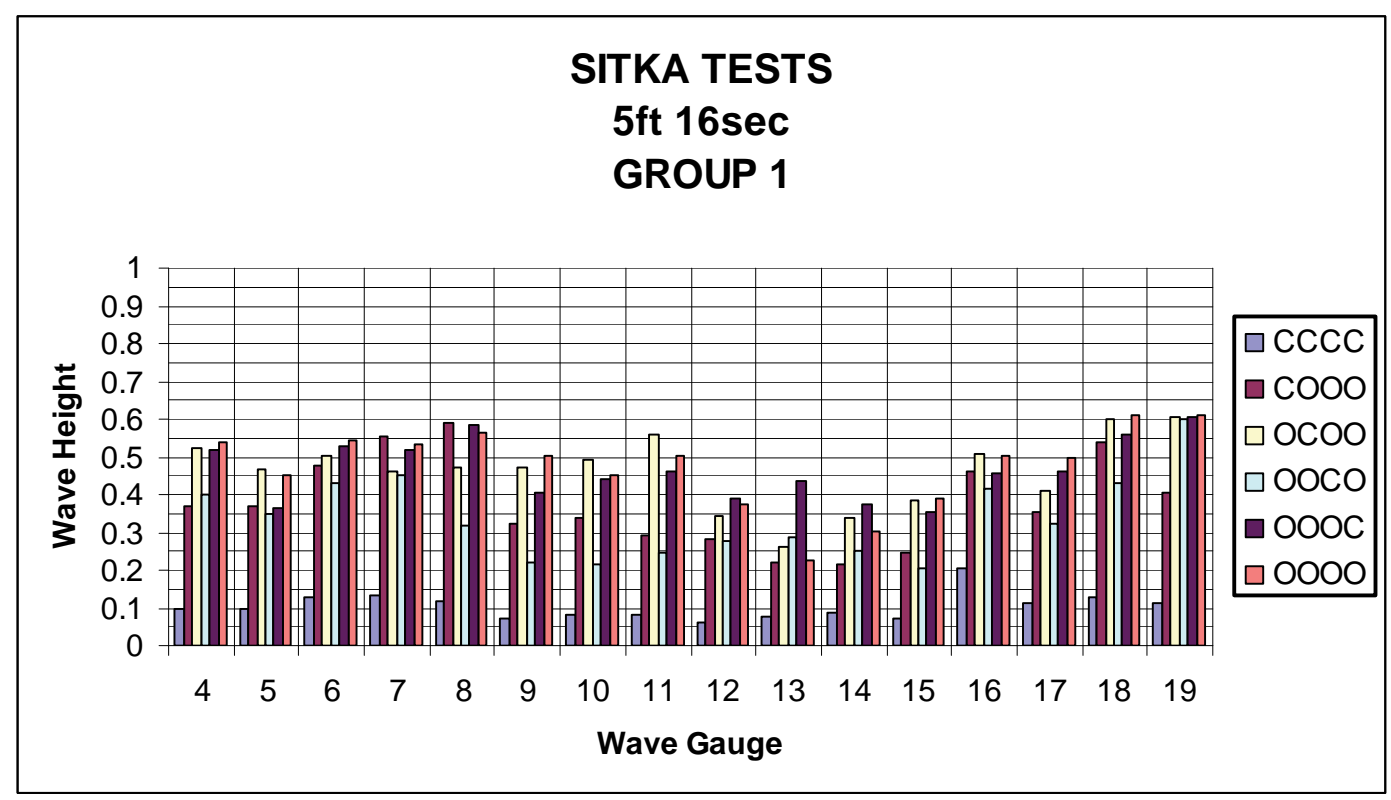

Figure 40. Group 1 wave heights for 5-ft, 16-sec waves

For all tested wave periods, the measured significant wave height along the floating dock never exceeded $0.6 \mathrm{ft}$ (prototype scale), which is well below the criterion for small boat harbors. Closure of the various gaps had a small impact with the closing of Gap 3 seeming to have the most effect.

All of the tests exhibited a trend of larger waves in the vicinity of wave gauges $6,7,8$, and 9 . This was thought to be related to the bathymetry around that portion of the floating dock as revealed in Figure 34. Some of the gauges that experienced larger wave heights are in shallower water, 
and waves approaching the harbor might be refracted and focused by the bathymetry. Alternately, those gauge locations might be at the intersection of incident waves and waves reflected off the northern shoreline revetment during high water levels. A third possibility is that the gauges might be at a location where incident wave trains entering through different breakwater gaps intersect, but this seems less likely because the trend is still evident when gaps are closed which would eliminate one of the incident wave trains.

Wave heights at the potential float plane site do not exceed about $0.6 \mathrm{ft}$ with larger waves occurring closer to the gap between the breakwater and J aponski Island shoreline. Closing this gap reduced the waves at gauge 19, but did not have much effect on the other gauges.

\section{Group 3 results}

Group 3 (tests 95- 110) had the same wave height and periods as Group 1, but wave gauges 16-19 were moved to the location in the lee of the south breakwater as shown in Figure 36. These tests looked at the differences in wave height caused by closing all but one of the gaps between breakwaters or between a breakwater and the shore. Measured significant wave heights at each wave gauge location are given in Figures 41- 44 for nominal peak wave periods of $10,12,14$, and $16 \mathrm{sec}$, respectively.

As expected, wave heights along the main floating dock (gauges 4- 15) are significantly reduced to around $0.2 \mathrm{ft}$ when only one gap remains open. The exception is leaving Gap 3 open (yellow bars), particularly at the longer wave periods, which had wave heights just over $0.5 \mathrm{ft}$.

Whereas closing multiple gaps between breakwaters is effective in reducing wave energy in New Thomsen Harbor, careful consideration must be given to how multiple gap closure would affect other physical and natural processes. Gap closures could affect tidal circulation and result in reduced water quality in the Western Channel. In addition, fish passage through the Sitka area might be adversely affected. Neither of these consequences was examined as part of this physical model study. 


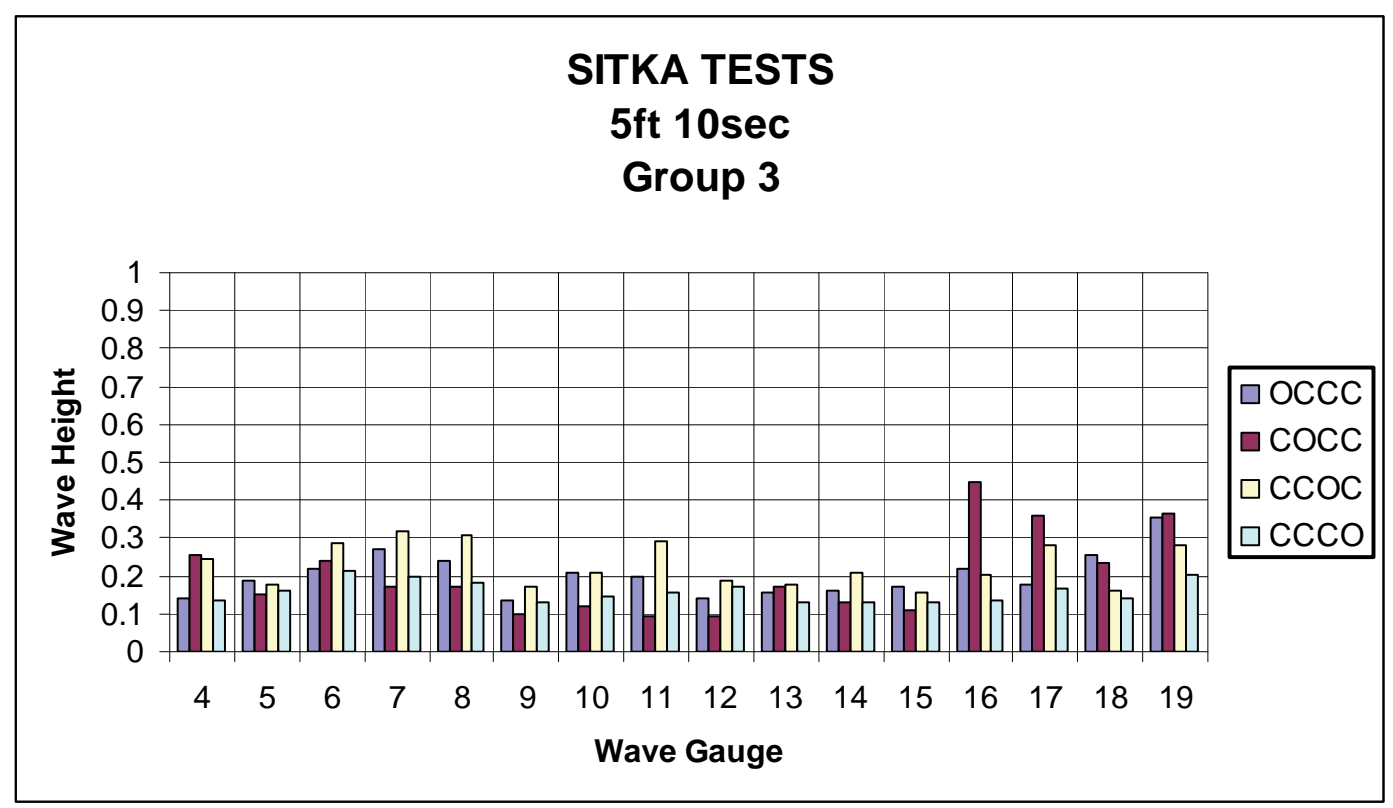

Figure 41. Group 3 wave heights for 5 -ft, 10-sec waves.

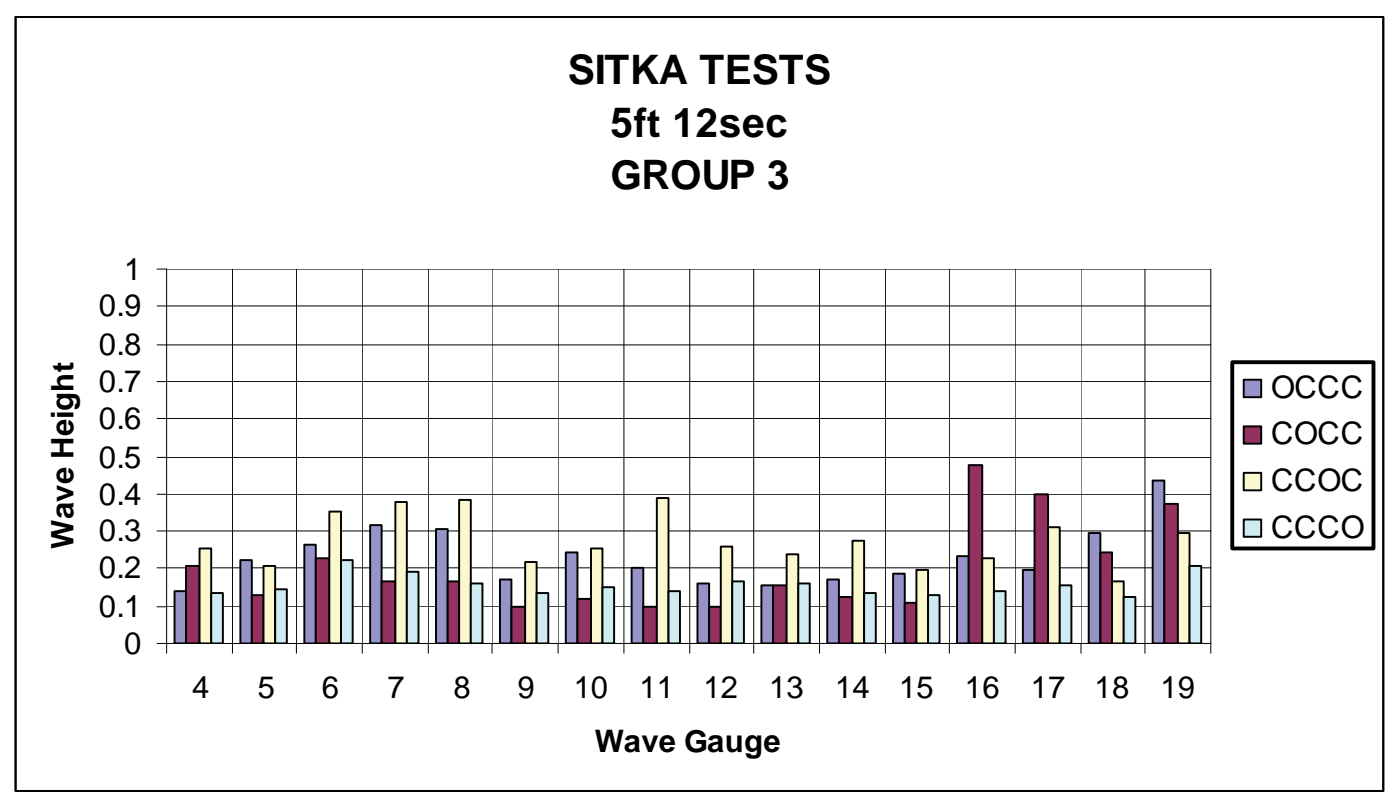

Figure 42. Group 3 wave heights for 5-ft, 12-sec waves. 




Figure 43. Group 3 wave heights for 5-ft, 14-sec waves.

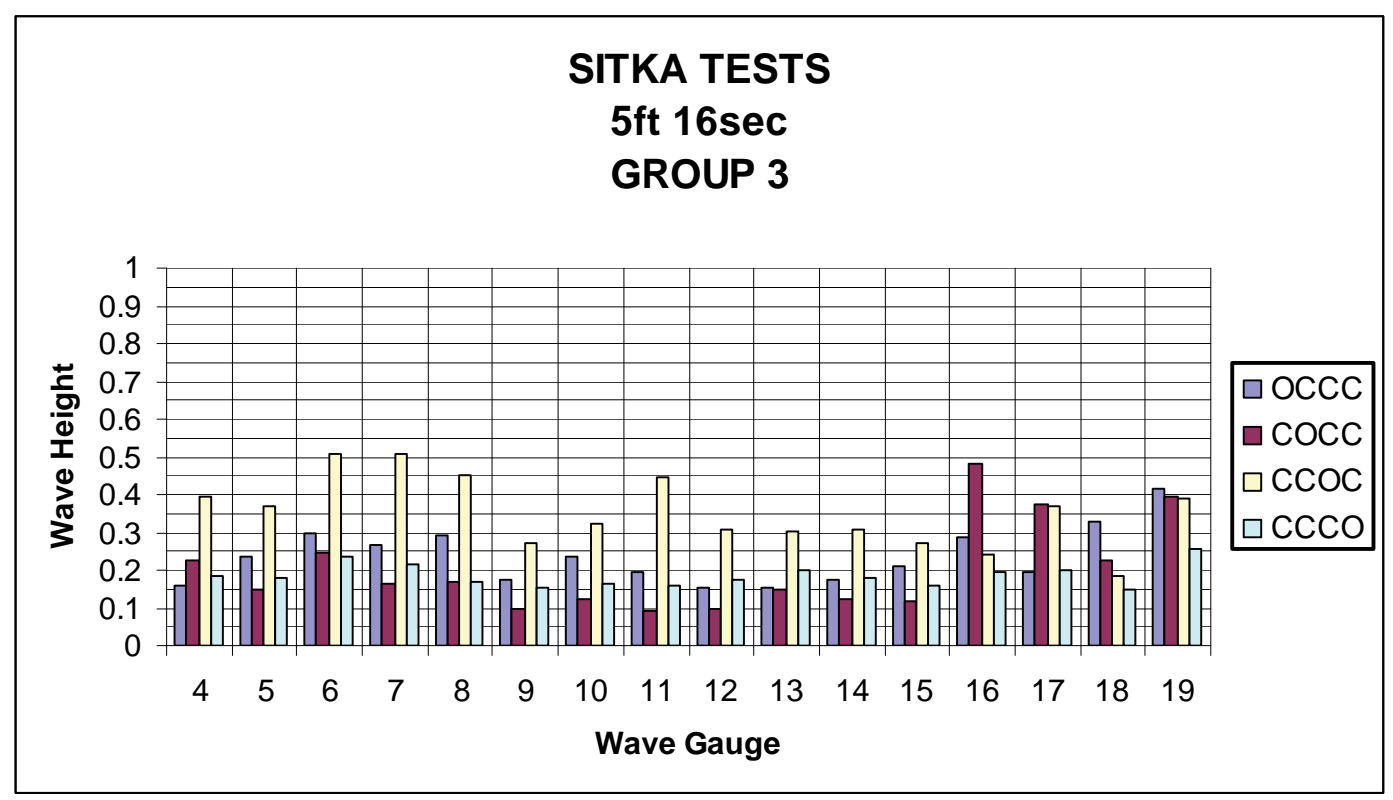

Figure 44. Group 3 wave heights for 5-ft, 16-sec waves.

\section{Group 4 results}

Group 4 (tests 111-130) was a repeat of the Group 1 tests with the only difference being that wave Gauges 16- 19 were located in the lee of the south breakwater as shown in Figure 36 for Group 4. The main purpose of these tests was to measure wave heights near the south breakwater for the cases of only one gap being closed at a time. These tests also serve as a test of experiment repeatability for the wave gauges located along the main 
floating dock. In general, repeatability was quite good with maximum differences between tests on the order of about $0.1 \mathrm{ft}$ (prototype scale).

Measured significant wave heights at each wave gauge location are given in Figures 45- 48 for peak wave periods of 10, 12, 14, and 16 sec, respectively. Similar trends are observed along the main floating dock as seen for the Group 1 tests. Wave heights measured at Gauges 16- 19 in the lee of the south breakwater were around $0.7 \mathrm{ft}$ maximum.



Figure 45. Group 4 wave heights for 5-ft, 10-sec waves.



Figure 46. Group 4 wave heights for 5-ft, 12-sec waves. 


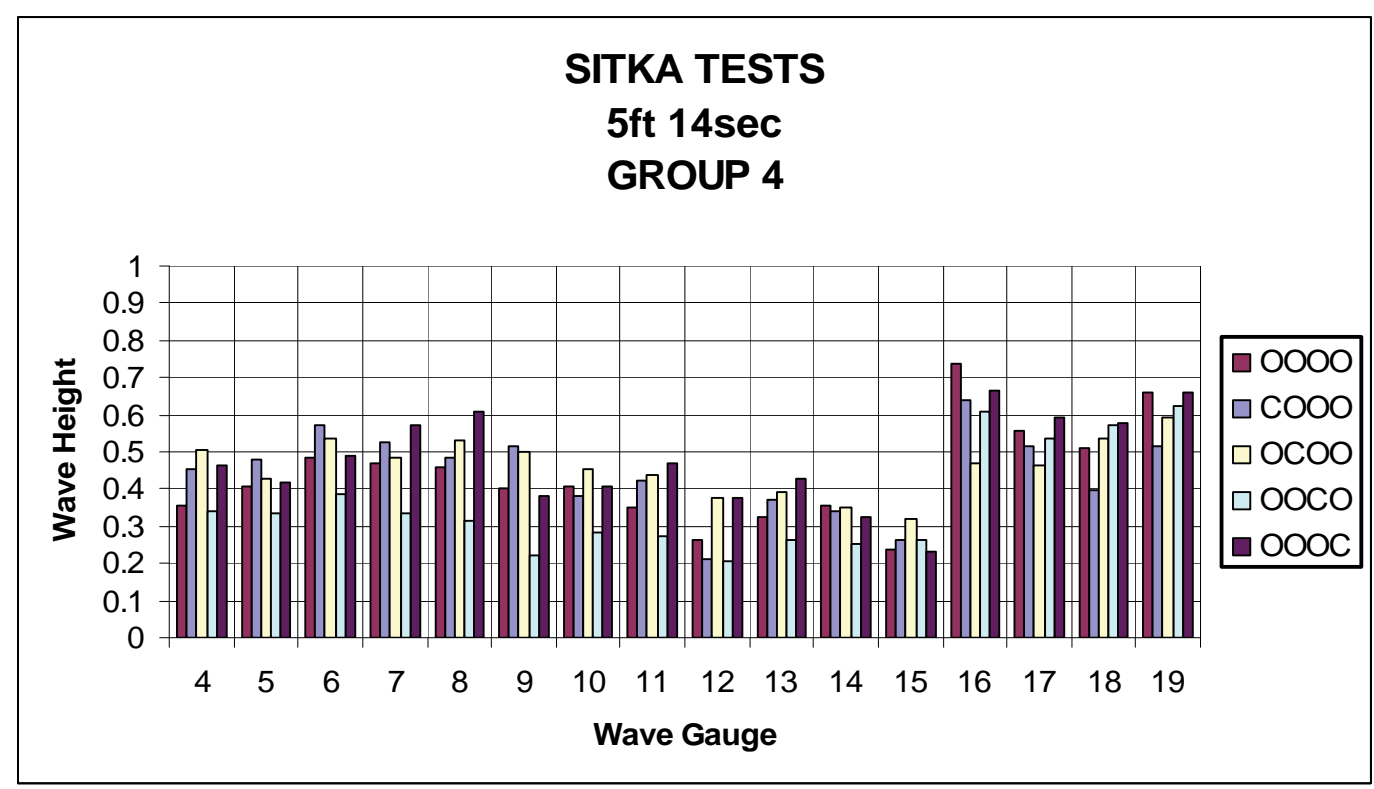

Figure 47. Group 4 wave heights for 5-ft, 14-sec waves.

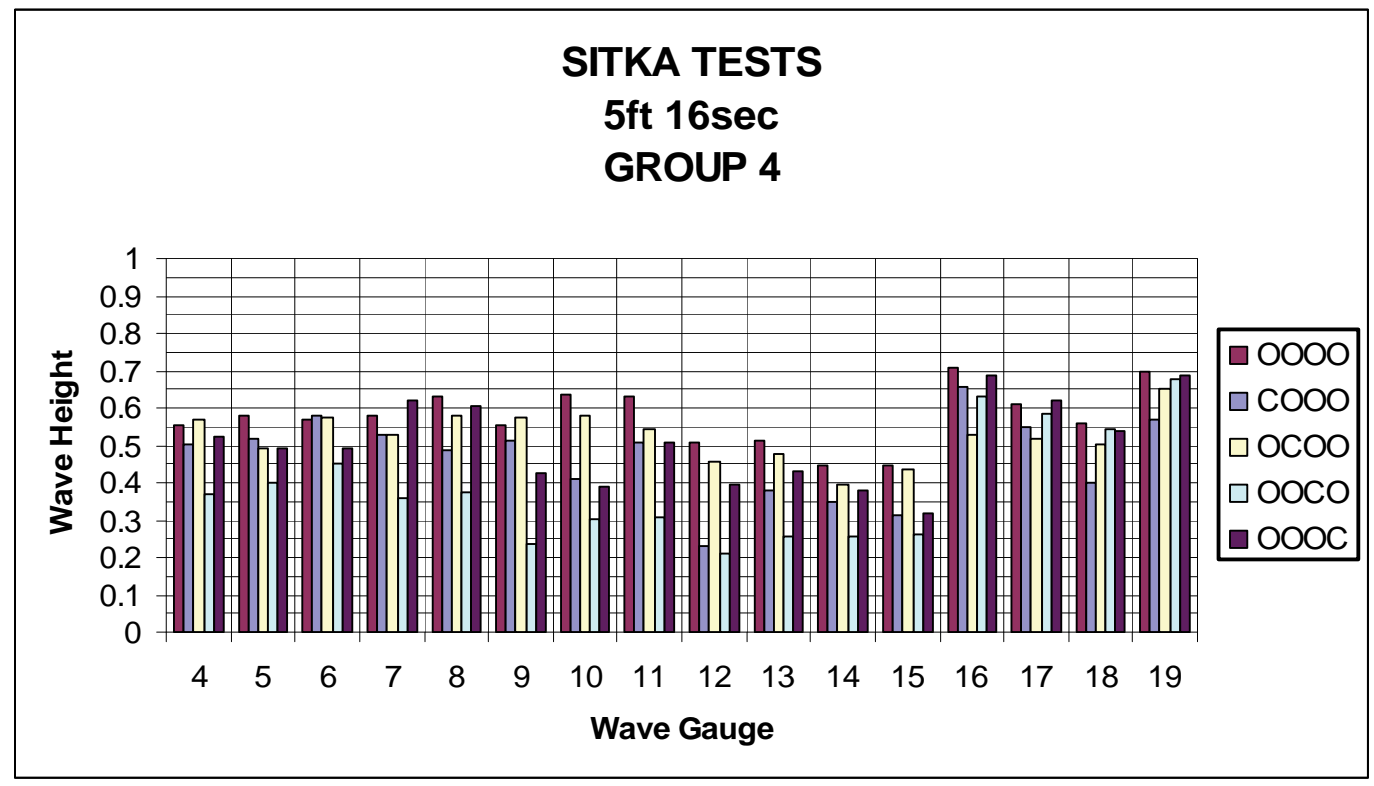

Figure 48. Group 4 wave heights for 5-ft, 16-sec waves.

\section{Wave focusing along main floating dock (tests 131-146)}

Groups 5- 8 looked for evidence of wave focusing that appeared to cause increased wave heights at a particular location along the floating dock. Table 10 summarizes the tests for Groups 5- 8. Measured parameter values in Table 10 have been converted to prototype scale. All tests were run with irregular waves, and the values of significant wave height $\left(H_{m 0}\right)$ and peak spectral period $\left(T_{p}\right)$ given in the table were obtained from measurements acquired at the three wave gauges directly in front of the 
wavemaker. The column labeled "Dir" is the direction from which waves came. All tests in the four groups had a nominal significant wave height of $H_{m 0}=5 \mathrm{ft}$, and nominal peak spectral wave periods of $T_{p}=10,16$, or 24 sec. Table 10 gives actual measured values. The notations in the column labeled "Gaps" indicates whether all gaps were open or closed.

\section{Group 5 results}

Group 5 (tests 131-132) kept wave gauges 4- 15 located along the main floating dock as shown in Figure 34, but Gauges 16- 19 were moved back to the positions shown in Figure 35 at the proposed future float plane facility for the duration of the study. The main purpose of these tests was to measure wave heights along the floating dock caused by 24-sec waves coming through the gaps and over the breakwater (all gaps open) and only over the breakwaters (all gaps closed).

Table 10. Experiment parameters for November 2006 tests for Groups 5-8.

\begin{tabular}{|c|c|c|c|c|c|c|}
\hline \# & $\begin{array}{l}\text { Water } \\
\text { Level } \\
\text { (ft) }\end{array}$ & $\begin{array}{l}H_{m 0} \\
\text { (ft) }\end{array}$ & $\begin{array}{l}T_{p} \\
\text { (sec) }\end{array}$ & Dir & Gaps & Notes \\
\hline \multicolumn{7}{|r|}{ Group 5} \\
\hline 131 & +11 & 4.8 & 23.3 & SW & All open & Gauges $16-19$ moved to proposed float plane facility \\
\hline 132 & +11 & 4.8 & 23.3 & SW & All closed & Gauges 16-19 moved to proposed float plane facility \\
\hline \multicolumn{7}{|r|}{ Group 6} \\
\hline 133 & +11 & 4.8 & 23.3 & SW & All closed & Main float gauge array moved to $-39 \mathrm{ft}$ contour \\
\hline 134 & +11 & 5.0 & 16.2 & SW & All closed & Main float gauge array moved to $-39 \mathrm{ft}$ contour \\
\hline 135 & +11 & 5.6 & 9.3 & SW & All closed & Main float gauge array moved to $-39 \mathrm{ft}$ contour \\
\hline 136 & +11 & 4.8 & 23.3 & SW & All open & Main float gauge array moved to $-39 \mathrm{ft}$ contour \\
\hline 137 & +11 & 5.0 & 16.2 & SW & All open & Main float gauge array moved to $-39 \mathrm{ft}$ contour \\
\hline 138 & +11 & 5.6 & 9.3 & SW & All open & Main float gauge array moved to $-39 \mathrm{ft}$ contour \\
\hline \multicolumn{7}{|r|}{ Group 7} \\
\hline 139 & +11 & 5.5 & 9.3 & SW & All open & Gauge array moved back to main dock, No absorber \\
\hline 140 & +11 & 5.6 & 9.3 & SW & All closed & Gauge array moved back to main dock, No absorber \\
\hline 141 & +11 & 5.5 & 9.3 & SW & All closed & Rerun of test 140 \\
\hline 142 & +11 & 5.5 & 9.3 & SW & All open & Rerun of test 139 \\
\hline \multicolumn{7}{|r|}{ Group 8} \\
\hline 143 & +11 & 5.7 & 9.3 & SW & All closed & Gauge array moved back to main dock, Absorber added \\
\hline 144 & +11 & 5.7 & 9.3 & SW & All open & Gauge array moved back to main dock, Absorber added \\
\hline 145 & +11 & 5.5 & 9.3 & SW & All open & Rerun of test 144 \\
\hline 146 & +11 & 5.5 & 9.3 & SW & All closed & Rerun of test 143 \\
\hline
\end{tabular}


Figure 49 presents wave measurements for the 5-ft, 24-sec wave condition with water level at $+11 \mathrm{ft}$. When all gaps were open, the maximum wave heights within New Thomsen Harbor were almost $0.7 \mathrm{ft}$ and fairly uniform along much of the wave gauge array (gauges $4-11$ ). Closing all gaps reduced the wave energy by more than 50 percent to less than $0.3 \mathrm{ft}$. The longer period waves did not reproduce the range of increased wave heights between gauges 7-9 that was observed for short period wave conditions. If this localized increase in wave heights is due to wave refraction by bottom bathymetry, it may be that the longer period waves cannot respond quickly to abrupt depth changes.

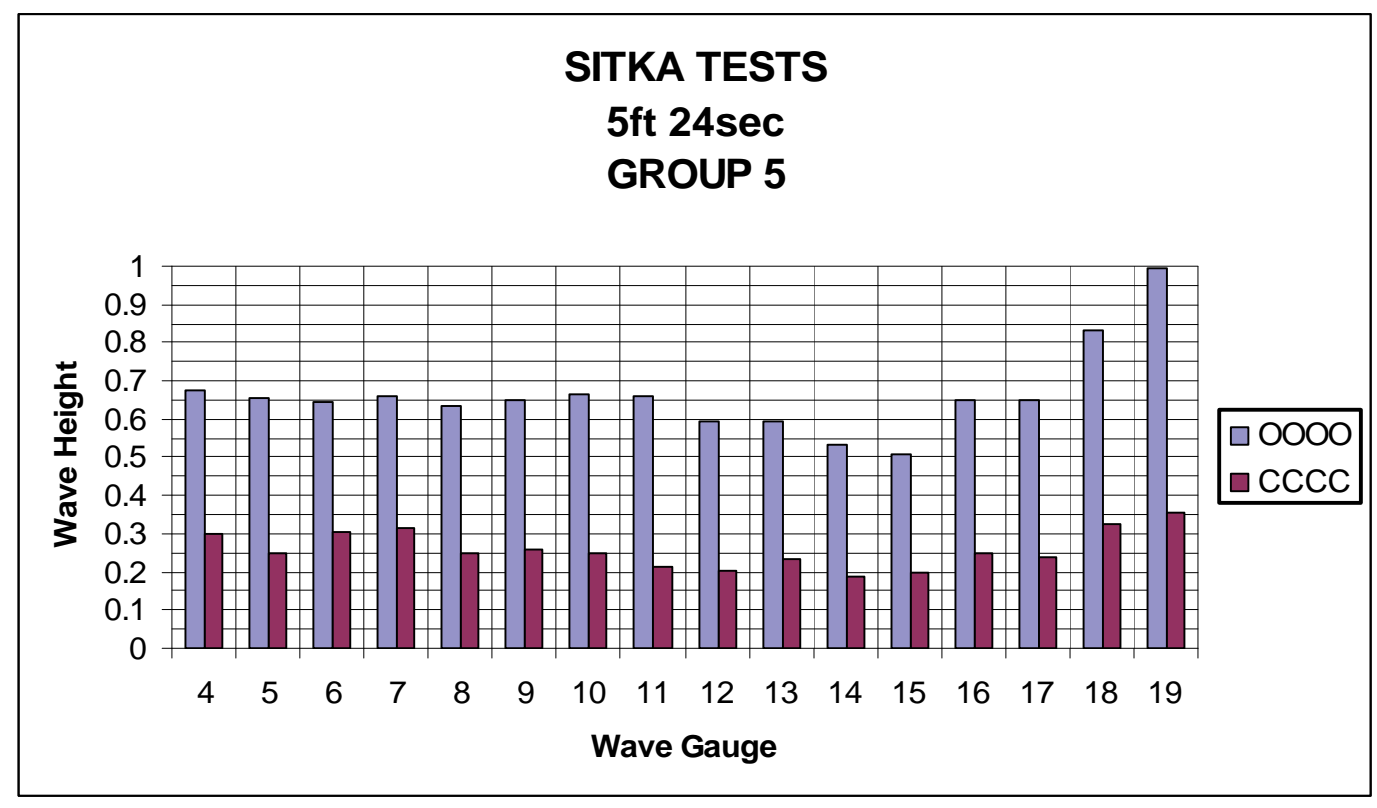

Figure 49. Group 5 wave heights for 5-ft, 24-sec waves.

\section{Group 6 results}

Group 6 (tests 133-138) tested the hypothesis that the localized increase in wave heights along the main floating dock is a result of bottom depth variations. The support framework holding wave gauges 4- 15 was shifted laterally to a location more or less directly over the - $39 \mathrm{ft}$ contour as shown in Figure 50. Measurements were acquired for irregular wave conditions with nominal significant wave height of $5 \mathrm{ft}$ and peak spectral wave periods of 10, 16, and $24 \mathrm{sec}$. Results are plotted on Figures 51, 52, and 53 for the three wave periods.

This group of tests did not reveal much insight into the process that causes focusing of wave energy along the main floating dock. In fact, a slight "hump" in wave heights is seen at gauge 6 for the 10 -sec wave and at 
gauge 8 for the 16-sec wave. Figure 54 compares equivalent tests from Group 1 that had the gauge array along the floating dock to tests from Group 6 with the array over the - $39 \mathrm{ft}$ contour. Wave heights are slightly larger when the array was at the location of the floating dock. Figure 55 compares Group 5 to the equivalent 24-sec wave condition from Group 6. This comparison indicates a definite decrease in wave heights at gauges 511 when the array was moved to a location having a more uniform, albeit deeper, depth. However, the possibility that this difference could be caused by something other than bathymetry difference (e.g., wave train interactions) cannot be discounted.

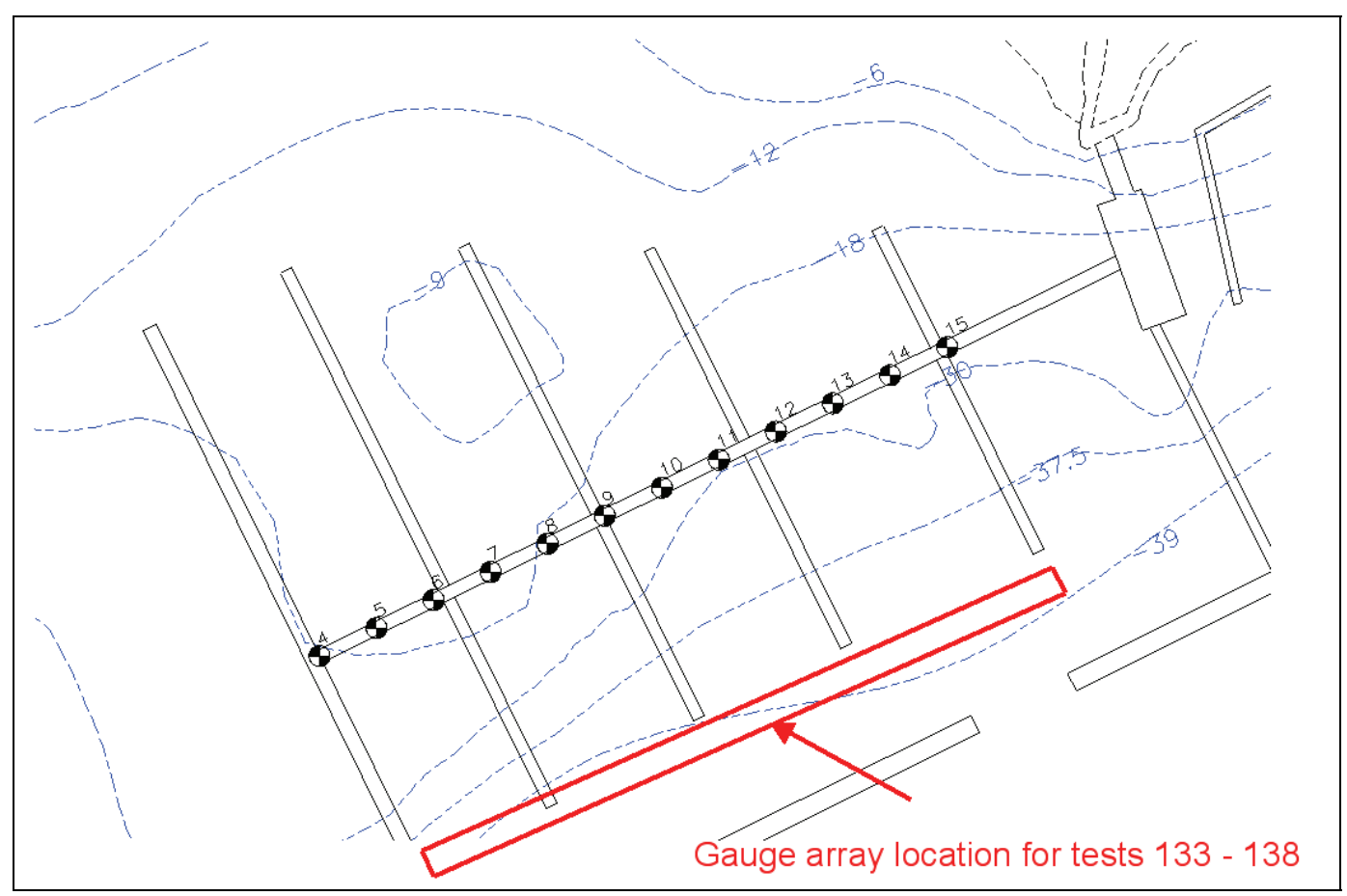

Figure 50 . Wave gauge array offset to the $-39 \mathrm{ft}$ contour. 




Figure 51. Group 6 wave heights for 5-ft, 10-sec waves.



Figure 52. Group 6 wave heights for 5-ft, 16-sec waves. 




Figure 53. Group 6 wave heights for 5-ft, 24-sec waves.
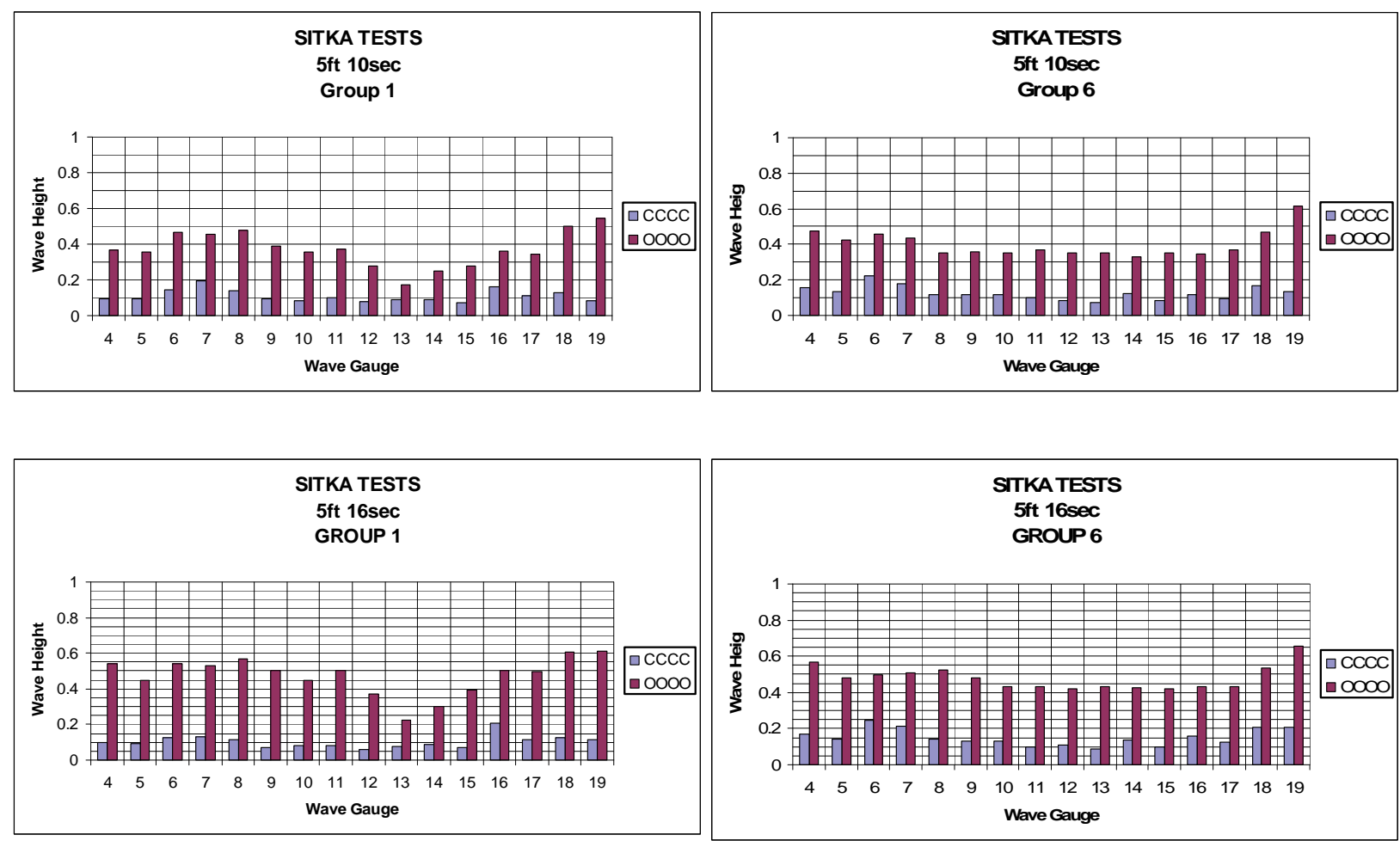

Figure 54. Comparison between Group 1 and Group 6 wave heights ( $T_{p}=10$ and $16 \mathrm{sec}$ ). 



Figure 55. Comparison between Group 5 and Group 6 wave heights $\left(T_{p}=24 \mathrm{sec}\right)$.

\section{Groups 7 and 8 results}

The support platform holding wave gauges 4-15 was moved back to its original position aligned with the main floating dock as shown in Figure 34. Group 7 (tests 139-142) were run for the nominal 5-ft, 10-sec wave condition with all gaps open and all gaps closed. Water level remained at the $+11 \mathrm{ft}$ mllw elevation.

Next, the shorelines adjacent to the Western Channel were lined with absorbing "horsehair" mats to decrease wave reflection from the shoreline. Figure 56 indicates the reaches of shoreline on which absorber was placed. (Note that the wave gauge locations shown in Figure 56 are from the September 2005 tests and not the November 2006 tests.) Group 8 (tests 143146) repeated the Group 7 test conditions. The purpose of the Group 7 and 8 tests was to see if the "hump" in wave heights along the main floating dock could be attributed to an interaction between incident waves and waves reflected off the shoreline revetment.

The first two tests of Group 7 were suspect because measured results did not match previous tests of the same condition (without wave absorbers). Also, Group 8 tests were run using a different wave calibration, and there was concern that this could have some influence on the comparisons. Therefore, The Group 7 and 8 tests were repeated using the same wave gauge calibration. 


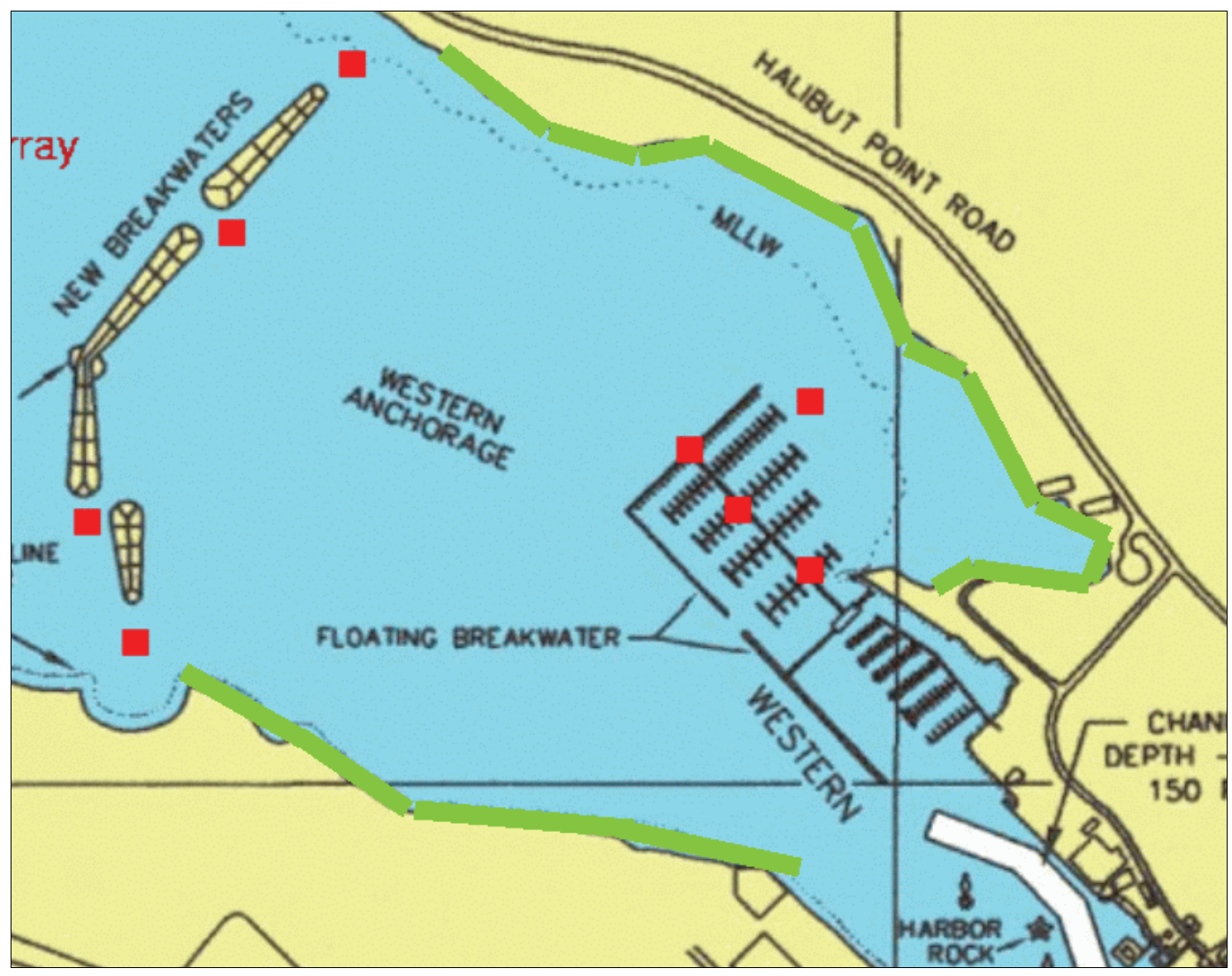

Figure 56. Shoreline wave absorbers for Group 8 (tests 143-146).

Figures 57 and 58 show measured results for the rerun Group 7 (no absorber) and Group 8 tests (with absorber). The characteristic "hump" in wave energy is apparent between gauges 6 and 9 for both cases with all gaps open, and only a slight reduction in maximum wave height occurs due to the addition of wave absorber. Based on this comparison, it appears that interaction of incident waves with wave reflected by the shoreline revetment contributes a small amount to the increase in wave energy along the main floating dock. 


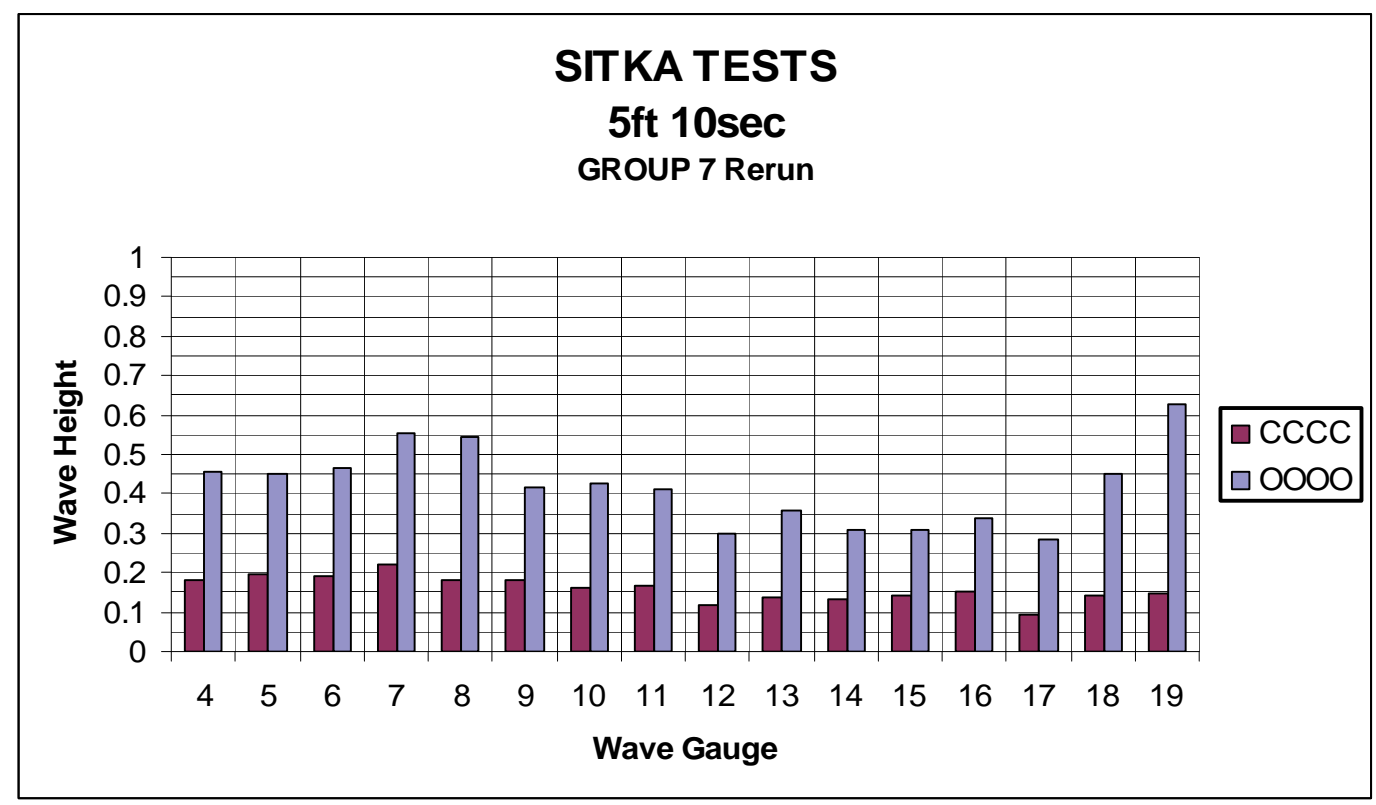

Figure 57. Group 7 wave heights for 5-ft, 10-sec waves without absorber.

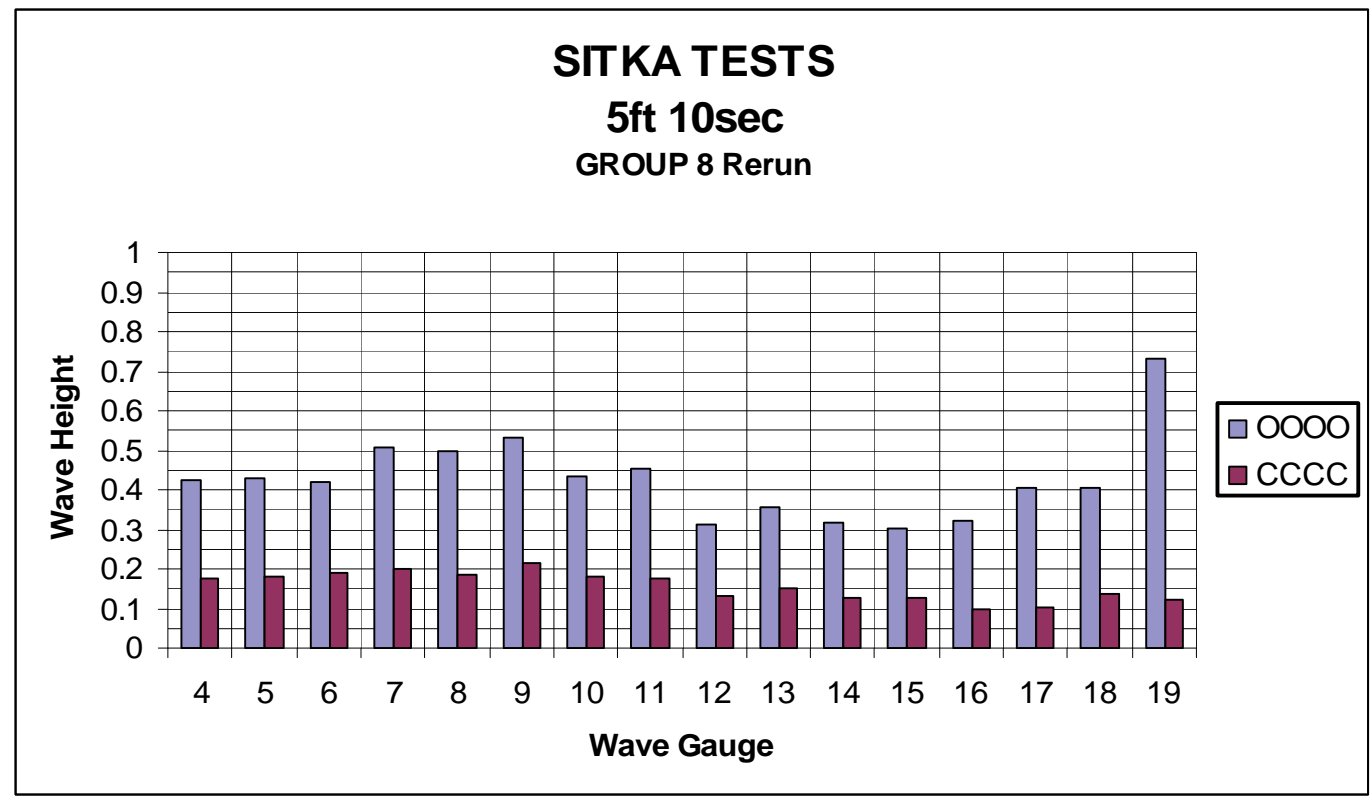

Figure 58. Group 7 wave heights for 5-ft, 10-sec waves with absorber.

\section{Effect of bathymetry modification (tests 147-161)}

Groups 9- 12 were run to determine if smoothing the bathymetric relief in the vicinity of wave gauges 6-10 along the main floating dock would lead to reduction in the wave height variations along the main dock (i.e., the "hump" in the wave height bar chart plots). Table 11 summarizes the tests for Groups 9-12. As in previous tables, values are given in prototype-scale 
equivalents, and all the other columns are the same as previously described. All of the tests had a nominal wave height of $H_{m 0}=5 \mathrm{ft}$, and the peak spectral period was either 10 or 24 sec.

Table 11. Experiment parameters for November 2006 tests for Groups 9-12.

\begin{tabular}{|c|c|c|c|c|c|c|}
\hline \# & $\begin{array}{l}\text { Water } \\
\text { Level } \\
\text { (ft) }\end{array}$ & $\begin{array}{l}H_{m 0} \\
(\mathrm{ft})\end{array}$ & $\begin{array}{l}T_{p} \\
\text { (sec) }\end{array}$ & Dir & Gaps & Notes \\
\hline \multicolumn{7}{|c|}{ Group 9} \\
\hline 147 & +11 & 5.4 & 9.3 & SW & All closed & Pea gravel bathymetry added, no absorber \\
\hline 148 & +11 & 5.4 & 9.3 & SW & All open & Pea gravel bathymetry added, no absorber \\
\hline \multicolumn{7}{|c|}{ Group 10} \\
\hline 149 & +11 & 5.4 & 9.3 & SW & All open & Pea gravel bathymetry added, no absorber \\
\hline 150 & +11 & 4.8 & 23.3 & SW & All open & Pea gravel bathymetry added, no absorber \\
\hline \multicolumn{7}{|c|}{ Group 11} \\
\hline 151 & +11 & 5.6 & 9.3 & SW & All open & Pea gravel bathymetry added, absorber on shoreline \\
\hline 152 & +11 & 4.9 & 23.3 & SW & All open & Pea gravel bathymetry added, absorber on shoreline \\
\hline \multicolumn{7}{|c|}{ Group 12} \\
\hline 153 & +11 & 5.5 & 9.3 & SW & All open & Additional pea gravel bathymetry added, no absorber \\
\hline 154 & +11 & 4.8 & 23.3 & SW & All open & Additional pea gravel bathymetry added, no absorber \\
\hline
\end{tabular}

Before commencing this series of tests, pea gravel was placed in the model to raise the bathymetry seaward of the end of the main floating dock to a uniform depth of about - $18 \mathrm{ft}$ mllw. The idea was to smooth the sharp curve in the-18-ft-contour line seaward of the harbor. (See the original contours shown in Figure 34.) Figures 59 and 60 show the extent of infilling placed in the model. This gravel placement provided a smoother contour and a uniform depth seaward of the floating dock area. 


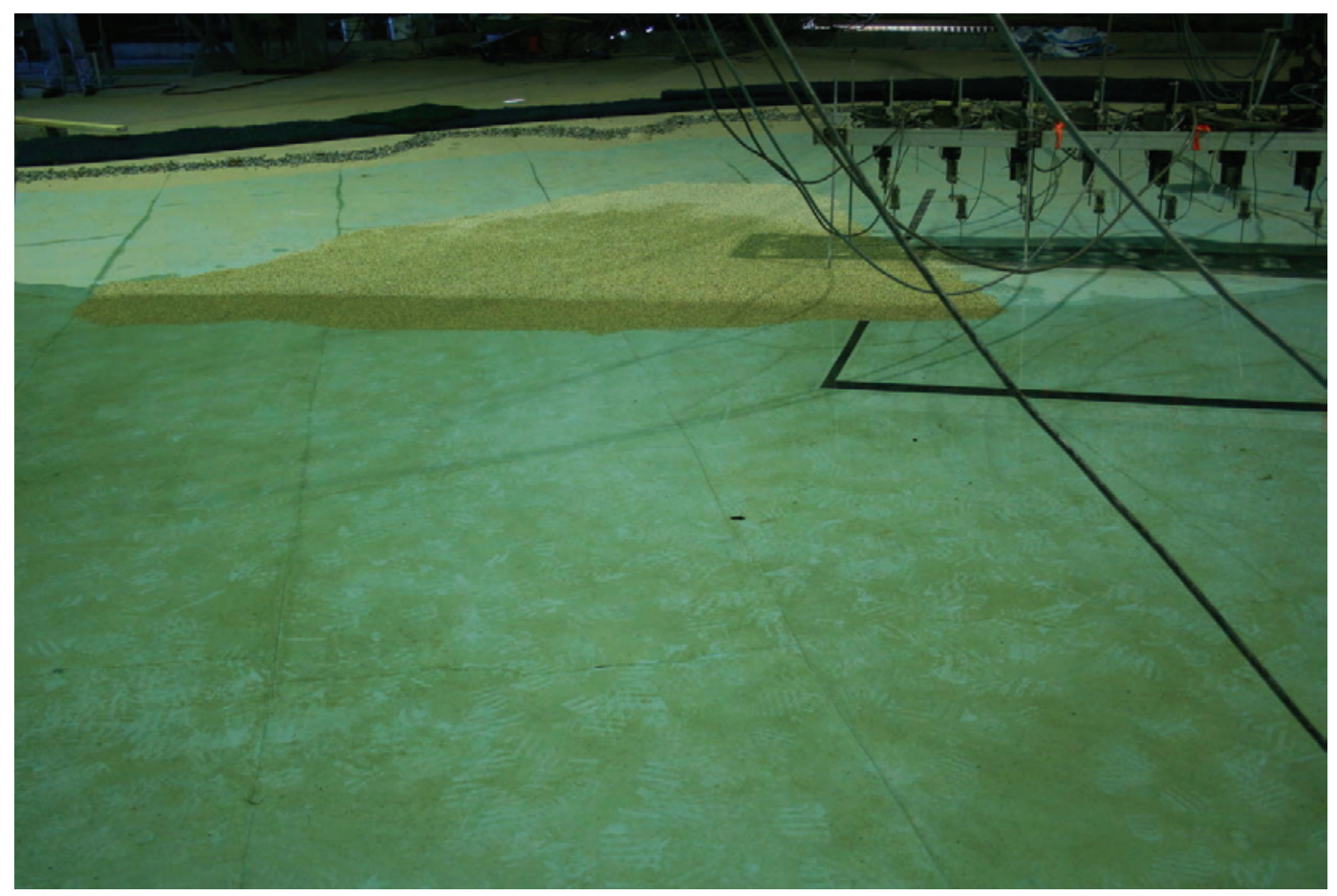

Figure 59. Pea gravel infill looking from Japonski Island toward seaward end of array.

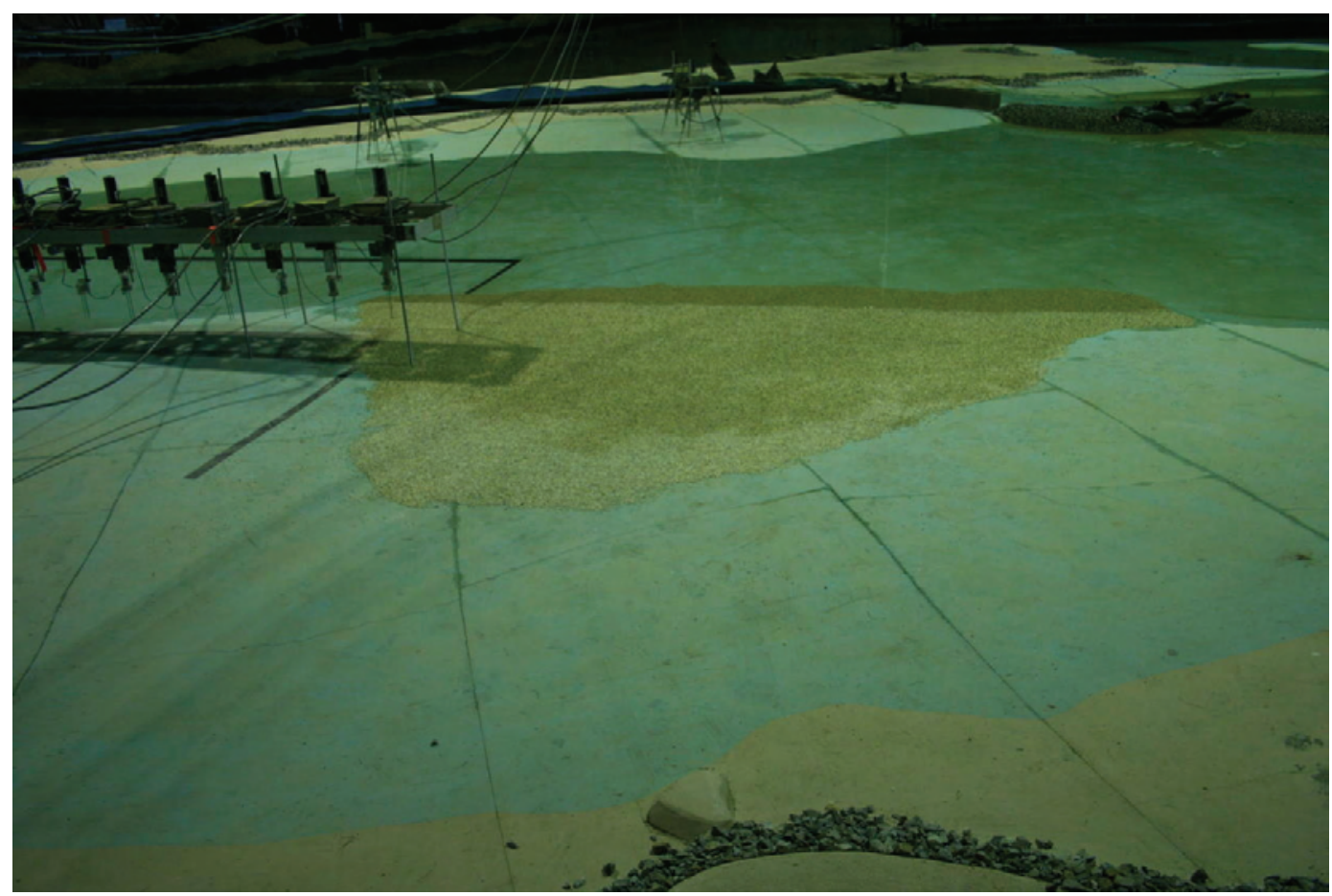

Figure 60. Pea gravel infill looking from shore toward Japonski Island.

\section{Group 9 results}

The same wave condition $\left(H_{m 0}=5.4 \mathrm{ft}, T_{p}=9.3 \mathrm{sec}\right)$ was run once with all gaps opens and once with all gaps closed. The water level was set at $+11 \mathrm{ft}$ mllw. Figure 61 shows the measured wave heights along the main floating 
dock. Placing the pea gravel appears to have had a smoothing effect in the region of gauges 7 and 8. Comparison with the Group 7 rerun given in Figure 57 shows that maximum wave heights have been reduced by about $0.15 \mathrm{ft}$ at gauges 7 and 8 . This finding suggests that wave refraction by bathymetry variations near New Thomsen Harbor can focus wave energy and increase wave heights locally.

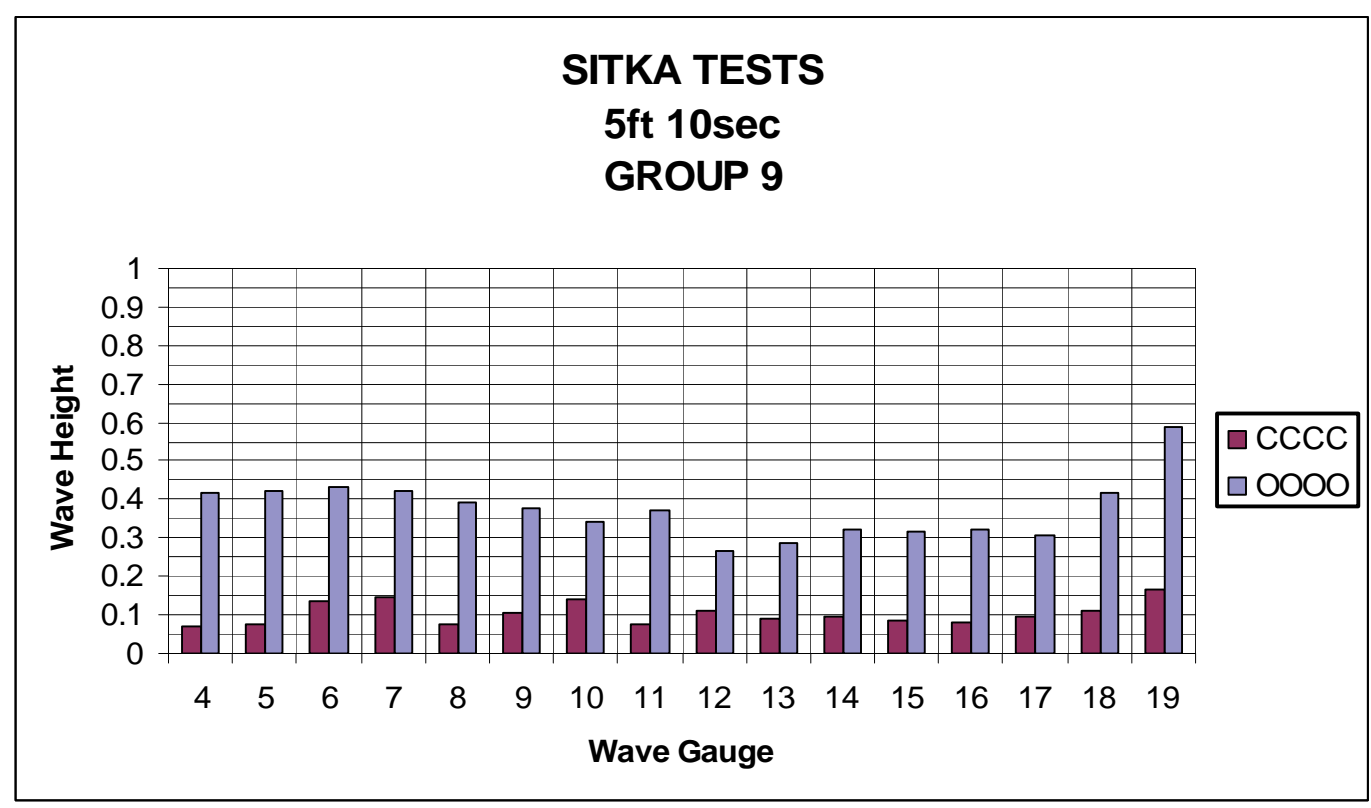

Figure 61.Group 9 wave heights for 5-ft, 10-sec waves with pea gravel added.

\section{Groups 10 and 11 results}

These related tests examined the effect of shoreline absorber in combination with the modified bathymetry. Tests were conducted with the same significant wave height and with nominal peak periods of 10 and $24 \mathrm{sec}$. Group 9 tests were conducted without any shoreline wave absorption, and Group 10 tests had both shorelines lined with wave absorbing "horsehair" mats. Figures 62 and 63 show the wave height comparisons for the 10- and 24-sec waves, respectively.

The wave absorbing shoreline made little difference for the shorter period 10-sec waves, but reductions up to $0.2 \mathrm{ft}$ were seen for the 24 -sec wave as shown in Figure 63. This difference indicates that the interaction of reflected with with incident waves is important only for longer waves. 


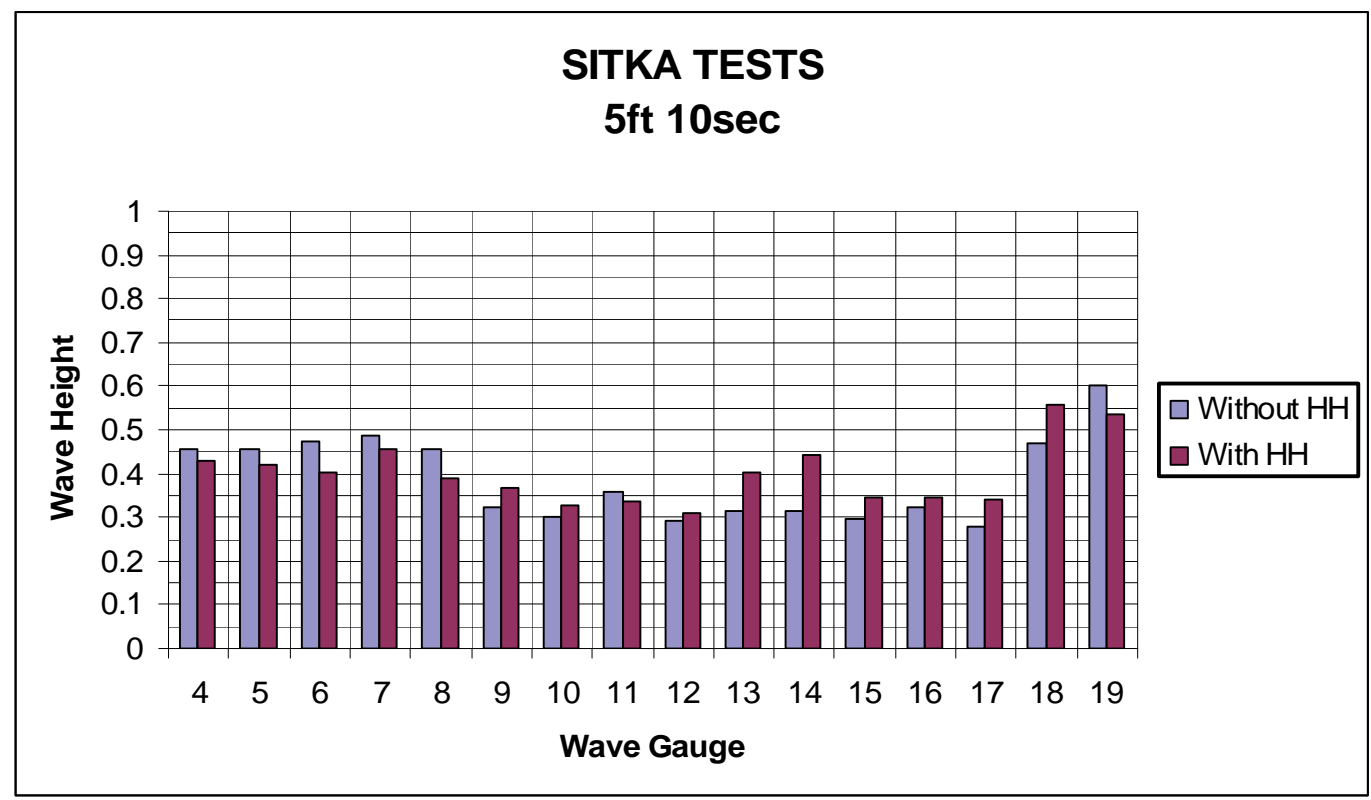

Figure 62. Effect of bathymetry and wave absorber for tests 149 and 151.



Figure 63. Effect of bathymetry and wave absorber for tests 150 and 152.

\section{Group 12 results}

Because of the apparent effect of modifying bathymetry shown in previous runs, additional pea gravel was added to fill in the deeper portions of the bathymetry beneath the main floating dock. This addition brought the bottom under the dock up to a uniform depth of - $18 \mathrm{ft}$ mllw. (See original contours on Figure 34). Figure 64 and 65 show the additional infilling placed in the physical model. 




Figure 64. Second pea gravel addition; view from Japonski Island.



Figure 65. Second pea gravel addition, view from Sitka.

The additional pea gravel added for the Group 12 tests is seen in Figure 64 beneath the wave gauge array that straddled the main floating dock. This view is from J aponski Island looking across the Western Channel to New Thomsen Harbor. The floating breakwater is indicated by the black lines 
painted on the floor of the model. The viewpoint for the image in Figure 65 is from the Sitka shore above the harbor looking out toward the three breakwaters.

Results from the Group 12 tests are plotted on Figures 66 and 67 for nominal peak periods of 10 and $24 \mathrm{sec}$, respectively. Plotted along with the Group 12 results are corresponding tests from Group 13 that used monochromatic waves.

Looking only at the irregular wave results on Figures 66 and 67 (noted as Spectral in the legend), it can be seen that leveling out the depth variations under the entire wave gauge array has resulted in a leveling of the measured wave heights along the array. Comparing the wave heights for the 10sec wave in Figure 66 to those of Figure 62, it is seen that the maximum wave height at gauge 7 in Figure 62 is nearly the same for gauges 5- 9 in Figure 66. The longer period 24-sec wave heights in Figure 67 are uniform, but lower than the maximum measured at gauge 7 in Figure 63. This result further reinforces the idea that wave interaction with harbor bathymetry might be responsible for observed uncomfortable wave action in New Thomsen Harbor. Note, however, that measured wave heights are still below the recommended criterion of $1 \mathrm{ft}$ for small boat harbors.

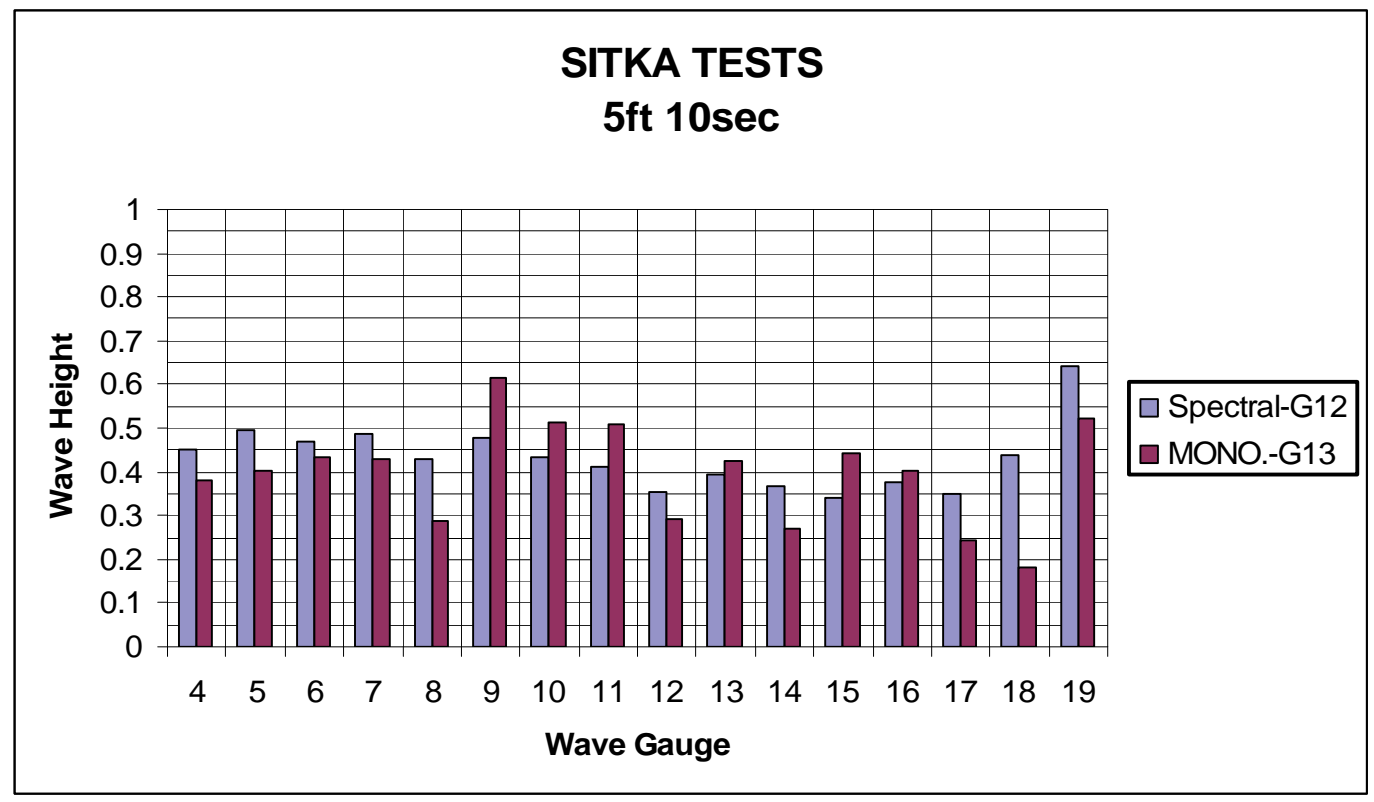

Figure 66. Effect of additional bathymetry modification, 5-ft, 10-sec wave. 


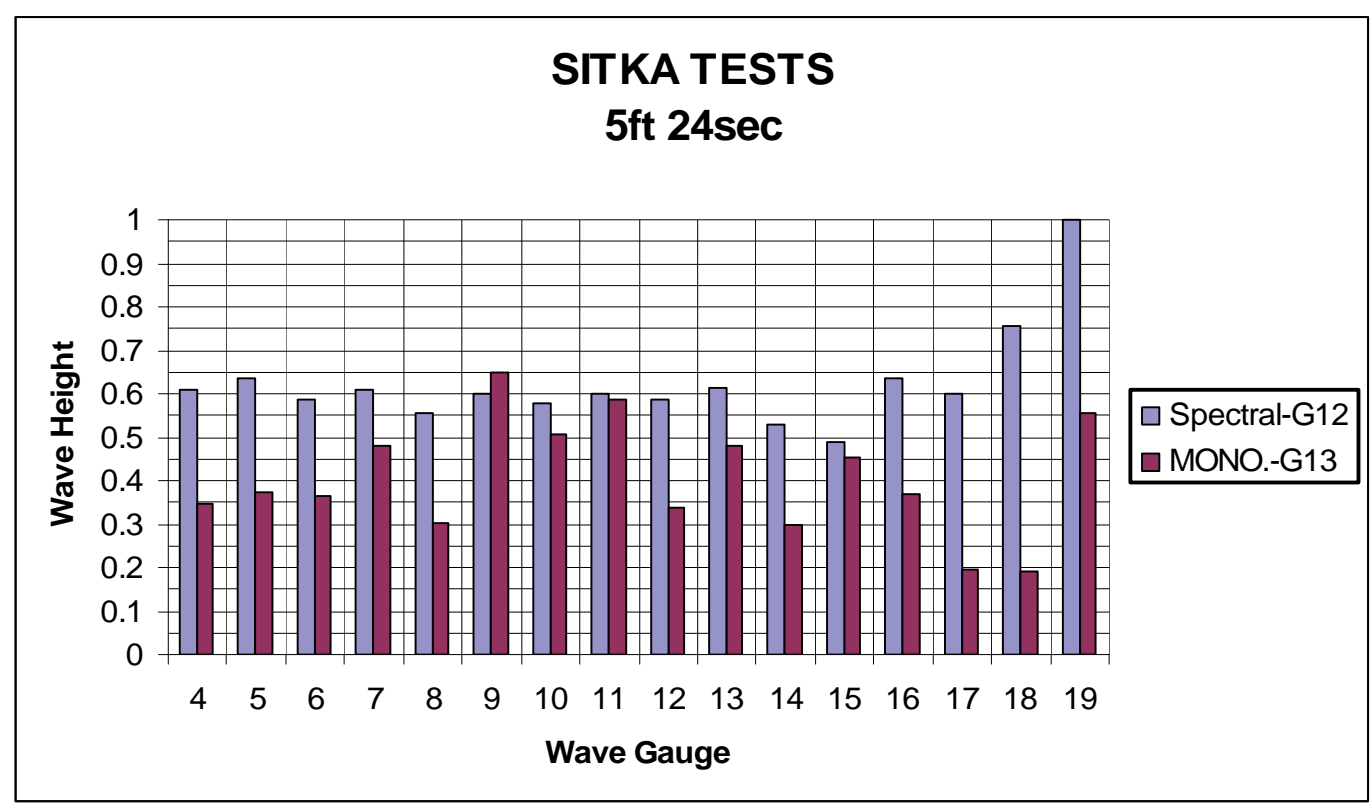

Figure 67. Effect of additional bathymetry modification, 5-ft, 24-sec wave.

\section{Groups 13 and 14 results}

Groups 13 and 14 used monochromatic (regular) waves instead of irregular waves, and the bathymetry changes made with pea gravel remained in the model for these tests. Table 12 lists test parameters for Groups 13 and 14. Wave heights in the table were determined by frequency-domain analysis for these tests, so the actual average wave heights were larger. Group 14 tests included shoreline wave absorber.

Table 12. Experiment parameters for November 2006 tests for Groups 13-14.

\begin{tabular}{|l|l|l|l|l|l|l|l|}
\hline \multirow{2}{|l|}{$\begin{array}{l}\text { Water } \\
\text { Level } \\
(\mathrm{ft})\end{array}$} & $\begin{array}{l}H_{m 0} \\
(\mathrm{ft})\end{array}$ & $\begin{array}{l}T_{p} \\
(\mathrm{sec})\end{array}$ & Dir & Gaps & Notes \\
\hline 155 & +11 & 3.4 & 10.0 & SW & All open & Additional pea gravel bathymetry added, no absorber \\
\hline 156 & +11 & 3.7 & 10.0 & SW & All open & Additional pea gravel bathymetry added, no absorber \\
\hline 157 & +11 & 3.7 & 10.0 & SW & All open & Additional pea gravel bathymetry added, no absorber \\
\hline 158 & +11 & 2.7 & 23.3 & SW & All open & Additional pea gravel bathymetry added, absorber added \\
\hline 159 & +11 & 2.7 & 23.3 & SW & All open & \\
\hline 160 & +11 & 2.7 & 23.3 & SW & All open & Additional pea gravel bathymetry added, no absorber \\
\hline 161 & +11 & 3.7 & 10.0 & SW & All open & Additional pea gravel bathymetry added, absorber added \\
\hline
\end{tabular}


The bar charts of these tests (not included in the report) showed similar reduction in wave heights due to shoreline absorber for the 24-sec waves with hardly any reduction seen for the 10 -sec waves. More interesting, however, was the quasi-standing wave patterns the monochromatic waves eventually created in the harbor basin. In nature the incident waves would have to be long-crested swell waves to have any similarity to the regular waves generated by the wave machine.

Figures 68 and 69 show the recorded time series of sea surface elevations along the main floating dock gauge array for a 10 -sec monochromatic wave. Gauges 4- 9 are shown in Figure 68, and gauges 10- 15 are given in Figure 69. Harmonics caused by interacting waves are easily seen on the time series. It could not be determined whether the interaction was between incident and reflected waves or incident waves entering through different gaps, or both. Notice in particular how the wave height at gauge 9 is larger than adjacent gauges indicating that location is at a place where the waves interact to reinforce each other. Also note the consistency of the patterns in the time series. This consistency means that once the basin settles into the rhythm, it maintains the same quasi-standing wave pattern indefinitely so long as the consistent forcing is maintained.

Figures 70 and 71 are zoomed portions of the time series between 1,200 and 1,400 sec (prototype time). The consistent variations in sea surface elevations are very evident in these time series. 


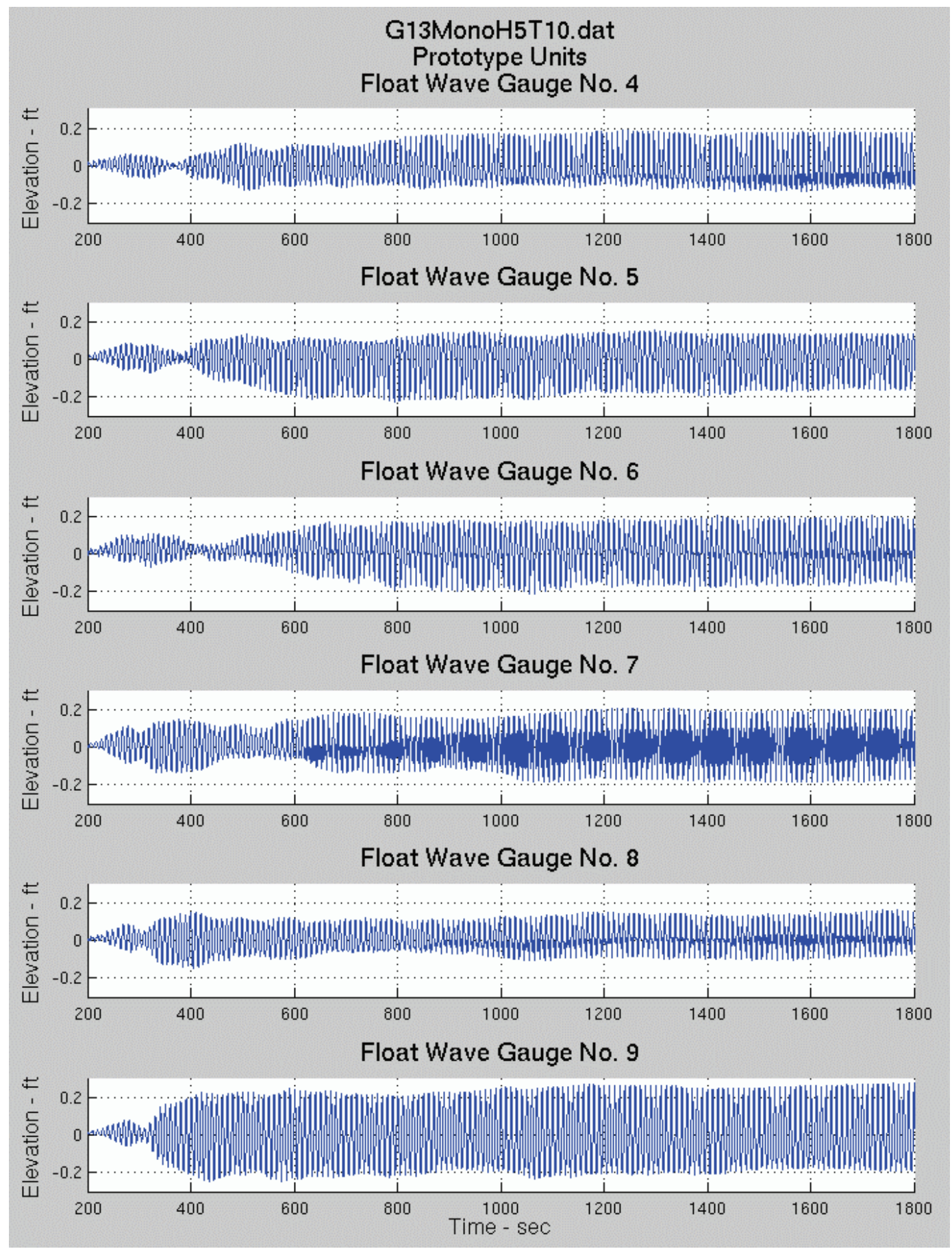

Figure 68. Sea surface elevation time series, gauges 4-9 (test 156). 


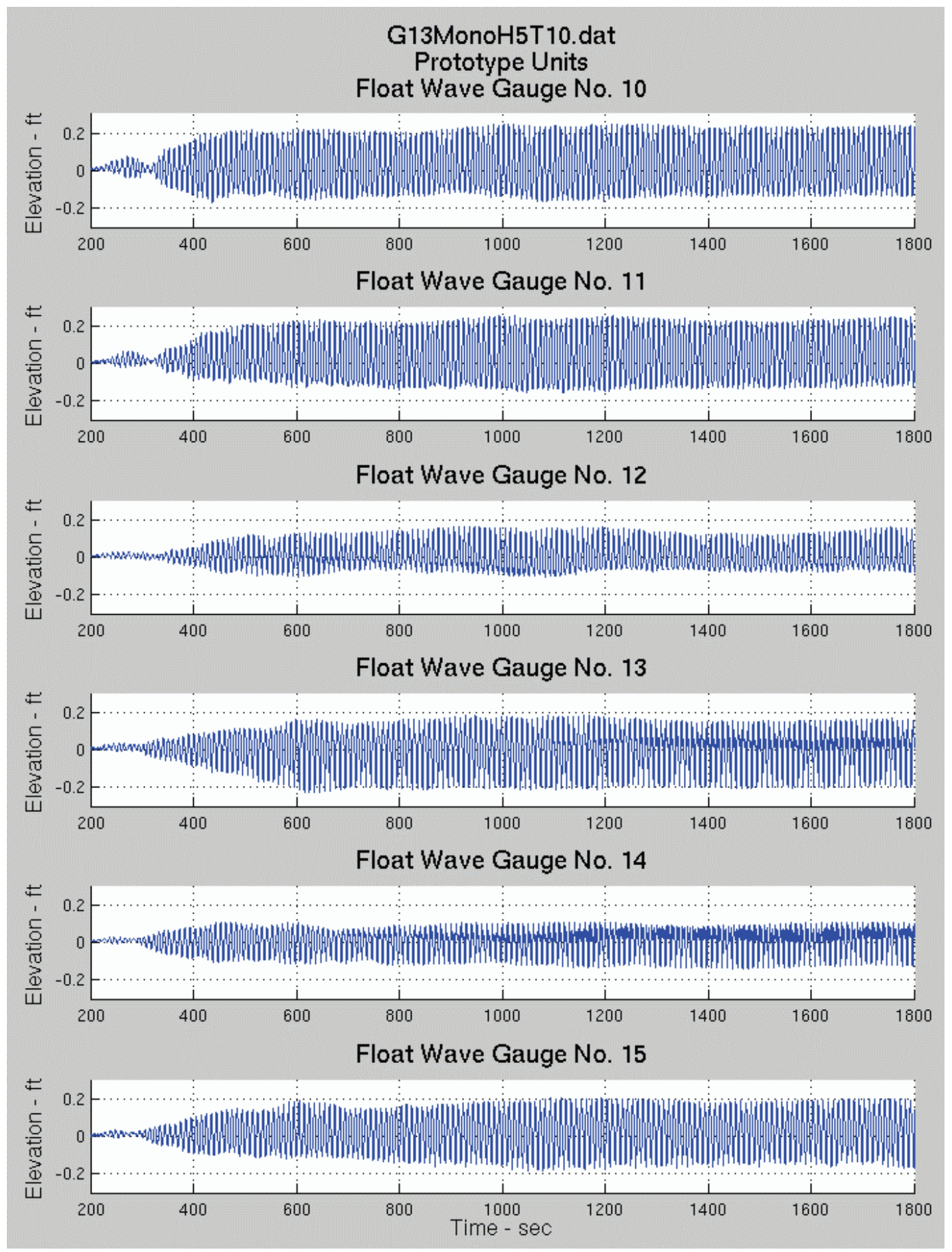

Figure 69. Sea surface elevation time series, gauges 10-15 (test 156). 


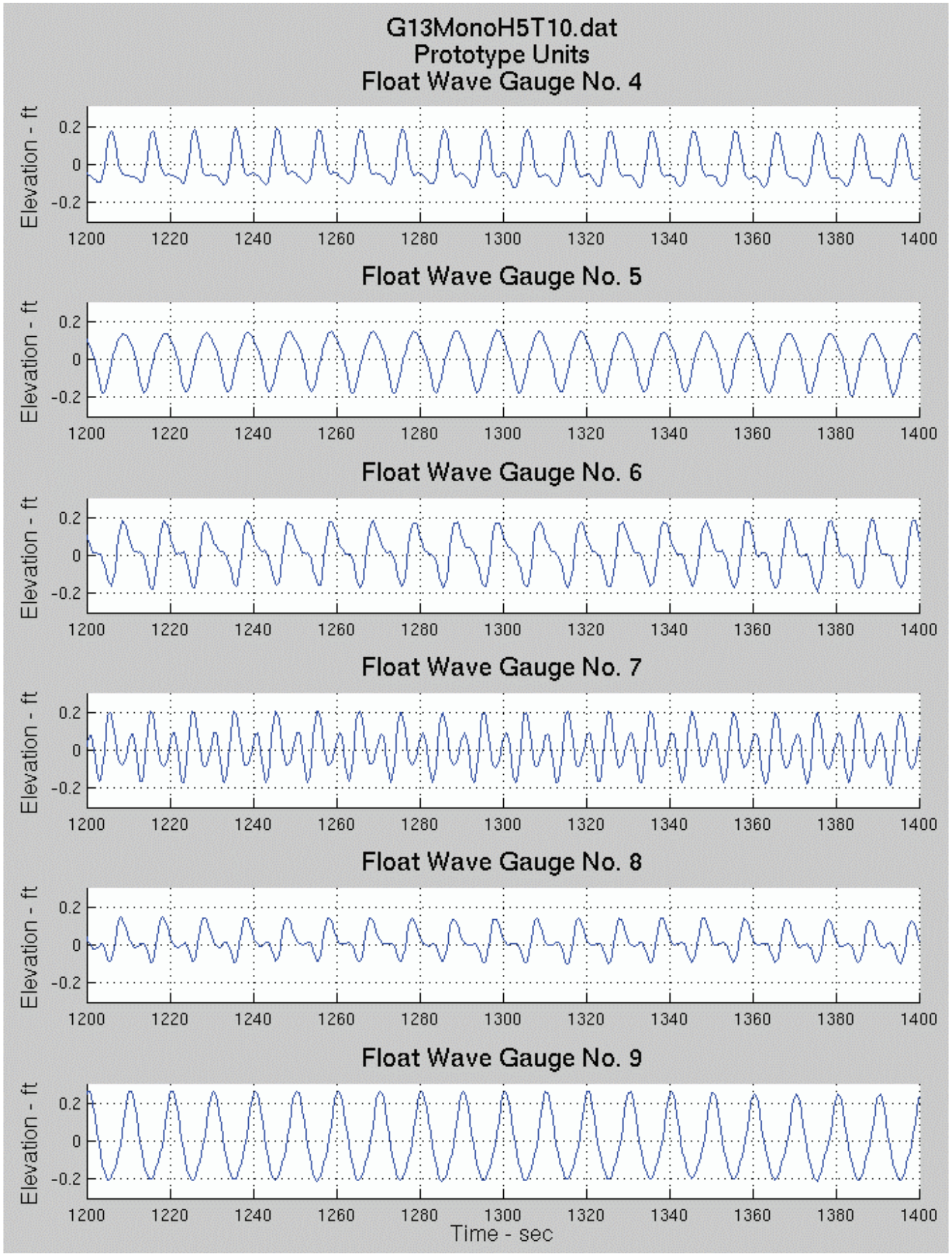

Figure 70. Extract of sea surface elevation time series, gauges 4-9 (test 156). 


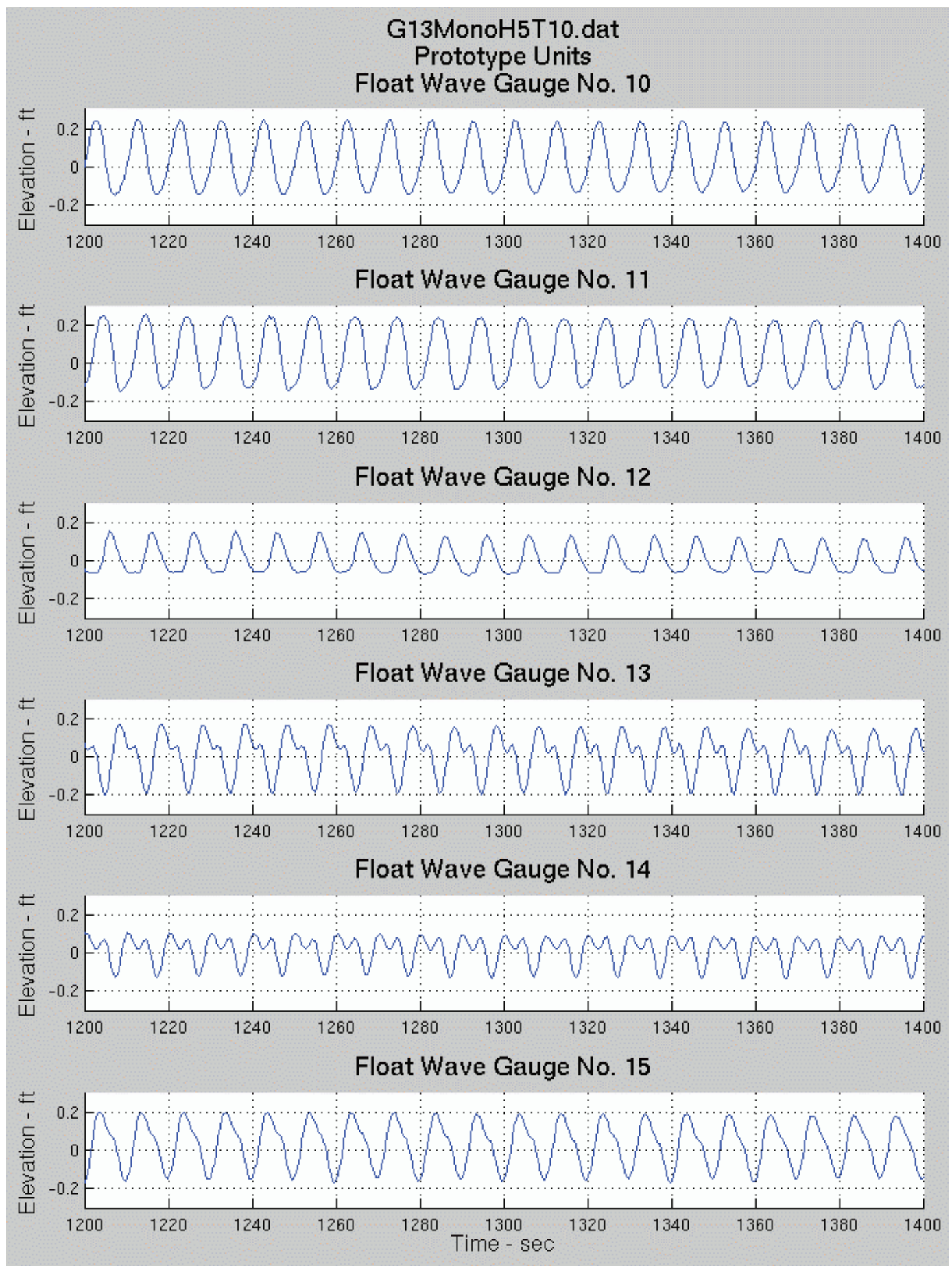

Figure 71. Extract of sea surface elevation time series, gauges 10-15 (test 156). 


\section{February/March 2007 Test Results}

This chapter describes 18 experiments conducted during February and early March 2007 as part of the New Thomsen Harbor physical model study.

\section{Summary of February/March 2007 tests}

Tests 162- 179 were conducted during February and early March 2007. The purpose of these 18 tests was to conduct a final set of tests to examine the hypothesis that extreme water levels could be responsible for adverse wave conditions at New Thomsen Harbor, and to acquire wave data in the proposed future float plane area when wind waves approach from the northwest.

Table 13 summarizes the tests for this testing period with given values converted to prototype scale. Six tests were run with irregular waves (tests 162-167), and the values of significant wave height $\left(H_{m 0}\right)$ and peak spectral period $\left(T_{p}\right)$ given in Table 13 were obtained from measurements acquired at the three wave gauges directly in front of the wavemaker. Wave heights for the 12 tests conducted with monochromatic waves (tests 168-179) were determined by upcrossing analysis of the recorded sea surface elevation time series. The column labeled "Dir" is the direction from which waves came. All gaps between adjacent breakwaters and between the breakwaters and shore were open for all tests.

\section{Wave gauge locations}

The 12 wave gauges 4 - 15 were positioned as a linear array positioned directly over the location of the main floating dock of New Thomsen Harbor as shown in Figure 34 (Chapter 7). The gauges were spaced at 75-ft intervals (12 in. model scale) with gauge 4 located at the seaward end of the main floating dock and gauge 15 nearest the landward end. Wave gauges 1- 3 remained in deeper wave near the wave machine. Gauges 1619 were placed in the proposed future float plane area as shown in Figure 35 (Chapter 7). Gauges 16 and 19 were approximately $200 \mathrm{ft}$ from shore, and gauges 17 and 18 were about $400 \mathrm{ft}$ from shore. All other aspects of the data collection were as described in Chapter 4 . 
Table 13. Experiment parameters for February 2007 tests.

\begin{tabular}{|c|c|c|c|c|c|c|}
\hline \# & $\begin{array}{l}\text { Water } \\
\text { Level } \\
\text { (ft) }\end{array}$ & $\begin{array}{l}H_{m 0} \\
\text { (ft) }\end{array}$ & $\begin{array}{l}T_{p} \\
(\sec )\end{array}$ & Dir & Gaps & Notes \\
\hline \multicolumn{7}{|c|}{ Extreme Water Elevation Test Series } \\
\hline 162 & +13 & 10 & 10.0 & SW & All open & Gravel bathymetry modification in model \\
\hline 163 & +13 & 10.3 & 22.0 & SW & All open & Gravel bathymetry modification in model \\
\hline 164 & +13 & 10.2 & 12.0 & SW & All open & Gravel bathymetry removed \\
\hline 165 & +13 & 10.4 & 22.0 & SW & All open & Gravel bathymetry removed \\
\hline 166 & +0 & 9.9 & 12.2 & SW & All open & Gravel bathymetry removed \\
\hline 167 & +0 & 9.0 & 20.3 & SW & All open & Gravel bathymetry removed \\
\hline \multicolumn{7}{|c|}{ Monochromatic Wave Test Series } \\
\hline 168 & +10 & 6.4 & 3.6 & SW & All open & Monochromatic waves, gravel removed \\
\hline 169 & +10 & 6.4 & 6.0 & SW & All open & Monochromatic waves, gravel removed \\
\hline 170 & +10 & 5.5 & 12.0 & SW & All open & Monochromatic waves, gravel removed \\
\hline 171 & +10 & 5.7 & 14.9 & SW & All open & Monochromatic waves, gravel removed \\
\hline 172 & +0 & 6.3 & 3.6 & SW & All open & Monochromatic waves, gravel removed \\
\hline 173 & +0 & 6.3 & 5.0 & SW & All open & Monochromatic waves, gravel removed \\
\hline 174 & +0 & 6.1 & 12.0 & SW & All open & Monochromatic waves, gravel removed \\
\hline 175 & +0 & 6.0 & 15.0 & SW & All open & Monochromatic waves, gravel removed \\
\hline \multicolumn{7}{|c|}{ Future Float Plane Area } \\
\hline 176 & +11 & 4.0 & 3.6 & NW & All open & Monochromatic waves from NW, existing condition \\
\hline 177 & +11 & 4.4 & 4.0 & NW & All open & Monochromatic waves from NW, existing condition \\
\hline 178 & +11 & 4.6 & 3.6 & NW & All open & Same as above but two breakwaters extended \\
\hline 179 & +11 & 4.5 & 4.0 & NW & All open & Same as above but two breakwaters extended \\
\hline
\end{tabular}

\section{Extreme water elevation test series (tests 162-167)}

Tests 162-167 were conducted primarily to examine wave action in New Thomsen Harbor when water elevation is at $+13 \mathrm{ft}$ mllw. This elevation is over $3 \mathrm{ft}$ higher than the mean higher high water elevation, $4 \mathrm{ft}$ higher than the breakwater impermeable cores, and $2 \mathrm{ft}$ higher than previous tests run in the physical model. For comparison, the same wave conditions were run with the water elevation set at $+0 \mathrm{ft}$ mllw. These tests required additional calibration runs because the wave machine had not been calibrated for these parameters. The irregular wave conditions should be considered extreme as well, and they were used only to amplify results. Significant wave 
height was $H_{m 0}=10 \mathrm{ft}$, and the two selected spectral peak periods were $T_{p}=12$ and $22 \mathrm{sec}$. Note there is no evidence to suggest waves with $H_{m 0}=10 \mathrm{ft}$ waves would ever reach the Channel Rock Breakwater.

The bathymetry modifications constructed with pea gravel for the November 2006 tests were left in place for the first two tests. Figure 72 shows the measured wave heights at all 19 wave gauges for this condition. Wave heights in New Thomsen Harbor exceeded the 1-ft criterion for the 12-sec wave condition, and reached $1.8 \mathrm{ft}$ for the 22 -sec wave. This dramatic increase is not surprising because the breakwaters are less effective in blocking wave energy, and the incident waves are twice as high as those used in previous tests. The bathymetry modification has reduced the wave height "hump" around gauges 6-9.

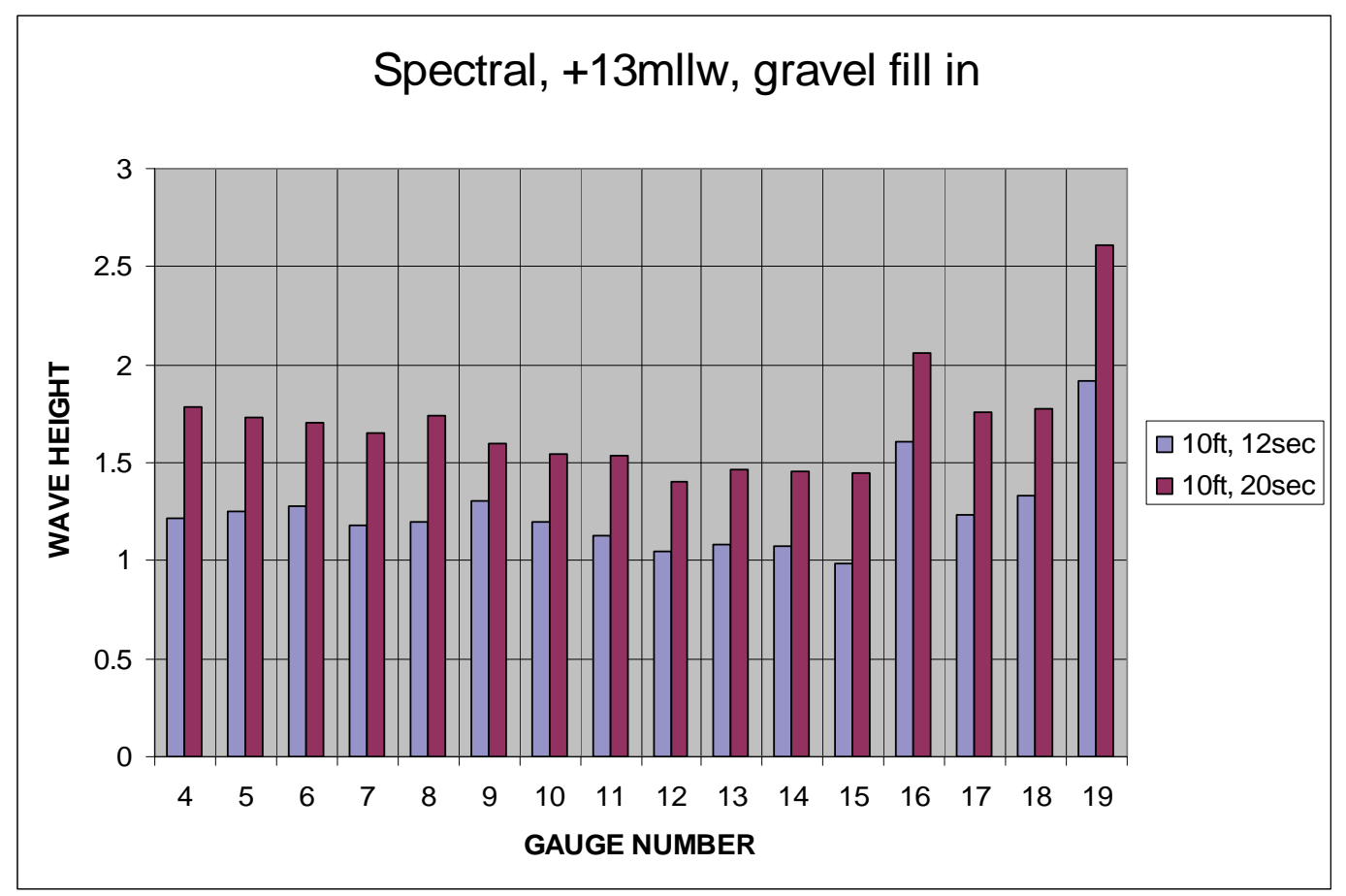

Figure 72. Extreme water level and waves with modified bathymetry (tests 162-163).

The gravel bathymetry modifications were removed for tests 164-167, and the same extreme conditions were repeated at water elevation of $+13 \mathrm{ft}$ mllw and at +0 mllw. Figures 73 and 74 present results for these tests. 


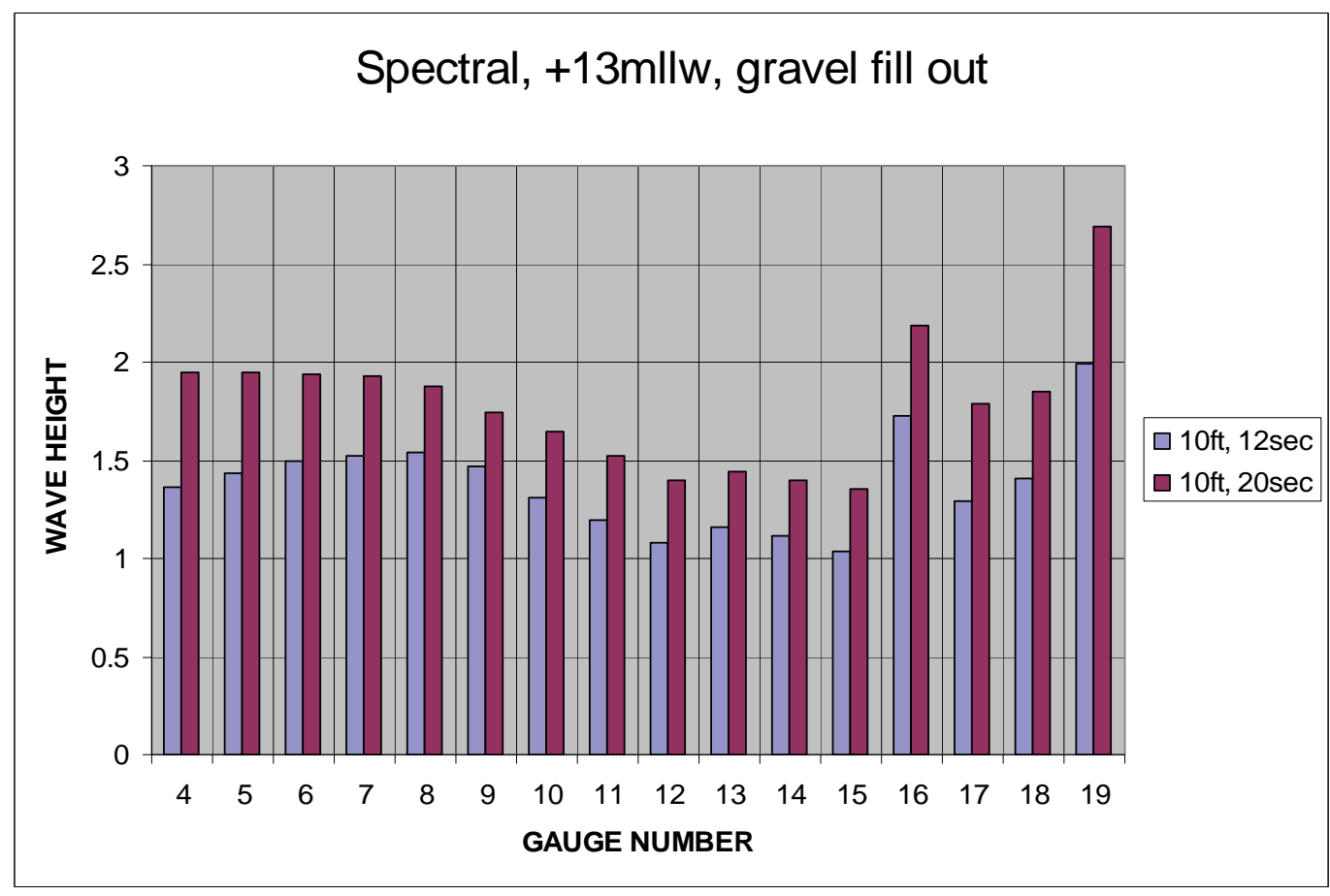

Figure 73. Extreme water level and waves with bathymetry removed (tests 164-165).

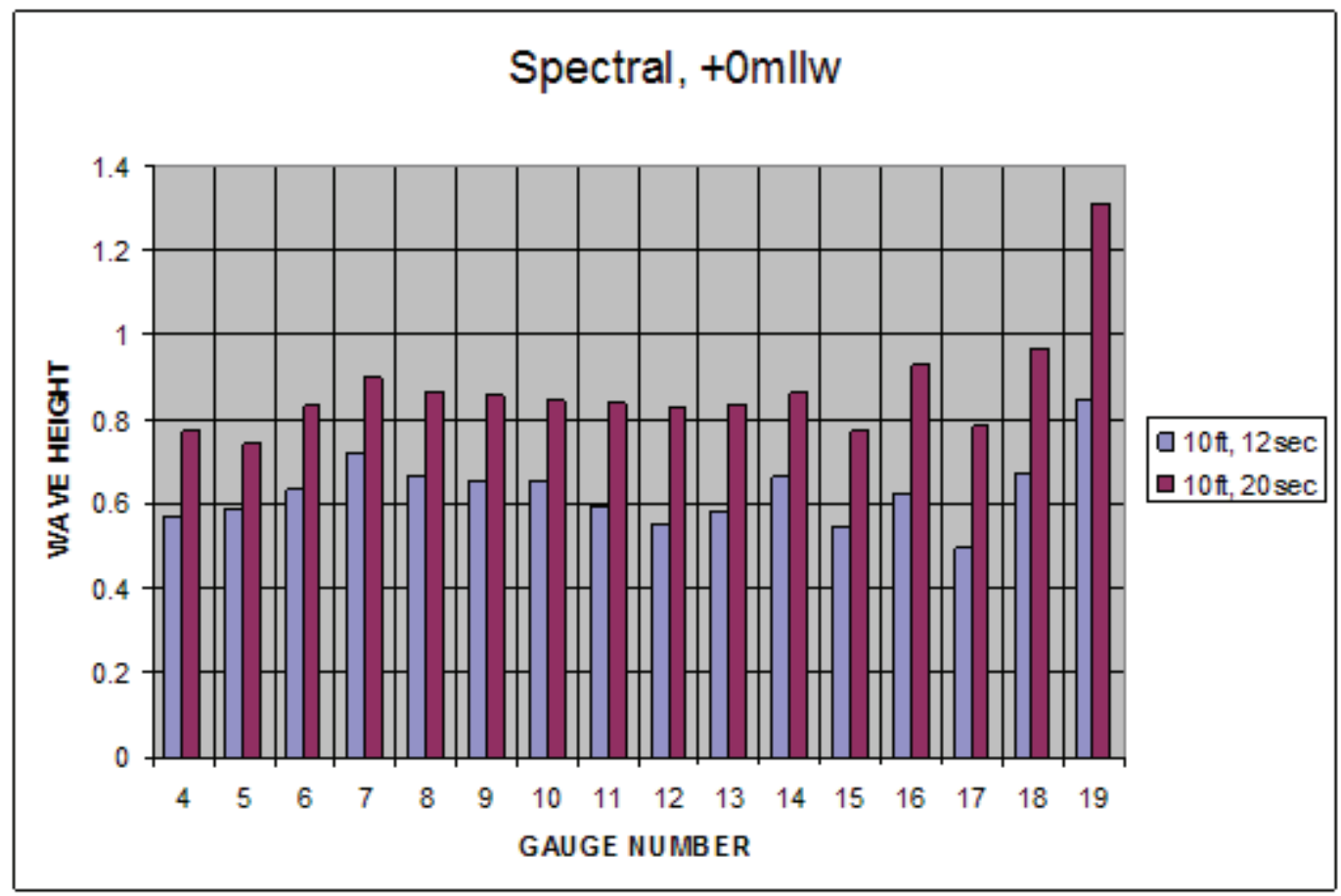

Figure 74. Extreme wave condition at low water (tests 166-167).

Removing the bathymetry modification restored the characteristic "hump" in wave heights along the main floating dock between gauges 6 and 9 for the 12-sec wave condition, indicating the shorter waves are more readily refracted by the bathymetry. Wave heights along the main floating dock 
have also increased with the maximum values close to $2 \mathrm{ft}$ for the 22 -sec waves. This increase is not large, but it does support the contention that bathymetry plays a role in the wave heights observed in the harbor.

Lowering the water level to +0 mllw significantly reduced wave heights along the floating dock with maximums of about $0.9 \mathrm{ft}$. This $1-\mathrm{ft}$ reduction in wave heights is due to the breakwaters that are preventing most of the wave energy from entering the harbor. The characteristic hump in wave heights along the floating dock is still apparent at both wave periods. One hypothesis was that the wave height hump might be caused by interaction of waves entering through different gaps. However, the hump is seen for the +13 -ft water level, 12-sec wave when significant wave energy is coming over the breakwaters, so wave interaction is probably not the primary reason for the wave height hump along the main floating dock.

\section{Monochromatic wave test series (test 169-175)}

Tests 168- 175 were conducted using monochromatic waves. Water elevations were $+10 \mathrm{ft}$ and $+0 \mathrm{ft}$ mllw. The purpose of these tests was to observe wave height variations due to monochromatic waves. Previous monochromatic wave tests had indicated that quasi-standing wave patterns are established in the harbor basin. The two water levels represent mhhw and mllw. Nominal wave heights were $6 \mathrm{ft}$, and the target wave periods were 3 , 5,12 , and $15 \mathrm{sec}$. The wavemaker was unable to generate the $3 \mathrm{sec}$ waves, so a period of $3.6 \mathrm{sec}$ was used instead. These tests required additional calibration runs because the wave machine had not been calibrated for these parameters.

Figures 75 and 76 present measured results for the $+10 \mathrm{ft}$ and $+0 \mathrm{ft}$ mllw water elevations, respectively. At $+10 \mathrm{ft}$ mllw, the shorter period waves do not cause wave heights along the floating dock greater than $0.6 \mathrm{ft}$. However, the 12- and 15-sec waves produced wave heights just over $1 \mathrm{ft}$ at the dock. Lowering the water level to $+0 \mathrm{ft}$ mllw resulted in much lower wave heights at the dock as seen in Figure 76. 


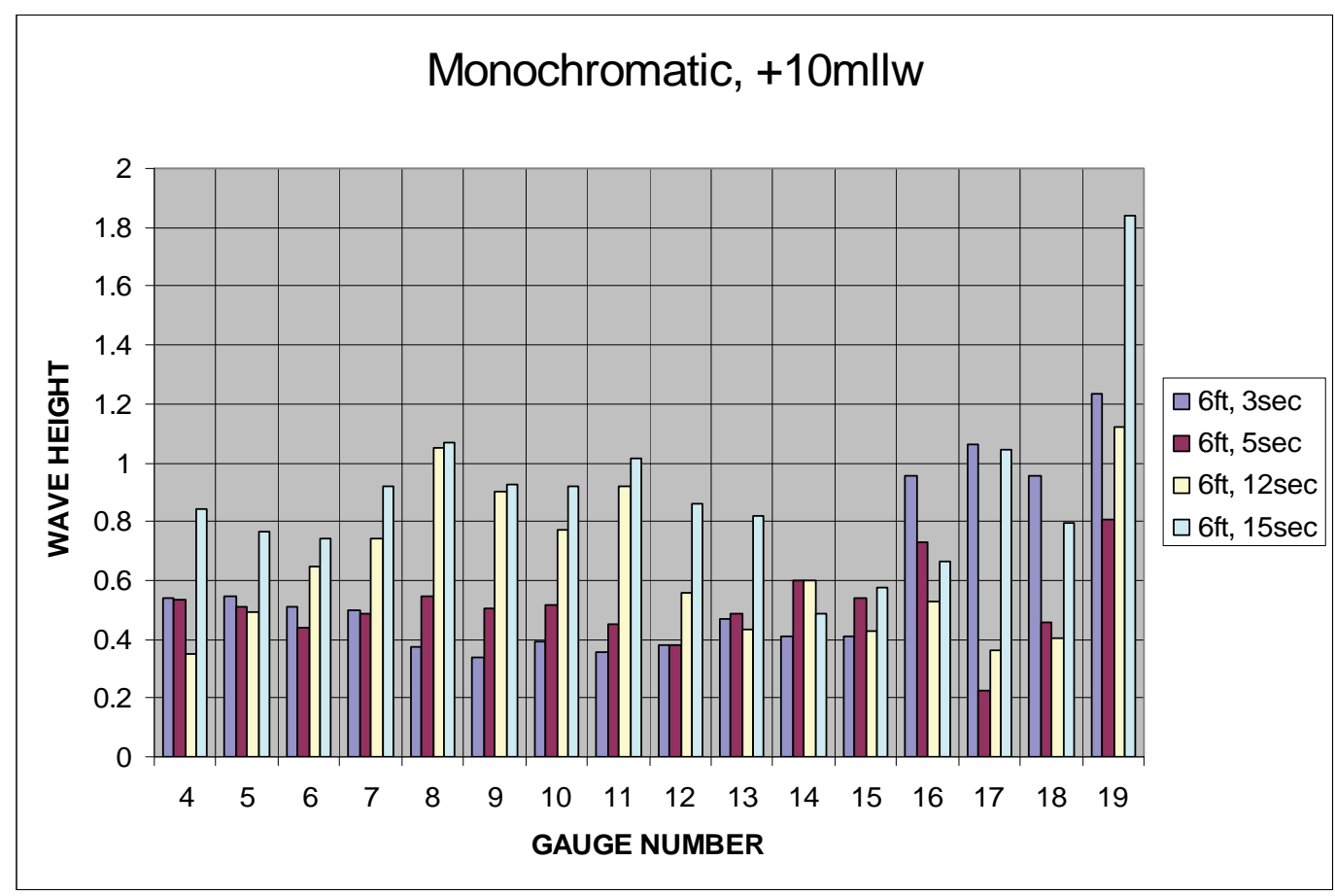

Figure 75 . Monochromatic tests at $+10 \mathrm{ft}$ mllw (tests 168-171).

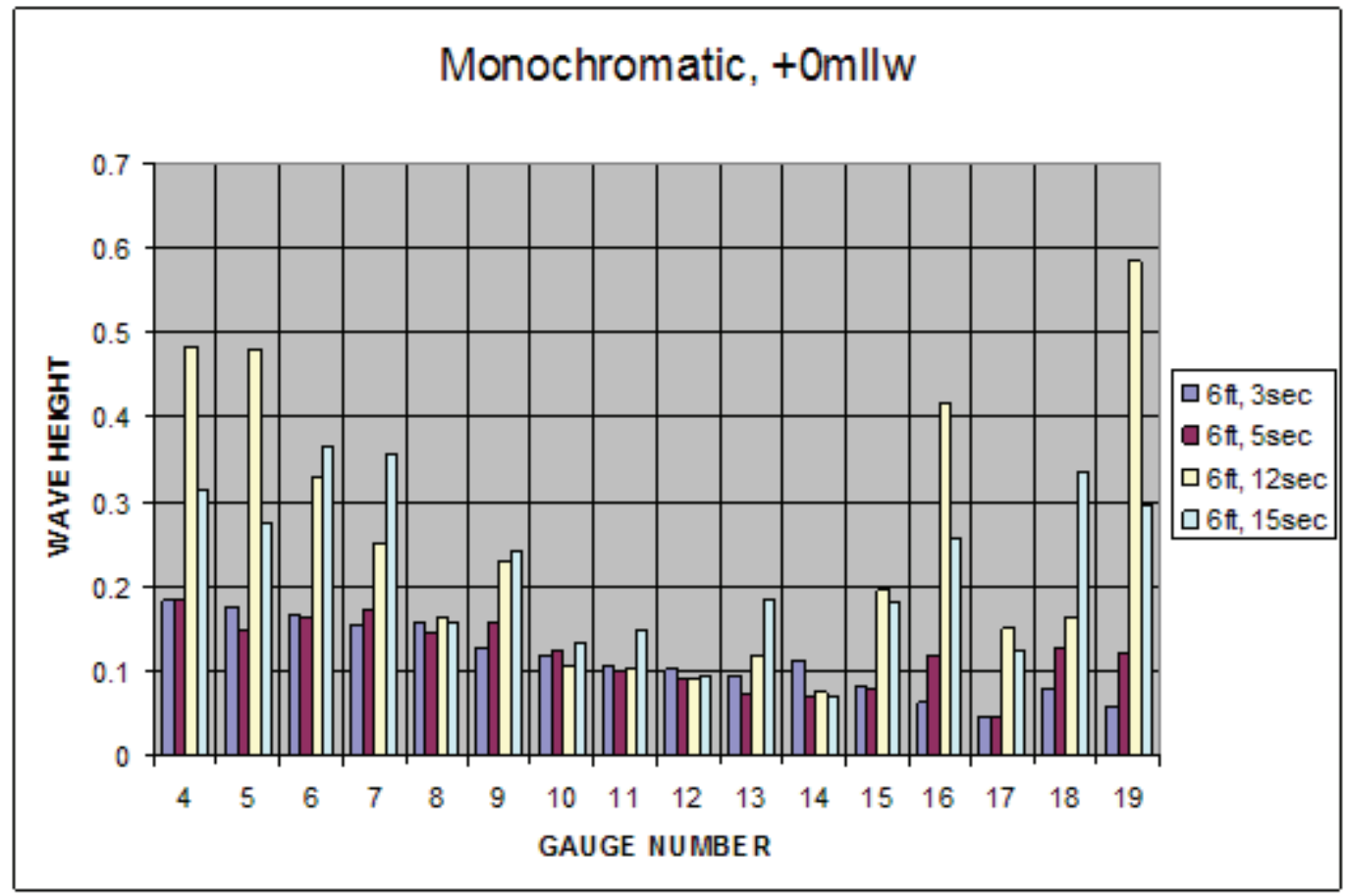

Figure 76. Monochromatic tests at $+0 \mathrm{ft}$ mllw (tests 172-175).

The wave height magnitudes of the monochromatic waves should not be compared directly with the values determined for irregular waves. The monochromatic wave heights were determined from upcrossing analysis as the average of the highest $1 / 3$ waves $\left(H_{1 / 3}\right)$. When all waves have nearly 
the same height, this average is close to the height of the maximum wave $\left(H_{\max }\right)$. With irregular waves, the significant wave height determined from frequency-domain analysis $\left(H_{m 0}\right)$ is nearly the same as $H_{1 / 3}$, but this value is quite a bit less than the maximum wave in the irregular wave train. In addition, the standing wave patterns from monochromatic waves are more pronounced and the interacting waves can produce large waves at certain locations. With irregular waves this interaction is smeared because each wave is different and standing wave patterns have smaller magnitudes. For these reasons, irregular waves are more valid for assessing wave height magnitudes for design purposes. Monochromatic waves are useful for identifying potential problem areas, but the magnitudes are less reliable than irregular wave results.

\section{Future float plane area (tests 176-179)}

Tests 176- 179 were the final tests conducted in this physical model study. The wave machine was moved so monochromatic waves could be generated from the northwest. The main purpose of these tests was to acquire wave height information in the vicinity of the proposed future float plane facility, and to see what wave height reduction could be achieved by adding extensions to the detached breakwaters.

The target wave height was $5 \mathrm{ft}$, but that could not be achieved by the wavemaker at short wave periods. The target 3-sec wave period could also not be achieved. As a consequence, the parameters between tests were not too different. Figure 77 shows results with waves from the northwest and the breakwaters in the existing configuration. Wave Gauges 16-19 were in the float plane region, and maximum observed wave heights were just over $0.7 \mathrm{ft}$. This may be too high for float plane operations, but bear in mind waves of this magnitude from the northwest would be generated by fairly high winds that could make float plane operations problematic.

Figure 78 shows the reduction achieved when the south end of the breakwater nearest to J aponski Island was lengthened by about $150 \mathrm{ft}$ and the south end of the center breakwater was lengthened by about $200 \mathrm{ft}$. Wave heights were substantially reduced except at gauge 19. 


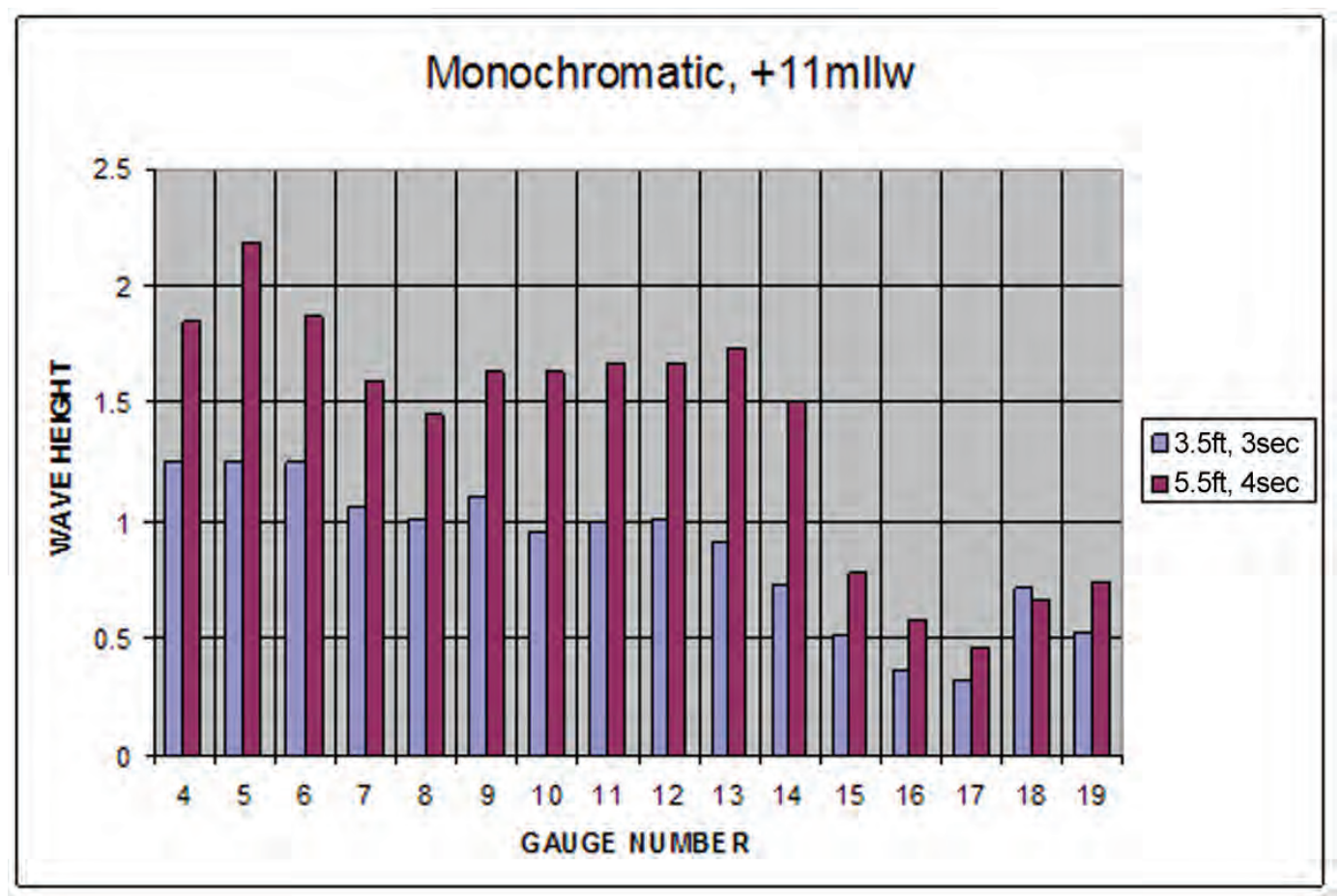

Figure 77. Monochromatic tests with waves from northwest (tests 176-177).

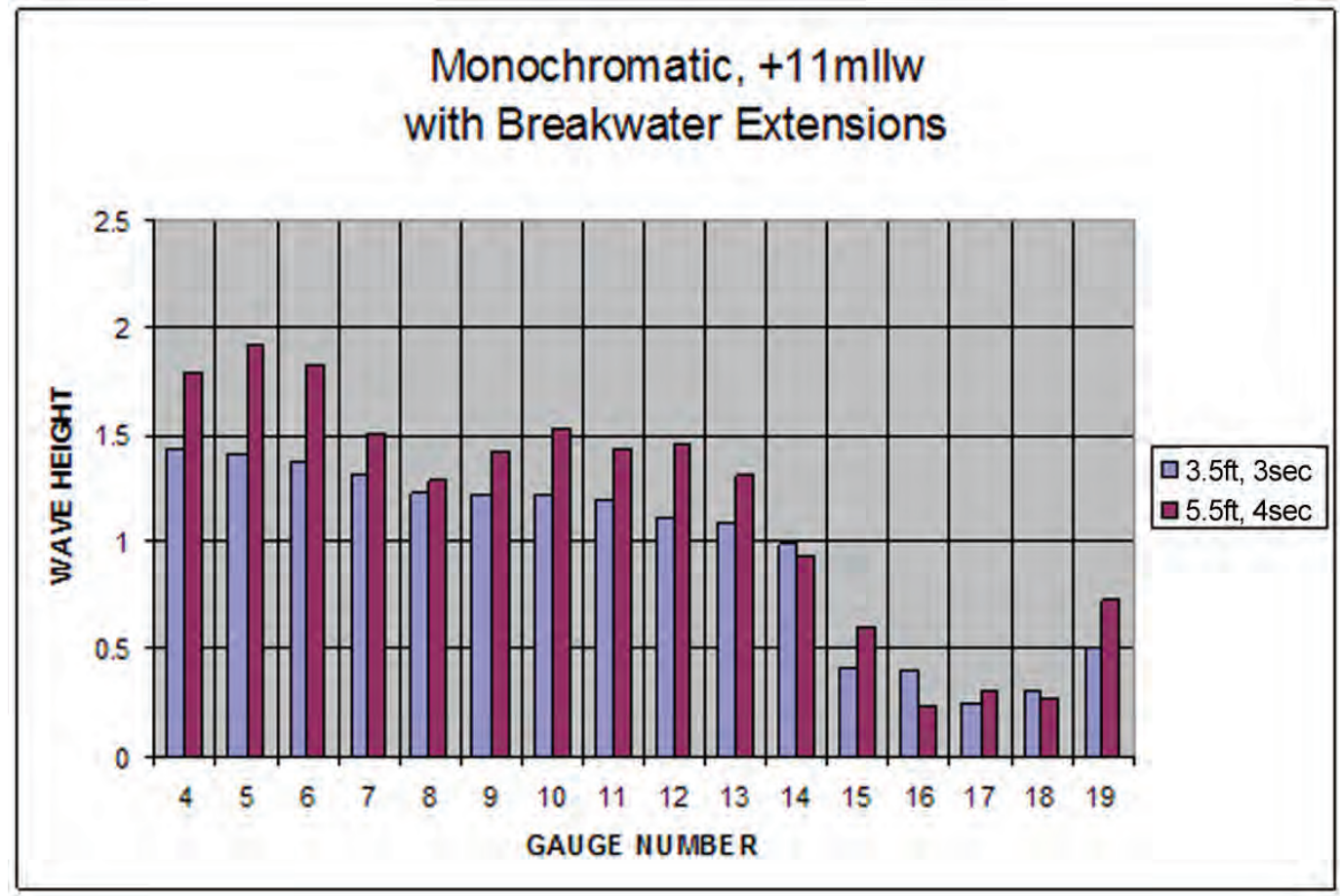

Figure 78. Breakwater extensions with waves from northwest (tests 178-179). 


\section{Summary and Conclusions}

This chapter summarizes the physical model study of New Thomsen Harbor at Sitka, Alaska, and it gives conclusions based on measured model response to different wave and water level conditions.

\section{Summary of physical model study}

\section{Problem}

Local interests at Sitka, Alaska, have reported that the floating docks sometime experience vertical wave-like motions that make walking on the docks difficult. Vessels moored to the floating dock experience similar motion. Unscientific observations estimated the period of wave motion causing problems for the slips and moored vessel to be in the range of 8 to $20 \mathrm{sec}$, and it has been reported that most episodes of increased dock motion occur during high tide.

\section{Study objectives}

The primary objectives of the studies associated with New Thomsen Harbor were to (1) establish the cause for wave action within the harbor causing vertical motion of the floating docks and (2) investigate potential engineering alternatives to reduce wave action within the harbor to acceptable levels. During the course of the study, wave measurements were also acquired at additional locations within the Western Channel to provide base information at potential sites for a proposed float plane facility.

\section{Physical model description}

A physical model encompassing portions of the Western Channel, the region protected by the three breakwaters, New Thomsen Harbor, and the Sitka and J aponski Island shorelines was constructed at the modeling facilities of the ERDC's CHL. The physical model was funded by the Alaska District of the USACE.

The physical model was designed to reproduce the following physical processes that were thought to be important: (a) elevated water levels; (b) short-period waves from the northwest; (c) longer period waves from the southwest; (d) wave diffraction, refraction, and shoaling processes, 
(e) wave reflection by shoreline revetments; and (f) wave overtopping and flow through the three detached breakwaters.

The fixed-bed undistorted physical model was built at a scale of 75-to-1 (prototype-to-model) and included approximately 1.4 square miles in the modeled domain. Bathymetry was reproduced out to the $-60 \mathrm{ft}$ contour, and enough additional area was included to allow correct reproduction of waves arriving from the southwest through to the northwest.

Waves were generated using an 80-ft-long plunger-type wave machine capable of producing long-crested regular or irregular waves with significant wave heights greater than $10 \mathrm{ft}$ and peak spectral wave periods in the range of 3.5 to $24 \mathrm{sec}$. The wave machine was moved for tests requiring waves from different approach directions.

Harbor and basin response to the incident wave conditions was measured using up to 19 capacitance-type wave gauges positioned at various locations in the model. Sea surface elevation time series were acquired at a $20-\mathrm{Hz}$ rate throughout the 10 -min duration of each test. Measured time series were analyzed using both frequency-domain and time-domain techniques.

\section{Overview of testing program}

A total of 179 tests were conducted in the Sitka physical model during four time periods occurring between the completion of the model in September 2005 and February 2007. Each testing session or series had one or more specific purposes related to understanding the cause for unacceptable wave action in New Thomsen Harbor and finding one or more possible engineering solutions to reduce wave action. The following is a brief description of each distinct testing period.

1. September 2005. The initial model test series consisted of 53 tests. The main purposes of the testing were to determine the cause for excessive wave action in the harbor, to examine the effect of closing one or more gaps between the breakwaters, and to look at several proposed engineering modifications. Details of the testing and test results are provided in Chapter 5.

2. June/July 20o6. These 17 tests looked at the instantaneous vertical differential between wave gauges aligned at 100-ft spacing along the main floating dock. The purpose of the tests was to see if waves passing 
through the harbor could cause enough vertical difference between gauges to create uncomfortable conditions. Details are given in Chapter 6.

3. November/December 20o6. Ninety-one tests were conducted during November and December 2006. Groups 1, 3, and 4 examined the effects of gap closure on waves along the main floating dock and wave action at areas suggested for a new float plane facility. Groups 5- 8 looked for evidence of wave focusing that appeared to cause increased wave heights at a particular location along the floating dock. Groups 9- 12 examined the impact of modifying bathymetry that was thought to cause wave focusing, and Groups 13 and 14 used monochromatic waves in an attempt to clarify the wave action. See Chapter 7 for details.

4. February/March 2007. The final test series consisted of 18 tests. Additional testing variations were tried with the purpose of determining more definitively the cause for the excessive wave action reported at New Thomsen Harbor and documenting waves at the proposed future float plan facility. Test variations included higher water levels, lower water levels with monochromatic waves, and waves from the northwest impacting the float plane facility location. Breakwater extensions were installed to decrease waves at the float plane facility location. Details are given in Chapter 8.

Generally, variations between tests and test series included gauge placement, installed engineering modifications, incident wave height, wave period, wave direction, water elevation, and bathymetry modifications. The primary results are given in terms of measured significant wave height at each gauge location.

\section{Study observations and conclusions}

This section summarizes observations made based on analysis of measured wave heights, and draws conclusions based on the data.

\section{Harbor wave agitation hypotheses}

Before and during the physical model study, several hypotheses were developed to explain why waves in New Thomsen Harbor would be large enough to cause adverse motions of the floating dock system. The various hypotheses are listed and discussed in the following paragraphs. 
Longer period waves from southwest to west

Waves approaching from the southwest to west directions have longer wave periods that include the period range of observed floating dock motion. Several hypotheses were tested in the physical model.

1. Wave energy penetration. Although the region is protected by three breakwaters, wave energy enters through gaps between the breakwaters. At lower water levels the energy can enter only through the gaps, but when the water level approaches the level of the breakwater impermeable cores ( $+9 \mathrm{ft}$ mllw) some energy can pass over the breakwaters and through the voids between armor stones.

All tests conducted with the water level at $+11 \mathrm{ft}$ mllw with waves having significant wave height of $H_{m 0}=5 \mathrm{ft}$ failed to produce significant wave heights exceeding about $0.6 \mathrm{ft}$ in the vicinity of the main floating dock at New Thomsen Harbor. This wave height is beneath the usual criterion for small boat harbors. (See Figures 18, 19, 37- 40, and 4548.) The one exception is shown in Figure 49 for a 24 -sec wave period that produced $H_{m 0}=0.68 \mathrm{ft}$.

2. Wave interaction with bathymetry and shoreline. Several types of wave interaction could produce increased harbor wave heights: (a) incident waves could interact with waves reflected off shoreline revetments (at high water) creating an enhanced quasi-standing wave in the harbor, (b) incident waves could be refracted by harbor bathymetry to give locally increased wave heights in the harbor, (c) incident waves entering through two different gaps could interact to produce higher waves in the harbor.

Results indicated that wave refraction by the bathymetry was causing an increase in wave heights toward the seaward end of the floating dock. For the 5-ft wave heights, the magnitude of harbor wave heights was not too high, but the differences between adjacent locations could cause some difficulty (see Figures 37- 40 and 45-48). Wave heights acquired at an adjacent location with uniform depths had less variation (see Figures 51- 53). Bathymetry modification also smoothed the wave height variation between gauge locations along the main floating dock (see Figures 61, 66, and 67). Thus, wave focusing by bathymetry does occur, but the magnitudes were not excessive for the tested wave conditions. Magnitudes would increase with increasing incident wave height. 
Interaction between incident waves and reflected waves was examined by tests with wave absorber placed along the Sitka and J aponski Island shorelines. The wave-absorbing shoreline made little difference for wave with periods shorter than about $10 \mathrm{sec}$ (see Figure 58), but wave height reductions up to $0.2 \mathrm{ft}$ were seen for waves with 24 -sec periods (see Figure 63). Thus, interaction between incident and reflected waves is only important for longer period waves.

Results from tests conducted with all gaps open and all gaps closed showed the characteristic "hump" in measured wave heights along the main floating dock, although the magnitudes were substantially less for the all-gaps-closed case. This result implies that wave interaction between waves entering through different gaps is small for irregular waves. However, monochromatic wave time series exhibited a distinct signature of interacting wave trains, so this hypothesis cannot be rejected totally (see Figures 68- 71).

3. Vertical differentials along the main float. As waves propagate into the harbor and along the main float, some portions of the dock will be at the wave crests and others at the trough. Analysis of wave gauges spaced at 100 -ft intervals along the main floating dock indicated this vertical differential approaches $1 \mathrm{ft}$ or more (see Figures 32 and 33). This vertical differential could cause difficulty walking on the docks, but several caveats were noted in Chapter 6 . The results are for water elevation differences only, and did not include any effects of the actual floating dock and moored vessels. Straight lines were drawn between points, and these lines should not be interpreted as rigid floating dock sections. The floating dock was not constructed in 100-ft-long rigid sections.

In addition, the docks will likely have a damped response to the wave motions that would decrease the differences indicated by the analysis. Finally, vessels moored to the dock will contribute to the damping or could even induce additional motions as the vessels move in response to wave action.

4. Influence of moored vessels. Waves (and wind stress) on vessels moored to the floating dock might cause vessel motions that are transferred to the dock in a nonlinear manner. This effect could result in adverse dock motions. This hypothesis could not be tested in the physical 
model, but further insight might be gained by monitoring vessel and dock response in New Thomsen Harbor.

\section{Shorter period waves from northwest}

Waves approaching from the northwest direction have shorter wave periods because of the relatively short fetch over which wind can generate waves. Wave periods from the northwest are not expected to exceed between 3 and $5 \mathrm{sec}$. Several hypotheses were tested in the physical model using waves from the northwest quadrant.

1. Wave energy penetration. Short-period wind wave energy will enter directly through the breakwater gaps (particularly Gap 3) with a clear path to the main float area. At lower water levels, the waves are diffracted with a corresponding decrease in wave height. At higher water levels, additional wave energy passes over and through the breakwaters, and this reduces the effects of diffraction.

Incident waves with $H_{m 0}=5 \mathrm{ft}$ and peak period of $4.4 \mathrm{sec}$ caused wave heights in New Thomsen Harbor up to $1.5 \mathrm{ft}$ when the water elevation was $+11 \mathrm{ft}$ mllw. This substantially exceeded the usual criterion, and this hypothesis provides a believable scenario for the cause of the problem. However, it is necessary to keep two facts in mind. First, this wave condition is a large wave height for fetch-limited waves from the northwest; and second, the floating docks protecting New Thomsen Harbor should be effective in reducing the heights of these short period waves to heights below the criterion. Nevertheless, episodes of unacceptable wave agitation caused by waves from the northwest could occur; but they will, without exception, be accompanied by high winds necessary to generate large waves over a short fetch.

2. Vertical differentials along the main float. Incident wind waves from the northwest would have crests almost perpendicular to the main floating dock, so the distance between crests and troughs would be on the order of half the wave length. For waves in 20 -ft depth with periods ranging between 3 and $5 \mathrm{sec}$, the wave lengths would be between 46 and $106 \mathrm{ft}$. Thus, there could be as much as $1 \mathrm{ft}$ vertical difference over 23 to $53 \mathrm{ft}$ lengths of floating dock. Once again this assumes the outer floating docks protecting New Thomsen Harbor do nothing to reduce short-period wave heights. 
Of the above hypotheses, wave focusing by local bathymetry near New Thomsen Harbor appeared to be the most plausible with incident waves interacting with waves reflected by the shoreline at high water being a possible contributor for longer period waves. Large, short-period waves from the northwest can certainly cause high waves in the harbor, but only when the wind is blowing hard from that direction.

\section{Effectiveness of engineering modifications}

Closing one or more gaps between adjacent breakwaters and/ or breakwaters and the shoreline reduced wave heights in New Thomsen Harbor. Of course closing all gaps had a profound reduction in wave heights, but this is not a practical solution because of vessel traffic, water circulation, and fish migration. Leaving only one gap open when waves came from the southwest reduced wave heights by about half at the harbor (see Figures 41- 44 and 18-19).

Closing only one gap while leaving the rest open did not create an appreciable wave height reduction when waves came from the southwest (see Figures 37-40). Closing Gap 2 seemed to work the best for the longer wave periods. When waves came from the northwest, closing Gap 3 was most effective in reducing wave heights in the harbor because it blocked direct approach into the harbor. However, before reducing or closing Gap 3 (between north end of center breakwater and south end of north breakwater) the potential for an incomplete solution should be evaluated. Waves from the northwest may not be responsible for the episodes of adverse wave action in the harbor.

Extension of the runway on J aponski Island a distance of 1,600 $\mathrm{ft}$ to the northwest resulted in a wave height reduction on the order of 50 percent in the harbor when waves approached from the southwest. (This expansion would not have any impact on waves from the northwest.) All other options tested caused little reduction of wave heights in New Thompson Harbor when waves approached from the southwest (see Figure 22).

When waves approached from the northwest, the plan to lengthen the south end of the center breakwater had no effect. However, the three alternatives that reduced Gap 3 distance did decrease wave heights in New Thomsen Harbor by about $0.5 \mathrm{ft}$ (see Figure 24). 


\section{Final remarks}

Even though measured waves in New Thomsen Harbor were below the usual 1-ft criterion for tests with 5-ft waves from the southwest and water elevation at $+11 \mathrm{ft}$ mllw, these values should not be viewed as the absolute maximum wave heights that might occur. Higher incident waves would cause higher waves in the harbor, and waves coming from a more westerly direction (not tested) might be less influenced by wave diffraction around Battery Island and Line Island. This more westerly wave approach direction would give the waves a slightly more direct approach through the breakwater gaps, and consequently more wave energy could enter the protected region in the lee of the breakwaters. Thus, there is the potential that wave heights along the main floating dock would be proportionately higher and perhaps exceed the 1-ft criterion.

Although not part of the modeling study, note that dock moorings consist of pilings that are susceptible to horizontal translation at high tide when loaded laterally by waves or moored vessels. The dock system frequency response may be associated with the pile motions.

Finally, note that the three breakwaters have been effective in reducing incident wave energy entering that reach of the Western Channel. Offshore waves of $5 \mathrm{ft}$ from the southwest are reduced to only $0.6 \mathrm{ft}$ in New Thomsen Harbor. This decrease is an 88 percent reduction in wave height and a 98 percent reduction in wave energy (wave height squared). Of course some of this reduction is due to diffraction around the offshore islands and refraction into the Western Channel, but the breakwater system appears to be functioning reasonably well with the exception of the periodic episodes of dock motion reported by local interests. 


\section{References}

Hudson, R. Y., F. A. Herrmann, R. A. Sager, R. W. Whalin, G. H. Keulegan, C. E. Chatham, and L. Z. Hales. 1979. Coastal hydraulic models. Special Report No. 5. Vicksburg, MS: U.S. Army Engineer Waterways Experiment Station.

Hughes, S. A. 1993. Physical models and laboratory techniques in coastal engineering. In Advanced Series on Ocean Engineering 7. Singapore: World Scientific.

Hughes, S. A. 2003. Physical modeling considerations for coastal structures. In Advances in Coastal Structure Design, R. Mohan, ed., ASCE, 97-115.

Kamphuis, J. W. 1991. Physical modeling. In Handbook of Coastal and Ocean Engineering 2, J. B. Herbich, ed. Houston, TX: Gulf Publishing Company.

Le Méhauté, B. 1976. Similitude in coastal engineering. Journal of the Waterways, Harbors and Coastal Engineering Division 102(WW3): 317-335, ASCE.

Warnock, J. E. 1950. Hydraulic similitude. In Engineering Hydraulics, H. Rouse, ed, 136176. New York: J ohn Wiley \& Sons. 


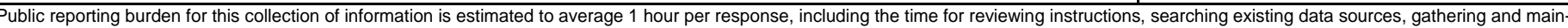



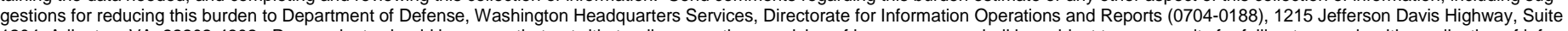


mation if it does not display a currently valid OMB control number. PLEASE DO NOT RETURN YOUR FORM TO THE ABOVE ADDRESS.
1. REPORT DATE (DD-MM-YYYY)
2. REPORT TYPE
February 2008
3. DATES COVERED (From - To)

Final report

4. TITLE AND SUBTITLE

5a. CONTRACT NUMBER

Physical Model Study of Wave Action in New Thomsen Harbor, Sitka, Alaska

5b. GRANT NUMBER

5c. PROGRAM ELEMENT NUMBER

6. AUTHOR(S)

5d. PROJECT NUMBER

Steven A. Hughes, Julie Cohen, and Hugh F. Acuff

5e. TASK NUMBER

5f. WORK UNIT NUMBER

7. PERFORMING ORGANIZATION NAME(S) AND ADDRESS(ES)

U.S. Army Engineer Research and Development Center

Coastal and Hydraulics Laboratory

8. PERFORMING ORGANIZATION REPORT NUMBER

ERDC/CHL TR-08-2

3909 Halls Ferry Road

Vicksburg, MS 39180-6199

9. SPONSORING I MONITORING AGENCY NAME(S) AND ADDRESS(ES)

U.S. Army Engineer District, Alaska

PO Box 6898

Elmendorf Air Force Base, AK 99506-0898

10. SPONSOR/MONITOR'S

ACRONYM(S)

11. SPONSOR/MONITOR'S REPORT NUMBER(S)

12. DISTRIBUTION I AVAILABILITY STATEMENT

Approved for public release; distribution is unlimited.

\section{SUPPLEMENTARY NOTES}

\section{ABSTRACT}

A 1-to-75 scale physical model of Sitka, Alaska, encompassing portions of the Western Channel, the region protected by the three breakwaters, New Thomsen Harbor, and the Sitka and Japonski Island shorelines, was constructed at the modeling facilities of the U.S. Army Engineer Research and Development Center's Coastal and Hydraulics Laboratory. The primary objectives of the physical model study were to (1) establish the cause for wave action within the harbor causing vertical motion of the floating docks and (2) investigate potential engineering alternatives to reduce wave action within the harbor to acceptable levels.

A total of 179 tests were conducted in the Sitka physical model during four time periods between the completion of the model in September 2005 and February 2007. Several hypotheses explaining increased wave action in New Thomsen Harbor were tested. Of these hypotheses, wave focusing by local bathymetry near New Thomsen Harbor appeared to be the most plausible; incident waves interacting with waves reflected by the shoreline at high water were a possible contributor for longer period waves. Large, shortperiod waves from the northwest could cause high waves in the harbor, but only when the wind blows hard from that direction. Distance between the rubble-mound breakwaters and harbor is also adequate to generate sizable short-period waves within the harbor. The short-wave energy could excite a harmonic frequency of the dock system resulting in adverse motions. At present the floating dock harmonics are unknown.

(Continued)

\section{SUBJECT TERMS}

Alaska

Harbor agitation

\section{Harbor model}

New Thomsen Harbor

Physical model
Sitka

Wave penetration

\begin{tabular}{|l|l|l|}
\hline \multicolumn{2}{|l|}{ 16. SECURITY CLASSIFICATION OF: } \\
\hline $\begin{array}{l}\text { a. REPORT } \\
\text { UNCLASSIFIED }\end{array}$ & $\begin{array}{l}\text { b. ABSTRACT } \\
\text { UNCLASSIFIED }\end{array}$ & $\begin{array}{l}\text { c. THIS PAGE } \\
\text { UNCLASSIFIED }\end{array}$ \\
\hline
\end{tabular}

NSN 7540-01-280-5500

18. NUMBER
OF PAGES

129 19a. NAME OF RESPONSIBLE PERSON

19b. TELEPHONE NUMBER (include area code) 


\section{ABSTRACT (Concluded)}

Closing one or more gaps between adjacent breakwaters and/or breakwaters and the shoreline reduced wave heights in New Thomsen Harbor. Leaving only one gap open when waves came from the southwest reduced wave heights by about half. Closing only one gap while leaving the rest open did not create an appreciable wave height reduction when waves came from the southwest. Extending the runway on Japonski Island by 1,600 ft to the northwest resulted in a wave height reduction on the order of $50 \%$ in the harbor when waves approached from the southwest. All other options tested caused little reduction of wave heights when waves approached from the southwest. 